Yeda Regina Venturini

MOS - Modelo Ontológico de Segurança para Negociação de Política de Controle de Acesso em Multidomínios

Tese apresentada a Escola Politécnica da

Universidade de São Paulo para obtenção do título de Doutor em Engenharia.

São Paulo 
Yeda Regina Venturini

\title{
MOS - Modelo Ontológico de Segurança para Negociação de Política de Controle de Acesso em Multidomínios
}

\author{
Tese apresentada a Escola Politécnica da \\ Universidade de São Paulo para obtenção do título \\ de Doutor em Engenharia.
}

Área de concentração: Sistemas Digitais

Orientador: Prof. Dr. Wilson Vicente Ruggiero

São Paulo 
Este exemplar foi revisado e alterado em relação à versão original, sob responsabilidade única do autor e com a anuência de seu orientador.

São Paulo, 7 de agosto de 2006.

Assinatura do autor

Assinatura do orientador

FICHA CATALOGRÁFICA

Venturini, Yeda Regina

MOS - modelo ontológico de segurança para negociação de política de controle de acesso em multidominios I Y.R. Venturini. -- ed.rev. -- São Paulo, 2006.

$130 \mathrm{p}$.

Tese (Doutorado) - Escola Politécnica da Universidade de São Paulo. Departamento de Engenharia de Computação e Sistemas Digitais.

1.Política de segurança 2.Redes de computadores ad hoc 3.Segurança da informação 4.Sistemas distribuídos 5.Ontologia I.Universidade de São Paulo. Escola Politécnica. Departamento de Engenharia de Computação e Sistemas Digitais II.t. 


\section{FOLHA DE APROVAÇÃO}

Yeda Regina Venturini

MOS - Modelo Ontológico de Segurança para Negociação da Política de Controle de Acesso em Multidomínios

Tese apresentada à Escola Politécnica da Universidade de São Paulo para obtenção do título de Doutor em Engenharia.

Área de concentração: Sistemas Digitais

Aprovado em:

Banca Examinadora

Prof. Dr.

Instituição: Assinatura:

Prof. Dr.

Instituição: Assinatura:

Prof. Dr.

Instituição: Assinatura:

Prof. Dr.

Instituição:

Assinatura:

Prof. Dr.

Instituição: Assinatura: 


\section{AGRADECIMENTOS}

Ao meu esposo pelo apoio e compreensão sempre oferecidos nas jornadas que me disponho a seguir.

A todos do LARC - Laboratório de Arquitetura e Redes de Computadores por construírem um ambiente agradável, acolhedor, dinâmico e produtivo.

Agradeço em especial ao grupo do projeto LARC-Ericsson pelos anos de trabalho em conjunto, pelo apoio nos momentos de minha ausência para o desenvolvimento deste trabalho e por todos os momentos agradáveis que passamos juntos.

Ao meu orientador agradeço pelo apoio, pelos preciosos comentários e contribuições, e pela paciência com que me conduziu neste processo de amadurecimento profissional. 


\section{RESUMO}

VENTURINI, Y. R. - MOS - Modelo Ontológico de Segurança para Negociação de Política de Controle de Acesso em Multidomínios. 2006. 130 f. Tese (Doutorado). Escola Politécnica, Universidade de São Paulo, São Paulo, 2006.

A evolução nas tecnologias de redes e o crescente número de dispositivos fixos e portáteis pertencentes a um usuário, os quais compartilham recursos entre si, introduziram novos conceitos e desafios na área de redes e segurança da informação. Esta nova realidade estimulou o desenvolvimento de um projeto para viabilizar a formação de domínios de segurança pessoais e permitir a associação segura entre estes domínios, formando um multidomínio. A formação de multidomínios introduziu novos desafios quanto à definição da política de segurança para o controle de acesso, pois é composto por ambientes administrativos distintos que precisam compartilhar seus recursos para a realização de trabalho colaborativo. Este trabalho apresenta os principais conceitos envolvidos na formação de domínio de segurança pessoal e multidomínios, e propõe um modelo de segurança para viabilizar a negociação e composição dinâmica da política de segurança para o controle de acesso nestes ambientes. O modelo proposto é chamado de Modelo Ontológico de Segurança (MOS). O MOS é um modelo de controle de acesso baseado em papéis, cujos elementos são definidos por ontologia. A ontologia define uma linguagem semântica comum e padronizada, viabilizando a interpretação da política pelos diferentes domínios. A negociação da política ocorre através da definição da política de importação e exportação de cada domínio. Estas políticas refletem as contribuições parciais de cada domínio para a formação da política do multidomínio. O uso de ontologia permite a composição dinâmica da política do multidomínio, assim como a verificação e resolução de conflitos de interesses, que refletem 
incompatibilidades entre as políticas de importação e exportação. O MOS foi validado através da análise de sua viabilidade de aplicação em multidomínios pessoais. A análise foi feita pela definição de um modelo concreto e pela simulação da negociação e composição da política de controle de acesso. Para simulação foi definido um multidomínio para projetos de pesquisa. Os resultados mostraram que o MOS permite a definição de um procedimento automatizável para criação da política de controle de acesso em multidomínios.

Palavras-chave: Política de segurança, Segurança da Informação, Controle de Acesso, Rede de computadores ad hoc, Sistemas Distribuídos, Ontologia. 


\section{ABSTRACT}

VENTURINI, Y. R. - MOS - Ontological Security Model for Access Control Policy

Negotiation in Multi-domains. 2006. 130 f. Thesis (Doctoral). Escola Politécnica, Universidade de São Paulo, São Paulo, 2006.

The evolution in the network technology and the growing number of portable and fixed devices belonging to a user, which shares resources, introduces new concepts and challenges in the network and information security area. This new reality has motivated the development of a project for personal security domain formation and security association between them, creating a multi-domain. The multi-domain formation introduces new challenges concerning the access control security policy, since multi-domains are composed by independent administrative domains that share resources for collaborative work. This work presents the main concept concerning the personal security domains and multi-domains, and proposes a security model to allow the dynamic security policy negotiation and composition for access control in multi-domain. The proposed model is called MOS, which is an ontological security model. The MOS is a role-based access control model, which elements are defined by an ontology. The ontology defines a semantic language, common and standardized, allowing the policy interpretation by different domains. The policy negotiation is made possible by the definition of the policy importation and exportation in each domain. These policies mean the partial contributions of each domain for the multi-domain policy formation. The use of ontology allows the dynamic multi-domain policy composition, as well as the verification and resolution of interest conflicts. These conflicts mean incompatibilities between the importation and exportation policy. The MOS was validated through the viability analysis for personal multi-domain application. The analysis was made through the definition 
of a factual model and the simulation of access control policy negotiation and composition. The simulation was taken place through the definition of a collaborative research projects multi-domain. The results demonstrate the MOS is feasible for implementation in automatic procedures for multi-domain access control policy creation.

Keywords: Security policy, Information security, Access control, Ad hoc computer network, Distributed systems, Ontology. 


\section{LISTA DE FIGURAS}

Figura 1 - Domínio de Segurança Pessoal.............................................................. 2

Figura 2 - Associação entre Domínios de Segurança Pessoal.................................... 3

Figura 3 - Domínios de Segurança Pessoal ......................................................... 18

Figura 4 - Diagrama UML de um Domínio de Segurança Pessoal ........................... 19

Figura 5 - Domínio de Segurança Estendido ....................................................... 20

Figura 6 - Diagrama UML de um Multidomínio de Segurança ................................ 21

Figura 7 - Serviço de Controle de Acesso ................................................................ 28

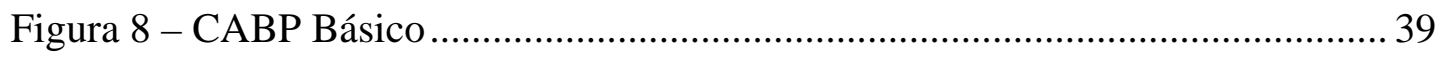

Figura 9 - Diagrama UML do CABP Básico ........................................................ 42

Figura 10 - Diagrama UML do CABP Hierárquico ............................................ 46

Figura 11 - Exemplo de Hierarquia em árvore invertida........................................ 46

Figura 12 - Diagrama UML do CABP Restrito ..................................................... 48

Figura 13 - A política de controle de acesso sob a perspectiva do usuário................ 68

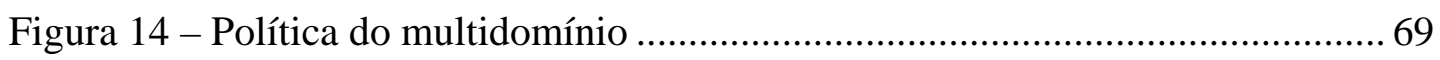

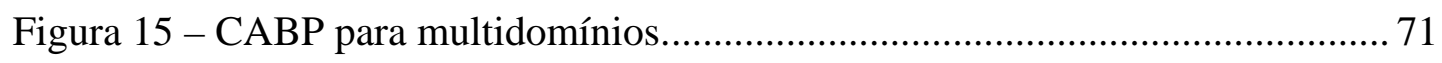

Figura 16 - Exemplo de representação de ontologia em UML ................................ 74

Figura 17 - Diagrama UML do Modelo Ontológico de Segurança............................ 76

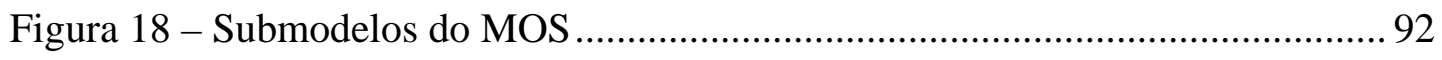

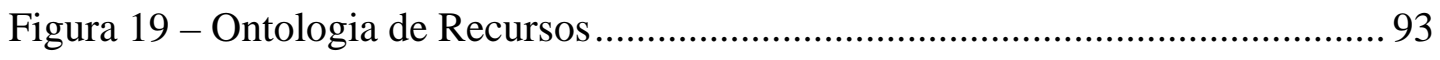

Figura 20 - Ontologia de Operações.................................................................... 94

Figura 21 - Restrições sobre relacionamentos: Compartilhamento de Arquivos ...... 95

Figura 22- Restrição sobre relacionamentos: Serviço de Impressão .......................... 96 
Figura 23 - Ontologia de Credenciais. 102

Figura 24 - Recursos Exportados para o Projeto de Pesquisa 104

Figura 25 - Papeis Importados para o Projeto de Pesquisa 104

Figura 26 - Exemplo da Política Composta para o Projeto de Pesquisa 105 


\section{LISTA DE TABELAS}

Tabela 1 - Multidomínio para Projeto de Pesquisa ................................................. 97

Tabela 2 - Lista de Autorizações do Projeto de Pesquisa.......................................... 98

Tabela 3 - Atribuições a Papéis para Projeto de Pesquisa......................................... 98

Tabela 4 - Exemplo de Política de Exportação ........................................................... 99

Tabela 5 - Exemplo de Política de Importação ..................................................... 100

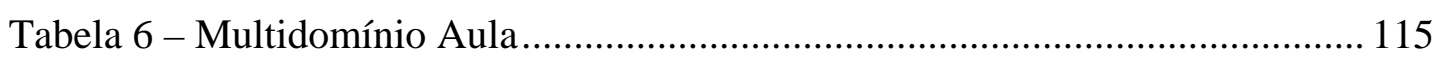

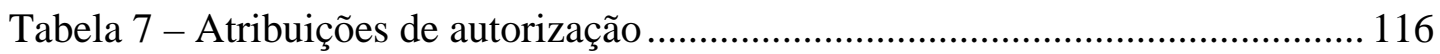

Tabela 8 - Recursos compartilhados pelos domínios ........................................... 116

Tabela 9 - Política de Exportação do Domínio Consultor......................................... 117

Tabela 10 - Política de Importação do Domínio Consultor..................................... 117

Tabela 11 - Política de Exportação do Domínio Redes .......................................... 117

Tabela 12 - Política de Importação do Domínio Redes........................................... 118

Tabela 13 - Política de Exportação do Domínio EquipeX........................................ 118

Tabela 14 - Política de Importação da EquipeX...................................................... 118

Tabela 15 - Política de Importação de Outros Domínios que não Compartilham

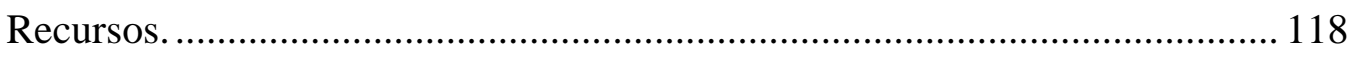

Tabela 16 - Política Resultante antes da Resolução de Conflitos: atribuição de

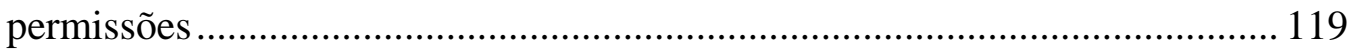

Tabela 17 - Política Resultante antes da Resolução de Conflitos: atribuições do usuário 120

Tabela 18 - Política Composta: atribuições de permissões ...................................... 120

Tabela 19 - Política Composta: atribuições do usuário ........................................... 121 
Tabela 20 - Política Composta: atribuições do usuário .......................................... 122

Tabela 21 - Política Composta: atribuições de permissões .................................... 122 


\section{LISTA DE ABREVIATURAS}

AC

ADSL

AMD

AP

CA

CABP

CAC

CAD

CPU

CRL

DAC

DAML-S

EPSD

FQDN

GUI

ICP

IEEE

LAN

LCA

LCR

MAC

MANET

MOAD

MOCA

MODA

MOS

MPSD

NIST

OWL

Autoridade de Certificação

Asymmetric Digital Subscriber Line

Ambiente MultiDomínio

Access Point

Certificate Authority

Controle de Acesso Baseado em Papéis

Controle de Acesso Compulsório

Controle de Acesso Discricionário

Central Processing Unit

Certificate Revocation List

Discretionary Access Control

DARPA Agent Markup Language

Extended Personal Security Domain

Fully Qualified Domain Name

Graphical User Interface

Infra-estrutura de Chave Pública

Institute of Electrical and Electronics Engineers

Local Area Network

Lista de Controle de Acesso

Lista de Certificados Revogados

Mandatory Access Control

Mobile Ad hoc NETwork

Modelo Ontológico de Associação de Domínios

Modelo Ontológico de Controle de Acesso

Modelo Ontológico de Delegação de Autoridade

Modelo Ontológico de Segurança

Multiple Personal Security Domain

National Institute of Standards and Technology

Web Ontology Language 


$\begin{array}{ll}\text { PAN } & \text { Personal Area Network } \\ \text { PC } & \text { Personal Computer } \\ \text { PDA } & \text { Personal Digital Assistant } \\ \text { PKI } & \text { Public Key Infrastructure } \\ \text { PSD } & \text { Personal Security Domain } \\ \text { RAS } & \text { Remote Access Service } \\ \text { RBAC } & \text { Role-Based Access Control } \\ \text { SAR } & \text { Serviço de Acesso Remoto } \\ \text { SD } & \text { Security Domain } \\ \text { SDSI } & \text { Simple Distributed Security Infrastructure } \\ \text { SPKI } & \text { Simple Public-Key Infrastructure } \\ \text { SR } & \text { Separação de Responsabilidades } \\ \text { SRD } & \text { Separação de Responsabilidades Dinâmica } \\ \text { SRE } & \text { Separação de Responsabilidades Estática } \\ \text { TOS } & \text { Trusted Operation System } \\ \text { UML } & \text { Unified Modeling Language } \\ \text { WLAN } & \text { Wireless Local Area Network } \\ \text { WPAN } & \text { Wireless Personal Area Network } \\ \text { XML } & \text { Extensible Markup Language } \\ \end{array}$




\section{SUMÁRIO}

CAPÍTULO 1 - INTRODUÇÃO ............................................................................. 1

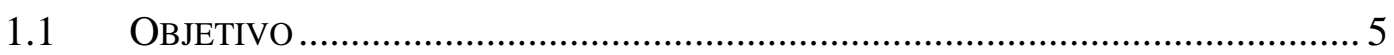

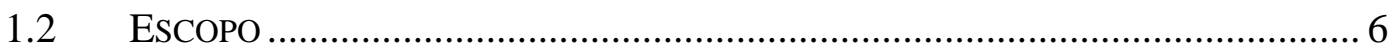

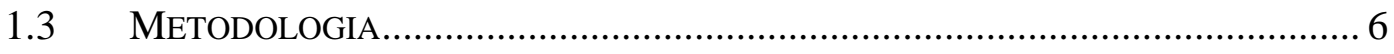

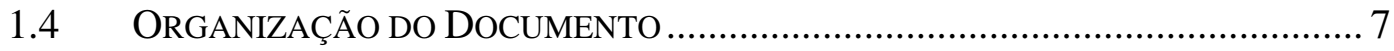

CAPÍTULO 2 - ASPECTOS DE SEGURANÇA...................................................8

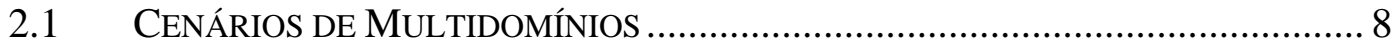

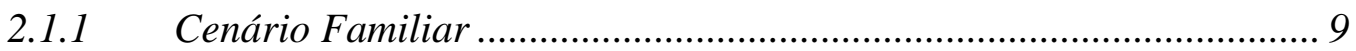

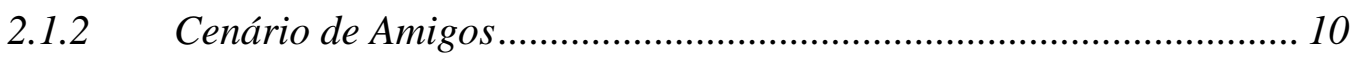

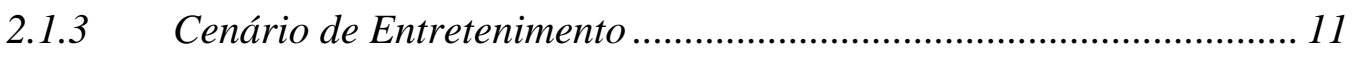

2.1.4 Cenário de Negócios ...................................................................... 13

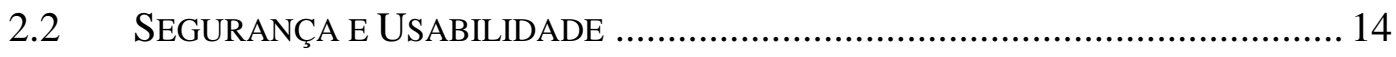

CAPÍTULO 3 - MULTIDOMÍNIO DE SEGURANÇA.......................................... 17

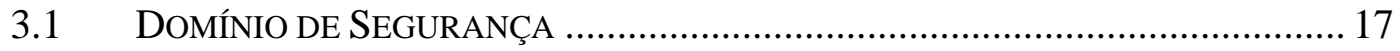

3.2 DomínIO De SEGURANÇA PESSOAL ............................................................ 18

3.3 Domínio de SEgURAnÇA PeSSOAL Estendido .......................................... 20

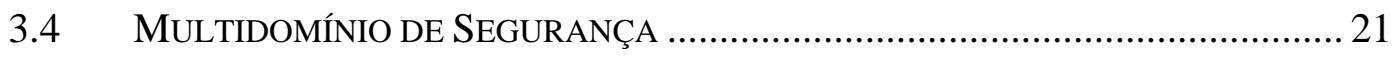

3.5 Política de Controle de Acesso em Multidomínios ........................... 22

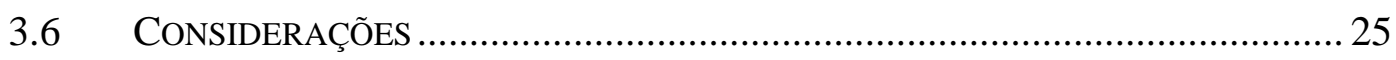

CAPÍTULO 4 - MODELOS DE CONTROLE DE ACESSO .............................. 27

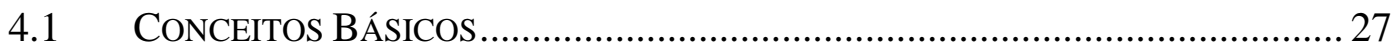

4.1.1 Autenticação................................................................................... 29

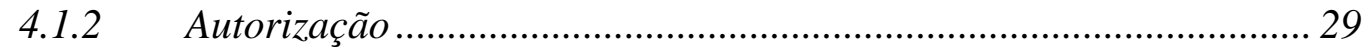

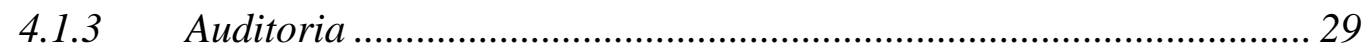

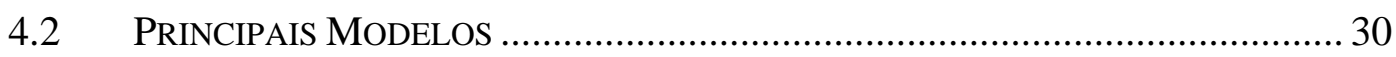

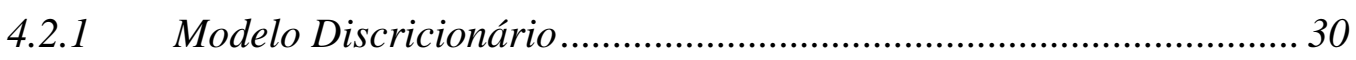

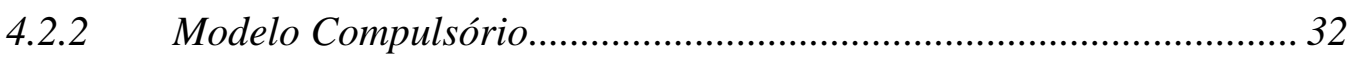

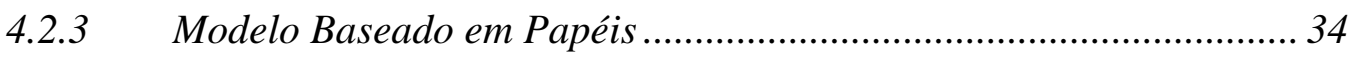


4.3 O PADRÃO CAPB PROPOSTO PELO NIST …............................................ 37

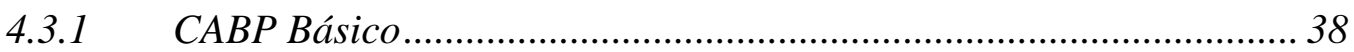

4.3.2 CABP Hierárquico ............................................................................. 45

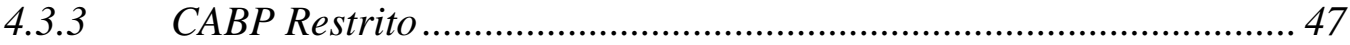

4.4 Trabalhos Relacionados ao Controle de ACESSO EM Multidomínios 49

4.4.1 DRBAC - Distributed Role-Based Access Control ............................. 49

4.4.2 C-RBAC - Collaborative Role-Based Access Control ......................... 50

4.4.3 X-RBAC - XML Role-Based Access Control ....................................... 52

4.4.4 ORBAC - Object-Oriented Role-Based Access Control..................... 54

4.4.5 Credential-Based Access Control ....................................................... 55

4.4.6 Ontology-Based Policy .................................................................... 57

4.4.7 Modelo Híbrido: Baseado em regras e em ontologia......................... 58

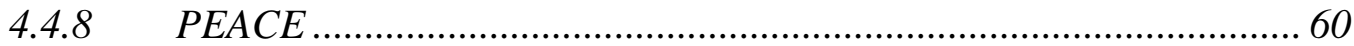

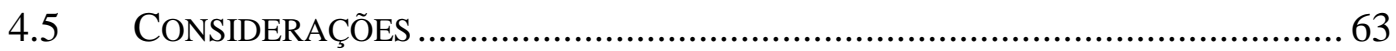

\section{CAPÍTULO 5 - MODELO ONTOLÓGICO DE SEGURANÇA........................67}

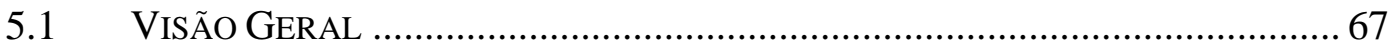

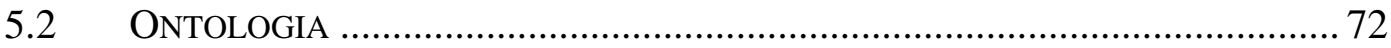

5.2.1 Nomenclatura e Representação .......................................................... 74

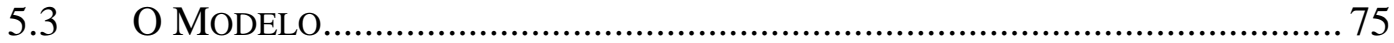

5.3.1 Definição dos Conceitos ................................................................... 76

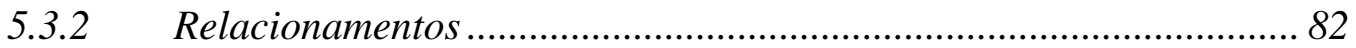

5.3.3 Definições Relacionadas ao CABP .................................................... 83

5.3.4 Negociação e Composição da Política ................................................ 84

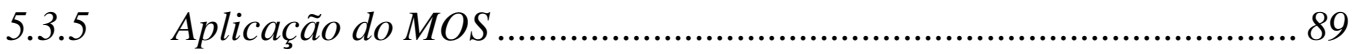

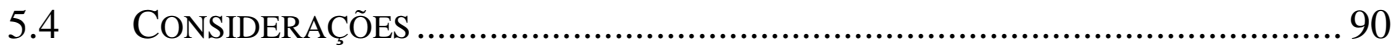

CAPÍTULO 6 - O MOS EM MULTIDOMÍNIOS PESSOAIS.............................. 91

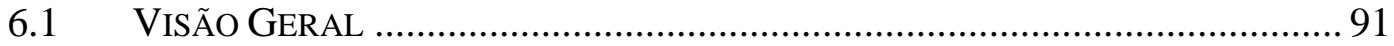

6.2 ONTOLOGIA DE RECURSOS E OPERAÇÕES .................................................. 92

6.3 MOdELO ONTOLÓGICO PARA A ASSOCIAÇÃO DE DOMÍNIOS ........................ 97

6.4 Modelo OnTOLÓGICO DE CONTROLE DE ACESSO ...................................... 99 
6.4.1 Política de Exportação e Importação ................................................ 99

6.4.2 Negociação e Composição da Política ............................................. 101

6.5 Modelo OntOlÓGico DE Delegação DE AutORIDAdE .......................... 102

6.5.1 Atribuição de Papéis aos Usuários.................................................... 103

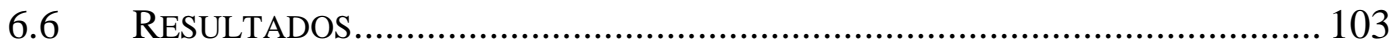

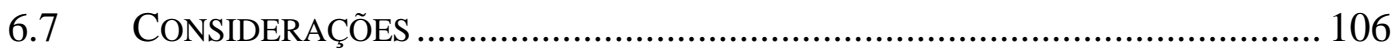

CAPÍTULO 7 - O MOS EM EAD ....................................................................... 108

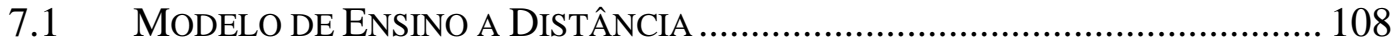

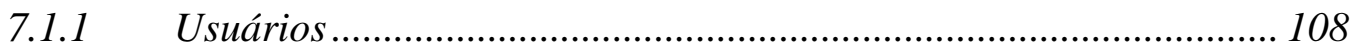

7.1.2 Multidomínios: Atividades colaborativas ........................................ 109

7.1.3 Recursos: Ferramentas e operações.................................................. 110

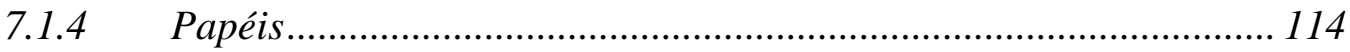

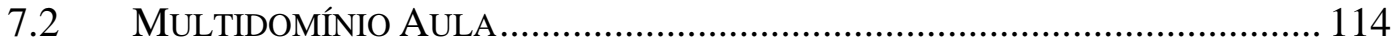

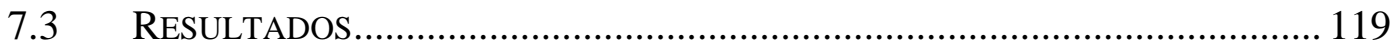

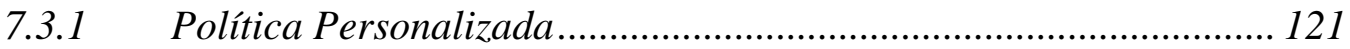

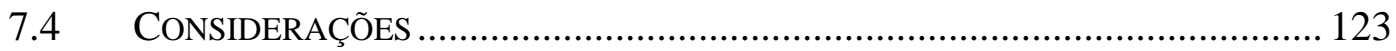

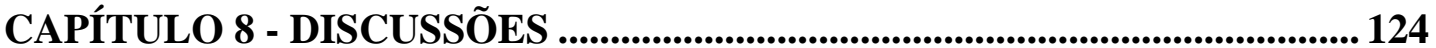

CAPÍTULO 9 - CONSIDERAÇÕES FINAIS..................................................... 130

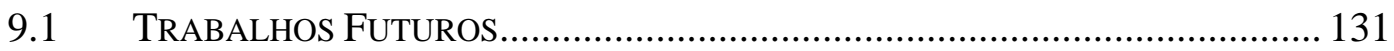

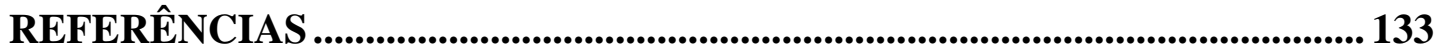

BIBLIOGRAFIA COMPLEMENTAR ......................................................... 138

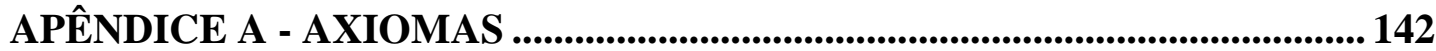




\section{Capítulo 1 - Introdução}

A popularidade das tecnologias de redes sem fio, aliado à evolução dos computadores e o crescente número de dispositivos fixos e portáteis pertencentes a um usuário, os quais compartilham recursos entre si, introduziram novos conceitos e geraram novos desafios na área de redes e segurança da informação. Entre estes conceitos estão: a definição de WPAN (Wireless Personal Area Network) e MANET (Mobile Ad Hoc NETwork). Uma WPAN é definida como uma rede sem fio pessoal, formada pelos dispositivos pertencentes a, ou acessíveis por, um usuário e distantes apenas de alguns metros entre si, como, por exemplo, uma rede que utiliza a tecnologia Bluetooth (IEEE 802.15.1, 2002). Enquanto uma MANET (BASAGNI, 2004) é uma rede sem fio formada sem qualquer administração central, independente de qualquer infra-estrutura de rede pré-existente ou relação de confiança ${ }^{1}$ previamente estabelecida entre os dispositivos. Logo, os serviços disponíveis nestas redes dependem dos nós participantes que se encontram no estado ativo e no raio de alcance num dado instante.

Essas formações recentes de redes (WPAN e MANET) trouxeram novos desafios quanto aos aspectos de segurança da informação. Por exemplo, não é possível a utilização de servidores de autenticação (administração centralizada), pois estas redes são formadas por dispositivos móveis e não podem depender de serviços fixos, que não estejam sempre ao alcance. Cada nó da rede deve ser responsável pela própria segurança. Numa MANET o desafio é ainda maior, pois sua formação não deve depender da existência de uma relação de confiança prévia (HUBAUX, 2001; ZHOU, 1999), pois devido à sua natureza fortemente dinâmica, em tais ambientes, essa relação prévia pode não existir a priori. Através da relação

\footnotetext{
${ }^{1}$ Relação de confiança: diz-se que existe uma relação de confiança entre duas entidades quando elas são capazes de se autenticarem e se reconhecerem como confiáveis entre si.
} 
de confiança inicial as entidades definem os parâmetros e mecanismos de segurança que serão utilizados para a autenticação. Por exemplo, num sistema baseado em senhas, o usuário é cadastrado juntamente com o registro de uma senha. O cadastro do usuário e senha estabelece a relação inicial de confiança entre o sistema e o usuário. O mesmo ocorre em sistemas baseado em certificados, quando um certificado é emitido para um usuário uma relação de confiança é estabelecida e o parâmetro de autenticação é definido. Outro desafio refere-se à definição da política de controle de acesso $^{2}$. Por exemplo, alguns modelos de controle de acesso (como CAD, Controle de Acesso Discricionário, e CAC, Controle de Acesso Compulsório apresentados em 4.2) baseiam-se na identificação do usuário para definir as regras para autorização de acesso, mas os usuários são desconhecidos até o primeiro acesso em MANETs. Existem outros modelos cuja política de controle de acesso não é definida sobre a identificação do usuário (como CABP, Controle de Acesso Baseado em Papéis, apresentado em 4.2), mas ainda assim é preciso definir previamente os perfis dos usuários (papéis) que estarão requisitando acesso e vincular dinamicamente os usuários (autenticados) aos perfis (papéis).

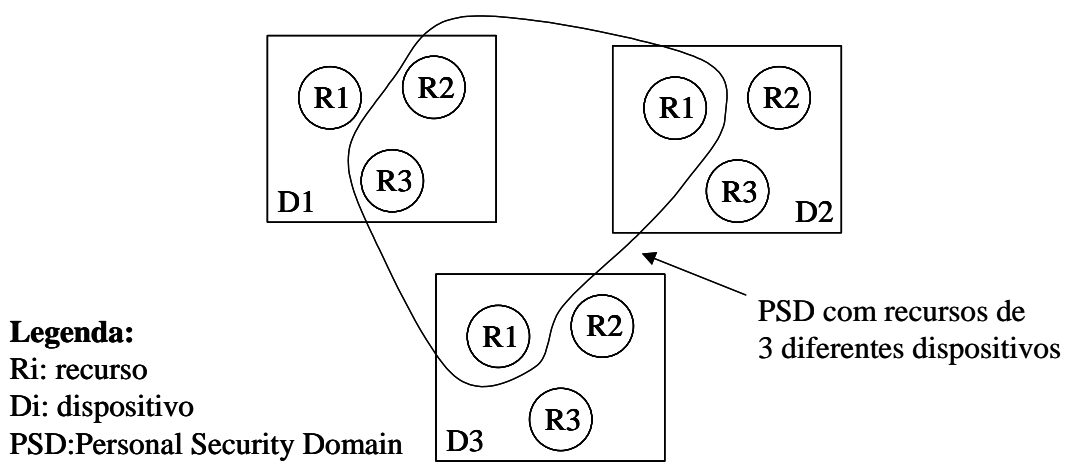

Figura 1 - Domínio de Segurança Pessoal

A característica fortemente dinâmica das redes pessoais e seus requisitos de segurança da informação levaram ao conceito de PSD (PAN Security Domain). O conceito de PSD foi

\footnotetext{
${ }^{2}$ Controle de acesso: consiste na capacidade de se permitir ou negar acesso aos serviços e recursos oferecidos pelo sistema
} 
primeiro introduzido pelo projeto SHAMAN (Security for Heterogeneous Access in Mobile Applications and Networks) (HOWKER, 2003). Um PSD no projeto SHAMAN é essencialmente um domínio lógico de segurança que pode envolver diferentes serviços em diferentes dispositivos nos limites de uma PAN. A figura 1 ilustra um PSD.

(CHANDRASIRI, 2003) propôs uma extensão ao conceito de PSD, sugerindo que um PSD pudesse ser formado por dispositivos geograficamente distribuídos. A sigla PSD passa a significar “Personal Security Domain”, que é formado pelos dispositivos pessoais do usuário, que podem estar além dos limites da PAN. A proposta vai além, sugerindo que os PSDs possam formar um novo PSD ad hoc, para compartilhar recursos entre si. Um PSD ad hoc é composto pelos recursos compartilhados pelos PSDs participantes. A figura 2 ilustra um PSD ad hoc (associação entre domínios de segurança pessoal).

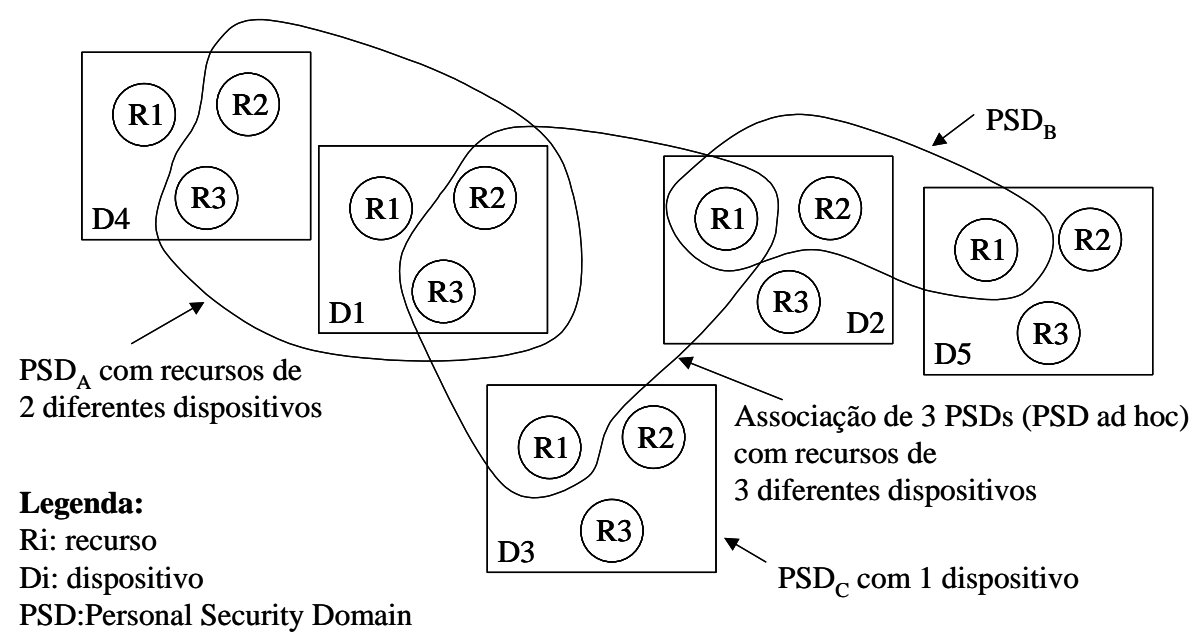

Figura 2 - Associação entre Domínios de Segurança Pessoal.

Baseado nos conceitos introduzidos em (HOWKER, 2003) e (CHANDRASIRI, 2003), o LARC - Laboratório de Arquitetura e Redes de Computadores da USP em conjunto com a Ericsson Research na Suécia, desenvolveram o projeto MPSD (Multiple Personal Security Domain) (VENTURINI, 2005; SAKURAGUI, 2005), para a especificação e implementação de uma arquitetura de segurança para a formação de domínios de segurança pessoal. Como uma evolução na nomenclatura, o projeto propôs uma generalização/especialização para o 
conceito de PSD definido anteriormente. A sigla SD (Security Domain) foi utilizada como uma generalização dos conceitos anteriores. Enquanto que as siglas PSD, EPSD e MPSD foram utilizadas para especializar os conceitos de PSD apresentados em (CHANDRASIRI, 2003). PSD (Personal Security Domain) passa a definir um domínio de segurança (SD) pessoal, formado pelos dispositivos, fixos e móveis, pertencentes a, ou sob responsabilidade de, um usuário, sendo que os dispositivos estão diretamente conectados entre si (mesmo domínio de multicast), através de uma PAN/WPAN ou LAN/WLAN. Um EPSD (Extended PSD) corresponde a um PSD cujos limites físicos (PAN/LAN) são estendidos, podendo ser composto por dispositivos geograficamente distribuídos. Enquanto que um MPSD (Multiple PSD) define um SD formado por múltiplos PSDs/EPSDs, como definido para um PSD ad hoc. A arquitetura definida pelo projeto MPSD concretiza os conceitos introduzidos em (CHANDRASIRI, 2003), através da especificação e implementação de um protótipo para a formação de PSD, EPSD e MPSD.

O projeto MPSD resolve uma série de desafios na formação de domínios de segurança pessoal, no entanto, a política de controle de acesso definida para o MPSD não permite o controle de compartilhamento individualizado por recurso ou serviço. Por exemplo, é possível que um PSD compartilhe diferentes recursos em cada MPSD que participa, mas não é possível a um PSD permitir o acesso diferenciado entre os participantes de um mesmo MPSD. Ou seja, uma vez autenticado como membro de um MPSD todos têm o mesmo direito de acesso aos recursos compartilhados naquele MPSD. A dificuldade na definição de uma política de controle de acesso para MPSDs está relacionada, principalmente, a sua natureza ad hoc, distribuída e multidomínio, além do fato dos domínios serem gerenciados por usuários, que não possuem conhecimento técnico para realizar procedimentos complexos de configuração e desconhecerem os conceitos avançados de segurança. O capítulo 2 discute em 
mais detalhes os desafios encontrados para a definição de uma política de controle de acesso neste tipo de domínio.

Os conceitos de domínio pessoal e multidomínio são os equivalentes, no idioma português, para os conceitos apresentados acima. Um domínio pessoal corresponde tanto ao PSD quanto ao EPSD, pois ambos definem um mesmo domínio lógico de segurança. Um multidomínio corresponde a um MPSD. O termo “domínio” está sendo utilizada neste trabalho para referir-se a um domínio lógico de segurança e “pessoal” significa que o domínio é centrado em uma pessoa, quem assume o papel de responsável pela administração do domínio.

\subsection{Objetivo}

Este trabalho tem o objetivo de propor um modelo de segurança para a negociação e composição dinâmica de políticas de segurança para o controle de acesso. O modelo encontra sua aplicação quando ambientes de domínios distintos precisam compartilhar parcialmente seus recursos para a realização de trabalho colaborativo.

O modelo de segurança define uma linguagem de comunicação comum entre os domínios e padroniza a definição da política de controle de acesso, tal que, a política definida pelos domínios possa ser interpretada pelos demais domínios e possíveis conflitos de interesses possam ser resolvidos. O modelo é o denominador comum entre os domínios e visa conduzir a negociação ao mesmo tempo em que busca minimizar a necessidade de renegociação. Adicionalmente, o modelo facilita a composição da política do multidomínio, a partir das políticas individuais definidas pelos domínios, mantendo o isolamento e autonomia administrativa dos domínios. 
Desta forma, o modelo busca abstrair os detalhes e fixar-se nos aspectos relevantes para a negociação e definição da política, deixando os detalhes para serem definidos e tratados pela política interna de cada domínio.

\subsection{Escopo}

A formação de multidomínios pode ocorrer nos mais diversos cenários e não existe um modelo de controle de acesso que atenda a diversidade de requisitos destes ambientes. Este trabalho visa propor um modelo que atenda aos requisitos de multidomínios formados por domínios pessoais, e suportem modelos de controle de acesso baseado em papéis.

\subsection{Metodologia}

A abordagem utilizada para atingir o objetivo deste trabalho foi definir uma política de exportação e importação para os domínios, onde a política de exportação reflete a política de um domínio como provedor de recursos e a política de importação reflete a política de um domínio como consumidor de recursos. A composição da política ocorre pela união das políticas de importação e exportação e pela verificação de conflitos de interesses entre consumidores e provedores de recursos.

O modelo de controle de acesso baseado em papéis, associado ao uso de ontologia, foram as técnicas utilizadas para estabelecer uma linguagem comum e uma padronização na política. Este recurso permite que as políticas de exportação e importação, assim como a política composta, possam ser interpretadas por todos durante a negociação, composição e operação do multidomínio. 


\subsection{Organização do Documento}

Este documento está organizado em capítulos como segue:

- Capítulo 1 - Introdução: Este capítulo, no qual contextualizamos os conceitos de domínio e multidomínio e apresentamos os objetivos, escopo e metodologia.

- Capítulo 2 - Aspectos de Segurança: Este capítulo apresenta alguns cenários para a formação de multidomínios com o objetivo de apresentar os aspectos particulares destes tipos de ambientes quanto à definição da política de controle de acesso.

- Capítulo 3 - Multidomínio de Segurança: Este capítulo apresenta a definição de domínio pessoal de segurança e multidomínio de segurança. Um multidomínio, no contexto deste trabalho, segue a definição proposta pelo projeto MPSD (VENTURINI, 2005; SAKURAGUI, 2005).

- Capítulo 4 - Modelos de Controle de Acesso: Este capítulo apresenta os principais modelos de controle de acesso encontrados na literatura e alguns trabalhos relacionados ao controle de acesso em multidomínios. O objetivo deste capítulo é expor o conjunto de idéias e técnicas utilizadas na definição do modelo proposto.

- Capítulo 5 - Modelo Ontológico de Segurança: Este capítulo descreve a contribuição principal desta tese, a qual se caracteriza pela proposta de um Modelo Ontológico de Segurança (MOS) para viabilizar a negociação de uma política de segurança para o controle de acesso em ambientes multidomínio.

- Capítulo 6 - O MOS em Multidomínios Pessoais: Este capítulo visa mostrar a aplicabilidade do MOS em multidomínios pessoais, através de uma especialização da ontologia proposta pelo MOS para a aplicação em domínios pessoais.

- Capítulo 7 - O MOS em EaD: Este capítulo visa apresentar um exemplo de aplicação do MOS em multidomínios para Ensino a Distância.

- Capítulo 8 - Discussões: Este capítulo discute as principais contribuições do trabalho e apresenta como o modelo proposto atende aos requisitos citados nos capítulos 1 e 2 .

- Capítulo 9 - Considerações Finais: Este capítulo tece algumas considerações finais sobre o trabalho e apresenta sugestões de trabalhos futuros. 


\section{Capítulo 2 - Aspectos de Segurança}

Este capítulo apresenta alguns cenários para a formação de multidomínios com o objetivo de apresentar os aspectos particulares destes tipos de ambientes quanto à definição da política de controle de acesso.

\subsection{Cenários de Multidomínios}

Multidomínios são formados para o compartilhamento seguro de recursos entre dispositivos pertencentes a diferentes domínios. Um multidomínio pode ser formado para o compartilhamento de músicas entre amigos, para uma reunião entre parceiros de negócio, ou qualquer outro fim. Os recursos compartilhados podem ser arquivos, serviços, informações pessoais, conectividade, etc.

A autenticação e o controle de acesso em multidomínios são serviços difíceis de serem executados, devido à natureza ad hoc e distribuída desses ambientes, tanto quanto à disponibilidade de recursos quanto à administração de segurança. Este capítulo busca identificar os aspectos de segurança característicos deste tipo de domínio, relativos à definição e execução de uma política de controle de acesso, com um nível de detalhamento e especificação que permita uma autorização diferenciada entre os membros de um mesmo multidomínio. É importante considerar a existência de algum mecanismo de autenticação dos membros do multidomínio, como, por exemplo, o mecanismo baseado em certificados digitais de chave pública (ADAMS, 1999; HOUSLEY, 1999), proposto pelo projeto MPSD (VENTURINI, 2005).

Uma política de controle de acesso é um conjunto de regras que define quem (usuário) tem direito a realizar quais operações sobre cada recurso em um determinado domínio. A 
política de controle de acesso é definida sobre um modelo de controle de acesso, que direta ou indiretamente permite definir autorizações para um usuário realizar operações sobre um recurso. Desta forma, para a definição da política é necessário, em algum momento, conhecer os recursos disponíveis, as possíveis operações sobre estes recursos e os usuários que atuam nesse domínio.

Os cenários apresentados abaixo visam exemplificar alguns aspectos relativos à segurança e usabilidade no que tange o controle de acesso em multidomínios. Tais cenários servem para ilustrar e exemplificar os conceitos mais importantes relacionados com segurança da informação em multidomínios.

\subsubsection{Cenário Familiar}

Suponha inicialmente o multidomínio de uma família, composto pelos domínios pessoais de seus membros. Neste caso, apesar de cada domínio pessoal ser independente, de novos dispositivos poderem ser adquiridos e outros abandonados a qualquer instante e dos recursos disponíveis dependerem de quem estiver em casa naquele momento, o conjunto de usuários do multidomínio é limitado (poucos), bem definido e conhecido. O nome dos usuários poderia ser utilizado para definir a política de controle de acesso em cada domínio, independente do mecanismo de autenticação definido (registro de senhas, certificados, etc.). Da mesma forma, o conhecimento dos usuários sobre os recursos disponíveis pode ser informalmente obtido através do relacionamento familiar. Apesar da pouca rigidez deste tipo de multidomínio, se houver o interesse ou necessidade de conhecer a política de controle de acesso do multidomínio, não é naturalmente possível. Seria necessário um procedimento manual ou automatizado para coletar a política de controle de acesso definida em cada dispositivo de cada domínio pessoal (ou, no mínimo, de um dispositivo “central” de cada domínio) e realizar a composição das políticas individuais. Essa tarefa pode não ser tão 
simples quanto parece, pois cada domínio pode utilizar modelos de controle de acesso diferentes, assim como identificar internamente os usuários por apelidos ou utilizar outra forma de vínculo indireto, como grupo (irmãos) ou papel (filho). Desta forma, compor políticas definidas em diferentes domínios administrativos de segurança, por um processo automatizado, sem uma padronização, pode ser, por si só, um desafio.

\subsubsection{Cenário de Amigos}

Considere um outro exemplo, um multidomínio de amigos. Se todos os amigos se conhecem e o número de amigos não é muito grande, ou ainda uma política única pode ser definida para todos, ou grupos deles, os problemas deste exemplo são os mesmos do multidomínio familiar. No entanto, apesar de ser formado por usuários conhecidos (amigos), se for permitido aos amigos inserirem outros amigos no multidomínio, o conhecimento sobre o conjunto de usuários do multidomínio pode ser dificultado, assim como o gerenciamento (atualização) da política de controle de acesso. A menos que a política não exija regras diferenciadas por usuário, como poderia ser o caso de um multidomínio com o objetivo de simplesmente compartilhar músicas, algum procedimento deveria permitir o conhecimento sobre os usuários para definir as regras de autorização adequadas. Este exemplo levanta três aspectos para a definição da política. Primeiro, o número de usuários pode inviabilizar a administração das políticas por um usuário comum (que não é um administrador de sistema), portanto, modelos de controle de acesso que permitem o mapeamento indireto, através de grupos ou papéis, podem melhorar a usabilidade e facilitar o gerenciamento da segurança. Segundo, a adição de novos domínios (amigos) em um multidomínio pode significar uma redefinição da política de segurança, dependendo do multidomínio. Terceiro, o exemplo mostra que o objetivo para a formação do multidomínio define algumas características da política necessária. Por exemplo, no caso do compartilhamento de música, uma mesma 
política poderia ser definida para todos os usuários; neste caso, não seria necessária uma renegociação da política quando um novo domínio fosse adicionado ao multidomínio.

\subsubsection{Cenário de Entretenimento}

Um multidomínio público, ou seja, um multidomínio que aceite quaisquer outros domínios, por exemplo, dentro da curta área de alcance de uma rede sem fio, também pode ter seus requisitos de segurança. Suponha que uma pessoa, enquanto espera seu vôo no aeroporto, resolve criar um multidomínio público ${ }^{3}$. Essa pessoa possui um vasto material cultural no seu notebook (ou em seu PC em casa, se houver conexão disponível), como fotos de locais históricos por onde passou, álbuns digitais sobre obras de arte, livros, filmes, músicas, etc. Embora esteja interessado em obter um filme que ainda não tenha assistido para passar o tempo e relaxar, cria um multidomínio para o compartilhamento de material multimídia, na intenção de que algum outro passageiro associe-se ao multidomínio e compartilhe um filme interessante, enquanto compartilha seu material. Para sua surpresa, obtém diversas requisições de associação de outros domínios, as quais aceita, compartilhando indistintamente seu material (autoriza a todos o direito de visualização sobre o material). Num multidomínio público seria de se esperar um compartilhamento sem distinção. No entanto, quando o criador do multidomínio busca por filmes compartilhados observa que os demais domínios apenas têm músicas compartilhadas, e nada coerente com seu gosto por músicas clássicas. Mas seu material pareceu bem atrativo aos outros domínios, obtendo diversos acessos. É possível imaginar o impacto desta associação: a pessoa não obteve o que procurava e ainda teve os

\footnotetext{
${ }^{3}$ Um mecanismo para a divulgação e busca por multidomínios públicos seria necessário. Isso não seria problema dentro da área de alcance de uma rede 802.11, por exemplo, utilizando serviços de localização conhecidos, como SLP (GUTTMAN, 1999), Jini (SUN MICROSYSTEM, 2001), UpnP (MICROSOFT CORPORATION, 2000), Salutation (THE SALUTATION CONSORTIUM, 1999), etc.
} 
recursos computacionais e de conexão do seu notebook consumidos em demasia. Este exemplo levanta algumas questões. Neste caso, a política de controle de acesso não necessita conhecer os usuários do multidomínio, no entanto, precisa de regras de controle sobre, por exemplo, o número de usuários simultâneos permitidos a acessar os recursos disponibilizados. Outro ponto é a falta de informação, durante a formação do multidomínio, para decidir se a associação atende, ou pelo menos tem chance de atender, aos seus interesses. Por exemplo, seria interessante que durante a criação do multidomínio o usuário pudesse informar com alto grau de abstração, seus interesses como consumidor de recursos (filmes) e sua disponibilidade como provedor de recursos (filmes, músicas, etc.). Da mesma forma, que os domínios informassem seus interesses e disponibilidade de recursos ${ }^{4}$ durante a associação. Desta forma, seria possível que houvesse uma verificação de conflito de interesses já durante a formação do multidomínio, não só por parte do criador, mas também dos demais membros, evitando que tempo e recursos fossem desperdiçados. O criador poderia atuar como responsável pela composição da política, a partir das políticas dos domínios individuais (interesses e disponibilidade), e detecção de eventuais conflitos. Neste caso, uma (re)negociação das políticas individuais poderia ser possível ou necessária.

Um conflito de interesse também poderia ocorrer por existirem operações que precisam ser autorizadas e executadas por algum usuário, ou recursos que precisam ser disponibilizados para a realização de uma operação obrigatória. Operações estas que são necessárias para que o motivo da criação do multidomínio se cumpra. Por exemplo, num multidomínio criado para reuniões de condomínio, quando os condôminos compartilham suas sugestões, colaboram na redação de normas decididas durante a reunião, e um redator redige a ata que deve ser impressa, assinada por todos e uma cópia digital deve ser armazenada num

\footnotetext{
${ }^{4}$ Parte-se do princípio que os domínios não agem de má fé ao informar sua disponibilidade de recursos. Caso contrário, a troca de informações seria inútil para os recursos disponibilizados pelo domínio faltoso, e os problemas apresentados no cenário se mantêm.
} 
repositório para este fim. Para que a reunião seja validada é necessário que haja um redator, recurso de impressão e um repositório para armazenamento, compartilhado, pelo menos, com o redator. Observe que o conflito pode ocorrer por requisito da política de uso definida para o multidomínio e não por interesses individuais. Portanto, pode ser interessante que o multidomínio possa ter, além de um objetivo para sua formação, políticas de obrigação definidas de forma semelhante ao que ocorre com a política de interesse do exemplo anterior.

\subsubsection{Cenário de Negócios}

Como um último exemplo, considere um multidomínio para uma reunião de negócios. Os representantes das empresas estabelecem um multidomínio para o compartilhamento de recursos. O representante da empresa que está hospedando a reunião, através de seu domínio pessoal, compartilha a conectividade com a Internet, serviço de impressão e projetor multimídia. Todos compartilham arquivos de interesse comum em seus notebooks, cartões pessoais em seus PDA e celulares, etc. Suponha que as negociações se prolongam por mais que uma reunião e que o multidomínio tem igual duração. Durante o período de negociação, pode ocorrer de um representante não poder comparecer e enviar um substituto, assim como pode ser necessário o apoio de outros membros da empresa para auxiliar na tomada de decisão. Isto significa a presença de outros usuários que precisam participar do multidomínio. Como visto anteriormente, novo usuário implica alteração na política de controle de acesso. Este exemplo possui algumas características específicas: a) o objetivo do multidomínio é compartilhar recursos entre empresas, independente de qual usuário estará representando cada empresa. b) o representante de uma empresa pode ter interesse em restringir o acesso de outros membros a algumas informações compartilhadas no multidomínio. Por exemplo, o diretor, representando a empresa, em dado momento, precisa do parecer técnico de um funcionário da produção, solicitando que o acompanhe em uma das reuniões. Este funcionário 
deve ter acesso apenas aos documentos com as especificações relativas a sua atividade e não outros documentos envolvidos na negociação. Essas características levantam alguns aspectos interessantes que podem ajudar na definição de um modelo mais flexível e adequado para este tipo de multidomínio. Seria interessante que a política de controle de acesso do multidomínio pudesse ser definida para um representante qualquer dos domínios e que os domínios tivessem autonomia e autoridade para definir ou alterar o(s) usuário(s) que os representarão a cada momento. Isto pode ser possível através da delegação de autoridade e uso de credenciais. O uso de delegação de autoridade e credenciais pode ter outra vantagem que é permitir a privacidade do usuário. Por exemplo, a credencial pode indicar que o possuidor da chave privada correspondente à chave pública, constante na credencial, está autorizado a assumir o papel $\mathrm{X}$, ou participar do grupo $\mathrm{Y}$, no multidomínio, não revelando a real identidade do usuário.

\subsection{Segurança e Usabilidade}

Os exemplos acima levantam alguns requisitos de segurança e usabilidade para a formação de multidomínios e definição de políticas de controle de acesso para tais ambientes, como segue:

- Política compartilhada e conhecida por todos: a definição da política de controle de acesso para o multidomínio deve seguir um modelo de controle de acesso que apresente um denominador comum entre todos os domínios interconectados. Este modelo pode então ser mapeado/traduzido para o modelo interno de cada domínio para sua execução. Isto é necessário para viabilizar a composição das políticas definidas pelos domínios individuais em uma política comum do multidomínio, mantendo o isolamento da política interna dos domínios. 
- Utilizar certo grau de abstração: a definição de uma política de controle de acesso com alto grau de abstração, que possa indicar os interesses e disponibilidade de recursos de cada domínio, pode auxiliar na negociação da política para o multidomínio. O alto grau de abstração facilita a interpretação e composição da política.

- Mapeamento indireto de autorização: a utilização de mapeamento indireto entre usuários e autorizações no modelo de controle de acesso pode permitir a utilização de políticas pré-definidas, o que contribui para a usabilidade e segurança. Um mapeamento indireto ocorre quando as autorizações são atribuídas às entidades abstratas do sistema, como papéis ou grupos, e essas entidades abstratas são posteriormente associadas aos usuários.

- Considerar o objetivo para a formação do multidomínio na definição da política: ter um objetivo bem definido para o multidomínio pode auxiliar na definição da política de controle de acesso, assim como definir se há ou não a necessidade de renegociação da política quando há uma alteração nos domínios (ou usuários) participantes.

- Detectar conflitos já durante a formação do multidomínio: deve ser possível detectar conflitos de interesses durante a formação do multidomínio, evitando o desperdício de tempo, recursos computacionais e banda de conexão, que são requisitos essenciais em redes ad hoc.

- Evitar a necessidade de renegociação: três situações podem alterar a política de controle de acesso do multidomínio: a) A adição ou remoção de domínios. b) Uma alteração nos usuários participantes em cada domínio. c) Uma alteração na política dos domínios individuais. Quando ocorre um destes casos pode ou não ser necessário informar a todos sobre a alteração, isto depende do objetivo e da política de formação 
do multidomínio. Uma renegociação da política pode ser necessária, o que pode acarretar um excesso de trocas de mensagens para uma rede ad hoc.

- Permitir a delegação de autoridade: a utilização de delegação de autoridade pode melhorar a autonomia dos domínios, ao mesmo tempo em que reduz a necessidade de alteração na política. Neste caso, é necessário o mapeamento indireto citado anteriormente.

- Permitir política com privacidade dos usuários: o uso de credenciais, em conjunto com a delegação de autoridade pode permitir a privacidade de usuários. A autoridade para a qual foi delegado o direito de emitir credenciais é capaz de autenticar o usuário e emitir uma credencial de acesso. Estas credenciais, utilizadas para obter acesso aos recursos, podem não conter informações sobre a identidade do usuário. 


\section{Capítulo 3 - Multidomínio de Segurança}

Este capítulo apresenta o conceito de multidomínio de segurança, que é um domínio lógico de segurança formado por múltiplos domínios de segurança, numa formação ad hoc. Um multidomínio, no contexto deste trabalho, segue a definição proposta pelo projeto MPSD (VENTURINI, 2005; SAKURAGUI, 2005).

A seção 3.1 apresenta o conceito geral de domínio de segurança. As sessões 3.2 e 3.3 apresentam a definição de domínio de segurança pessoal e pessoal estendido. Finalmente, a seção 3.4 define multidomínios de segurança e a seção 3.5 apresenta alguns aspectos de segurança deste tipo de formação.

\subsection{Domínio de Segurança}

Um domínio de segurança é um conjunto de entidades geograficamente distribuídas, constituindo uma rede virtual aderentes a um conjunto comum de parâmetros de segurança. Esses parâmetros definem a relação de confiança entre as entidades do domínio tal que possam ser autenticadas e reconhecidas como membros do domínio, e estabelecerem uma comunicação segura, com confidencialidade e integridade das mensagens. A autenticação é obrigatoriamente mútua, pois ambos dispositivos precisam reconhecer estarem se comunicando com outro membro do mesmo domínio. Os dispositivos membros de um domínio estão sob mesma política administrativa de segurança, ou seja, existe um (ou um conjunto de) responsável por administrar as regras de segurança para todos os membros do domínio. Em outras palavras, um domínio de segurança tem administração centralizada. O termo simples “domínio” será utilizado neste trabalho para referir-se a um domínio de segurança. 


\subsection{Domínio de Segurança Pessoal}

Um domínio de segurança pessoal se caracteriza por ser composto pelos dispositivos que uma pessoa possui ou pelo qual é responsável, ou seja, um domínio pessoal é centrado numa pessoa, quem é responsável pela administração da política de segurança do domínio, como mostra a figura 3. Os dispositivos pertencentes a um domínio pessoal operam como se fossem elementos ativos dentro do domínio com capacidade de se comunicarem e autenticarem. Com o objetivo de representar o responsável pela segurança de um domínio pessoal, existe o papel do controlador. O controlador é a entidade em um domínio pessoal responsável pela sua criação e gerenciamento da política de segurança deste domínio. A figura 4 apresenta o modelo conceitual de um domínio em diagrama UML (Unified Modeling Language) (LARMAN, 2002).
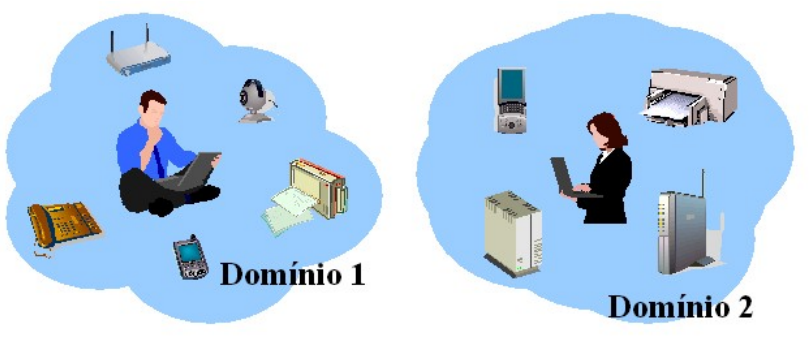

Figura 3 - Domínios de Segurança Pessoal

O domínio de segurança pessoal está representado na figura 4 pelo conceito “DomínioPessoal”. Um domínio é definido por conter membros (elementos ativos), que conhecem os procedimentos de segurança do domínio, e, portanto, são capazes de se reconhecerem e estabelecerem uma comunicação segura. Os membros de um domínio podem ser usuário (pessoa), dispositivos ou sistemas autônomos.

O objetivo da criação de um domínio é compartilhar os recursos (serviços e objetos) entre os membros deste domínio. Esses recursos estão sob a responsabilidade do controlador e podem estar distribuídos em diferentes dispositivos. Um domínio provê serviços, os quais permite aos membros executar operações sobre os objetos compartilhados no domínio. 


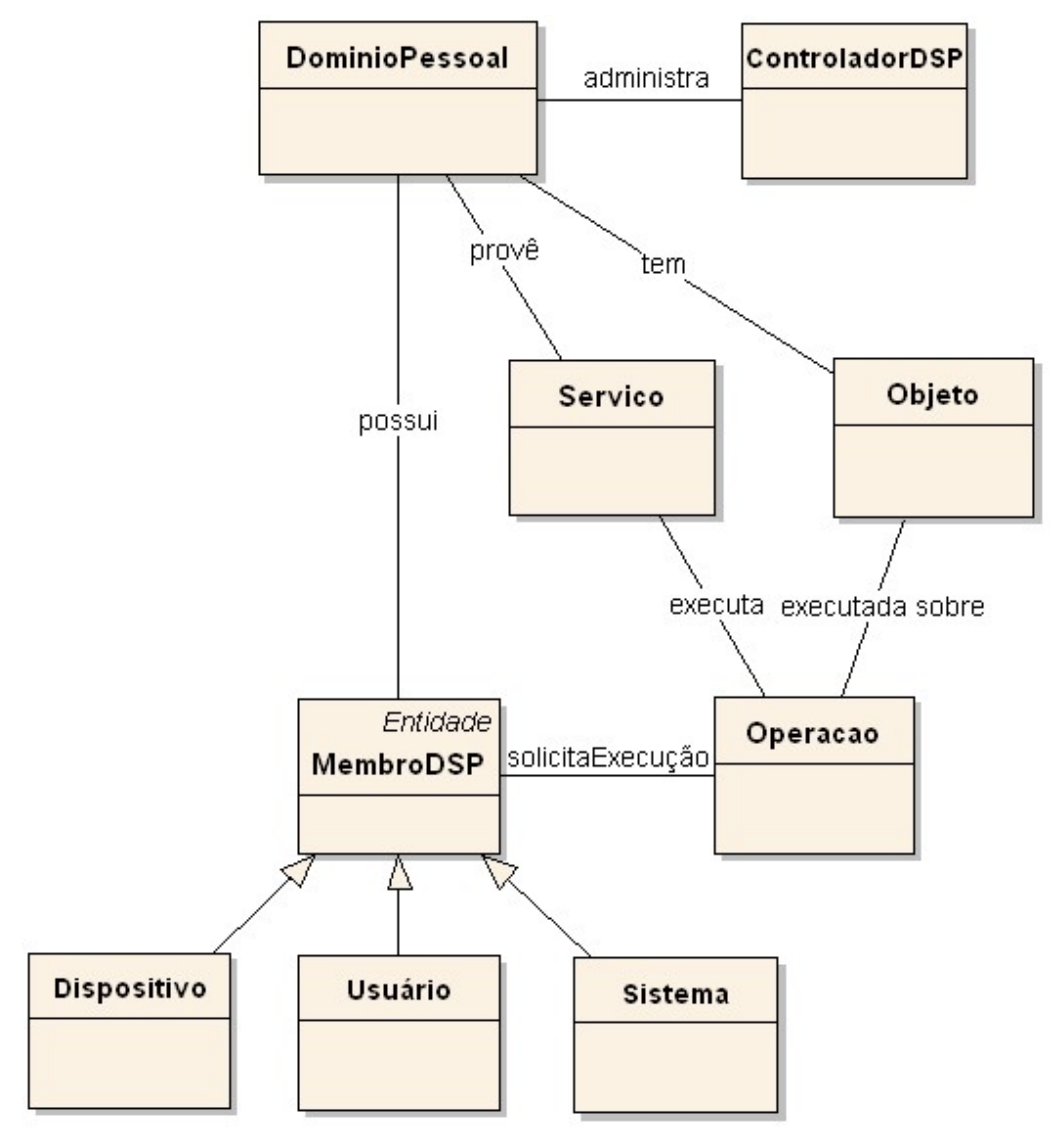

Figura 4 - Diagrama UML de um Domínio de Segurança Pessoal

No contexto do projeto MPSD, o objetivo para a formação de um domínio de segurança pessoal é a comunicação segura entre os dispositivos, sob responsabilidade de uma pessoa, para o compartilhamento de serviços e objetos entre estes dispositivos. Devido à natureza ad hoc de um domínio, os dispositivos e serviços que estão presentes e ativados (habilitados para a comunicação) em cada instante podem mudar. Para facilitar a localização dos serviços disponíveis em dado instante, todo domínio suporta um serviço especial, chamado serviço de localização (SAKURAGUI, 2005). Este serviço pode estar ativo em qualquer dispositivo membro.

O modelo original de controle de acesso do projeto MPSD é baseado em lista de controle de acesso (LCA). Uma LCA corresponde a uma lista de regras de autorização, que permite ou restringe o acesso de membros aos serviços, operações ou objetos. Modelos baseados em LCA, tipicamente, definem as regras de autorização diretamente vinculadas aos 
usuários do sistema, no caso, aos membros do domínio. Por exemplo, uma regra de autorização define que o membro X do domínio tem permissão para utilizar o serviço Y para realizar qualquer operação que este serviço seja capaz de executar.

\subsection{Domínio de Segurança Pessoal Estendido}

Um domínio de segurança pessoal estendido é um domínio de segurança pessoal que se estende além dos limites de uma PAN ou LAN. Quando membros de um mesmo domínio estão ativos e fora do domínio de multicast um do outro, dizemos que eles pertencem a partições distintas de um mesmo domínio. Se a entidade Controlador estiver ativa em uma partição do domínio, esta partição é chamada de partição local, caso contrário, é chamada de partição remota. Um domínio pode ter várias partições remotas, mas apenas uma partição local. Um domínio de segurança pessoal estendido suporta a comunicação segura entre partições de um mesmo domínio, através de um serviço especial, chamado Serviço de Acesso Remoto (SAR, ou RAS - Remote Access Service), como mostra a figura 5.

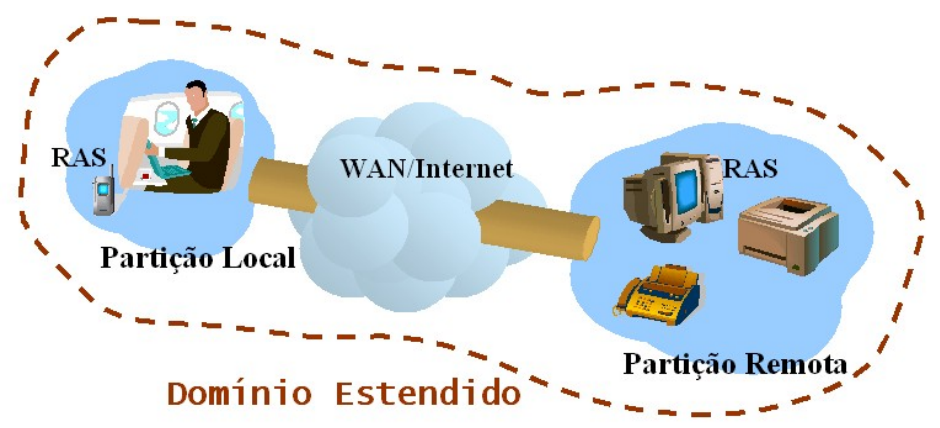

Figura 5 - Domínio de Segurança Estendido

A única diferença conceitual entre o domínio de segurança pessoal estendido e não estendido é a presença de um serviço especial, o SAR. A partir deste ponto, por simplificação, ao utilizarmos o termo domínio de segurança pessoal estaremos nos referindo indistintamente ao domínio estendido ou não, uma vez que, para o modelo de controle de acesso não há distinção entre os serviços comuns e especiais. 


\subsection{Multidomínio de Segurança}

Um multidomínio é um “domínio de segurança composto”, formado a partir da associação entre domínios de segurança, e se distingue por não possuir uma administração centralizada. Um multidomínio de segurança é bastante semelhante ao domínio de segurança pessoal e envolve um conjunto de participantes que são membros dos domínios associados. A figura 6 apresenta o modelo conceitual de um multidomínio em diagrama UML.

O multidomínio de segurança está representado na figura 6 pelo conceito “Multidomínio”. Dizemos que um membro de um domínio associado é um possível participante do multidomínio. Um participante do multidomínio (ParticipanteMD) conhece os procedimentos de segurança e, portanto, está apto a reconhecer e estabelecer uma comunicação segura com outros participantes.

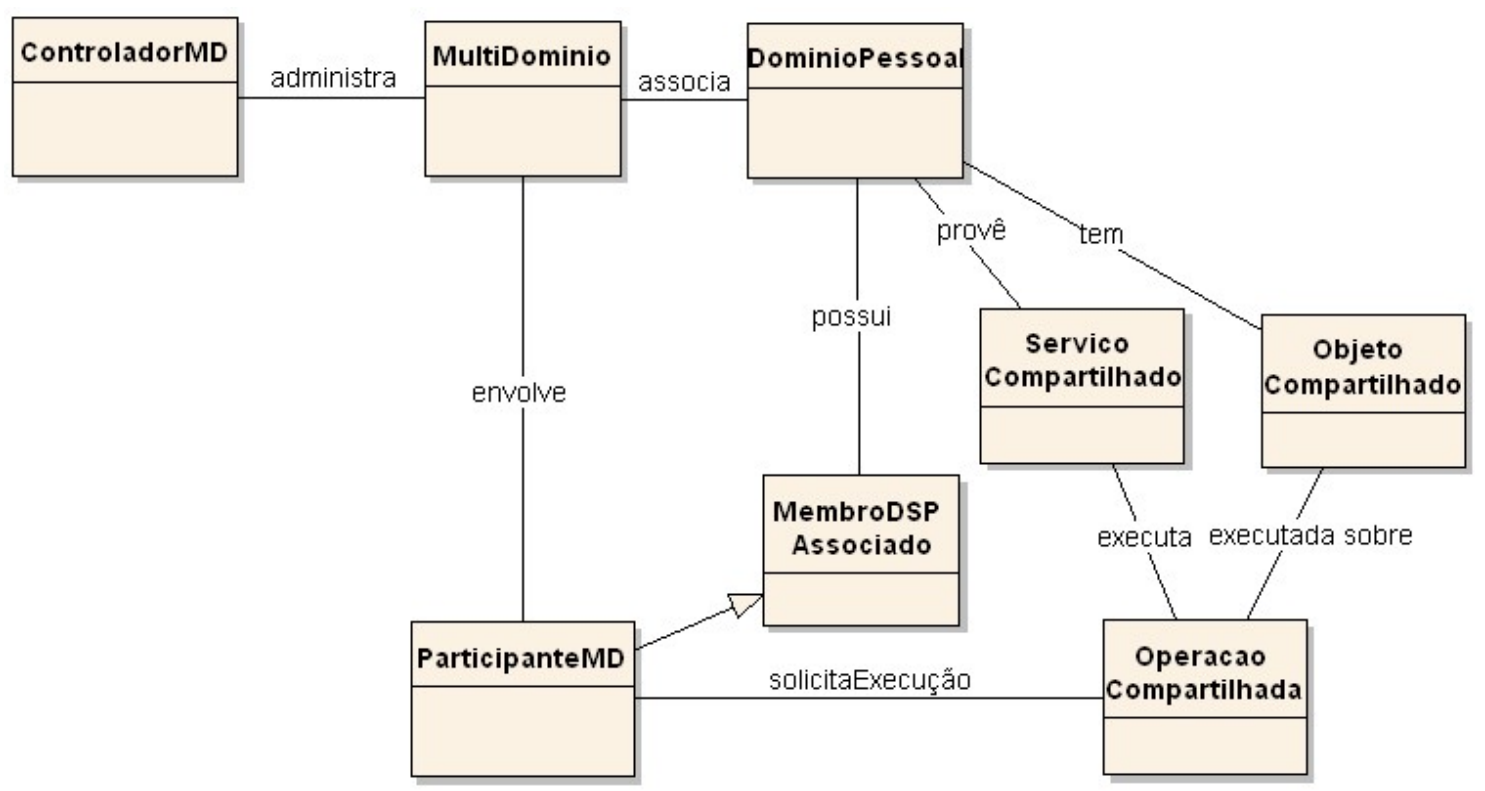

Figura 6 - Diagrama UML de um Multidomínio de Segurança

Os recursos disponíveis em um multidomínio são providos pelos domínios associados, ou seja, cada domínio compartilha parcialmente seus serviços e objetos com os participantes do multidomínio. O Controlador de cada domínio é responsável por definir quais de seus membros participarão do multidomínio. Da mesma forma, o Controlador de cada domínio é 
responsável por criar regras de autorização que permita que participantes do multidomínio possam usar os serviços de seu domínio. O controlador do multidomínio tem apenas a função de associar domínios, não tendo autoridade para atuar sobre os recursos e membros dos domínios associados.

O projeto MPSD atualmente implementa a entidade Controlador do MPSD como um papel que pode ser assumido pelo controlador de um dos domínios associados, normalmente aquele que inicia a formação do multidomínio. Mas esta entidade poderia ser implementada utilizando chaves de grupo ou Autoridade Certificadora (AC) distribuída (ASOKAN, 2000; ZHOU, 1999; HUBAUX, 2001, FOKINE, 2002), passando a ser um papel compartilhado entre um grupo de controladores de domínio.

O modelo de controle de acesso do projeto MPSD é o mesmo para domínios e multidomínios, porém são criadas regras diferenciadas para cada um. Por exemplo, uma regra define que qualquer participante do multidomínio $\mathrm{M}$ tem direito de acessar o serviço $\mathrm{S}$ para realizar a operação O sobre qualquer objeto sobre o qual esta operação atua.

\subsection{Política de Controle de Acesso em Multidomínios}

O conjunto de serviços providos em multidomínios é um subconjunto dos serviços providos pelos domínios associados. Para que os participantes do multidomínio possam acessar estes serviços é preciso que o controlador de cada domínio crie regras de autorização, permitindo o acesso aos serviços que deseja compartilhar com os demais participantes. Isto significa que cada domínio cria sua política de controle de acesso separadamente, através das autorizações, e os demais participantes só terão conhecimento se têm ou não direito em utilizar determinado serviço no momento de acesso.

A política de controle de acesso dos domínios é baseada em LCA. Uma LCA corresponde a uma lista de regras de autorização, que permite ou restringe o acesso de 
membros aos serviços, operações ou objetos. O modelo de controle de acesso definido suporta que regras sejam criadas com alto grau de especificidade, ou seja, é possível definir uma regra autorizando um membro X a utilizar apenas o serviço Y (ex. serviço de compartilhamento de arquivos), para executar a operação Z (obter cópia de arquivos), sobre o objeto W (arquivo.xyz). Por outro lado, também é possível utilizar a palavra reservada “ANY” para autorizar qualquer membro, serviço, operação ou objeto.

A mesma granularidade de regras, aplicada para o domínio, é possível para os participantes do multidomínio. Mas a identidade dos participantes do multidomínio, que não são membros do próprio domínio sendo configurado, é, a princípio, desconhecida. Dito isto, seguem algumas possibilidades:

- Definir uma mesma regra de acesso para todos (ANY) os membros de um multidomínio. Esta solução é muito geral e não atende à necessidade de muitos cenários.

- Definir regras diferenciadas por domínio associado ao multidomínio. Esta solução exigiria a consulta, por parte do controlador de cada domínio, ao controlador do multidomínio para conhecer os demais domínios associados. Neste caso, uma regra seria do tipo: qualquer membro do domínio X é permitido acessar o serviço Y, etc. Esta solução é mais flexível que a anterior, e, a princípio, parece razoável para multidomínios formados por domínios pessoais. Porém, pode não ser adequada para domínios que possuem mais que um usuário.

- Definir regras por participante do multidomínio. Neste caso, cada controlador de domínio teria que perguntar ao controlador do multidomínio sobre os demais domínios associados, e, posteriormente, perguntar a cada controlador dos demais domínios sobre seus membros ${ }^{5}$. Apesar de possível, a quantidade de troca de mensagens e a

\footnotetext{
${ }^{5}$ O próprio Controlador do multidomínio poderia “coletar” a identidade dos membros dos domínios.
} 
quantidade de regras a serem criadas seriam inadequadas para uma rede sem fio ad hoc $^{6}$ e de uso pessoal, mesmo para pequenos domínios. Sem falar que não escala para domínios maiores.

Um dos problemas das duas últimas soluções é a manutenção da política de controle de acesso, pois quando um novo domínio (ou membro) é associado, novas regras precisam ser criadas para aquele domínio (ou membro). Embora o controlador do multidomínio possa disparar o processo de atualização da política, este processo exige a intervenção dos responsáveis pelos domínios, o que pode ser um inconveniente.

Por simplificação, a implementação atual permite apenas que a mesma regra seja aplicada para todos os membros do multidomínio, deixando o problema em aberto para a definição de um modelo que se ajuste a política interna dos domínios e ao mesmo tempo flexibilize a política de controle de acesso em multidomínios. Esta simplificação implica na criação de um multidomínio distinto por perfil de direitos de acesso.

O processo de autorização ocorre após a autenticação do membro requisitante. A infraestrutura de segurança do projeto MPSD é capaz de autenticar qualquer membro pertencente a um domínio, ou participante de qualquer multidomínio ao qual o domínio está associado. A informação sobre o participante autenticado é passada para o módulo de autorização, para que possa ser verificado se existe uma regra que permite ao requisitante acessar o serviço solicitado. Isto significa que é possível distinguir entre participantes de um multidomínio no momento de execução da autorização, mas existe uma dificuldade de se conhecer, a priori, a identidade do participante para que as regras sejam criadas.

\footnotetext{
${ }^{6}$ Um multidomínio deve ser simples para formações de curta duração e ao mesmo tempo permitir a persistência da formação por tempos mais longos quando necessário.
} 


\subsection{Considerações}

Este capítulo apresentou a definição de domínios de segurança pessoal e multidomínios, no contexto do projeto MPSD, com suas características de segurança. Alguns aspectos de segurança relativos ao mecanismo de controle de acesso adotado para multidomínios foram apresentados, mostrando a necessidade de um modelo que melhor atenda aos requisitos destes ambientes.

As argumentações apresentadas em 3.5 mostram que:

- O uso de Lista de Controle de Acesso (LCA) é adequado para domínios pessoais, que possuem uma administração centralizada, quando a adição de novos membros é menos freqüente e os membros são bem conhecidos pela pessoa responsável pela administração da segurança. Não é adequado para ambientes multidomínio.

- No caso de multidomínios, o grau de especificidade necessário para a definição de regras de autorização, relativo ao requisitante (multidomínio, domínio ou membro/participante), depende das características tanto dos domínios quanto do multidomínio. Por exemplo:

o Em um multidomínio para o compartilhamento de músicas entre amigos, pode ser suficiente definir a mesma regra para todos os membros do multidomínio (grau de especificidade: multidomínio).

o Enquanto que, um multidomínio formado por domínios de laboratórios de pesquisa de diversas universidades, com o objetivo de colaborarem sobre um projeto de pesquisa, pode exigir que regras distintas sejam definidas aos participantes do multidomínio (grau de especificidade: membro).

Resumindo, existem três pontos importantes com relação aos requisitos do modelo de controle de acesso para multidomínios: 
- Permitir a definição flexível de regras de autorização, viabilizando que membros de um mesmo domínio possam ter autorizações diferenciadas, quando participando de um multidomínio.

- Evitar que a associação, ou desassociação, de domínios em um multidomínio exijam uma redefinição ou atualização das regras de autorização. Mesmo a adição ou remoção de membros dos domínios já associados, pode implicar numa alteração das regras, dependendo do modelo.

- Viabilizar que os domínios tenham conhecimento de seus direitos de acesso, mesmo que com alto grau de abstração, sem necessidade de requisitar o acesso.

O próximo capítulo apresenta os principais modelos de controle de acesso encontrados na literatura e alguns trabalhos relacionados que formam a base do modelo proposto. 


\section{Capítulo 4 - Modelos de Controle de Acesso}

Este capítulo apresenta os principais modelos de controle de acesso encontrados na literatura e alguns trabalhos relacionados ao controle de acesso em multidomínios. O objetivo deste capítulo é expor o conjunto de idéias e técnicas utilizadas na definição do modelo proposto.

A seção 4.1 apresenta os conceitos básicos relacionados ao controle de acesso. Em 4.2 são apresentados os principais modelos, amplamente conhecidos na literatura. O modelo de controle de acesso baseado em papéis, padronizado pelo NIST, é apresentado em 4.3. Esses modelos podem ser estendidos ou agrupados para formar outros modelos. Alguns trabalhos relacionados ao controle de acesso são apresentados em 4.4. Finalmente, a seção 4.5 apresenta algumas considerações sobre o conteúdo apresentado e expõe como os trabalhos relacionados contribuíram para este trabalho.

\subsection{Conceitos Básicos}

A segurança de sistemas computacionais pode ser obtida através da adequada utilização dos serviços de segurança: autenticação, confidencialidade, integridade, disponibilidade, controle de acesso e irretratabilidade (STALLINGS, 1998). O propósito do controle de acesso é limitar as ações ou operações que um usuário legítimo de um sistema de computação pode desempenhar (SANDHU, 1994), baseado em autorizações verificadas no momento do acesso. O controle de acesso não pode ser visto como um serviço isolado, pois ele interage com os outros serviços para prover segurança. Por exemplo, o controle de acesso atua sobre a confidencialidade quando permite que dados sigilosos sejam acessíveis apenas a usuários autorizados. De certa forma, também protege a integridade dos dados quando não 
permite a sua alteração não autorizada. A disponibilidade de um serviço pode ser obtida pelo controle de acesso, se devidamente implementado.

A figura 7 mostra os componentes envolvidos no controle de acesso. O requisitante ${ }^{7}$, neste contexto, representa a entidade ${ }^{8}$ que solicita o acesso, podendo ser uma entidade lógica (sistema) ou física (pessoa, equipamento). O alvo sobre o qual o requisitante solicita acesso, para executar uma ação, é genericamente chamado de objeto, podendo ser um serviço, recurso, rede, domínio, etc. O executor do controle de acesso é chamado de monitor de referência, responsável por receber as solicitações do requisitante autenticado, verificar as regras de autorização e liberar ou bloquear o acesso ao objeto do sistema.

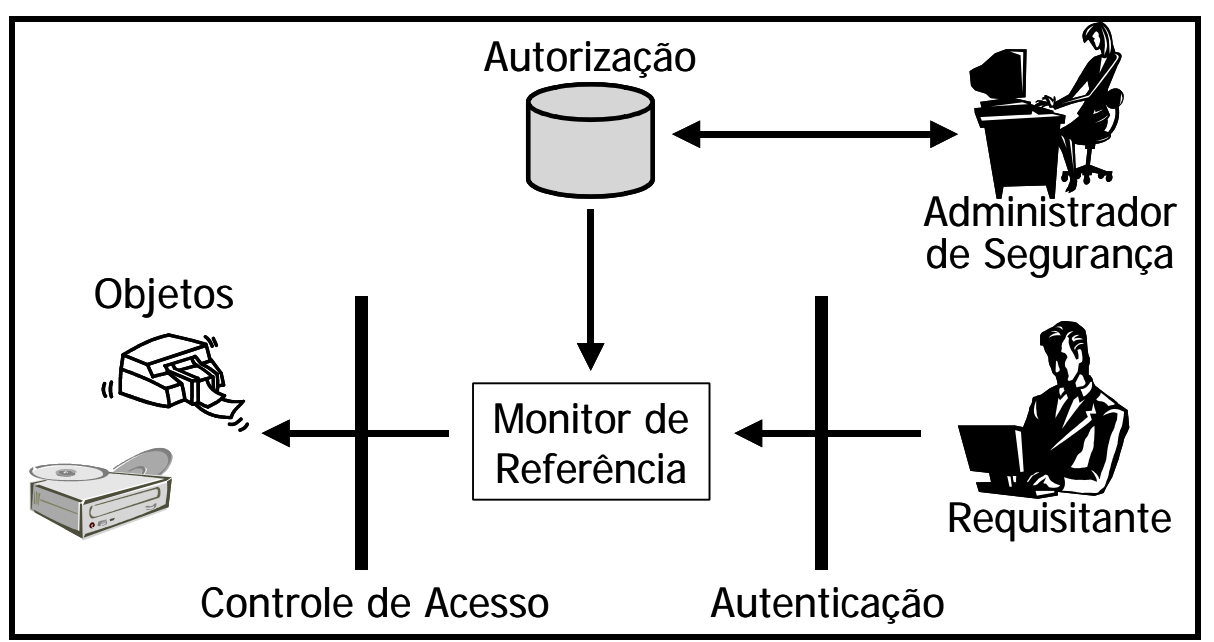

Figura 7 - Serviço de Controle de Acesso

O monitor de referência depende da correta autenticação do requisitante e da lista de autorizações para que possa realizar o controle de acesso com segurança. Uma falha em qualquer um desses serviços significa uma falha também no controle de acesso. Para completar a segurança é necessário também um serviço de auditoria (SANDHU, 1994), capaz

\footnotetext{
${ }^{7} \mathrm{O}$ termo requisitante está sendo utilizado para se referir à entidade que está solicitando acesso ao sistema, portanto se sujeitando a autenticação e controle de acesso.

${ }^{8} \mathrm{O}$ termo entidade está sendo utilizado para se referir genericamente aos usuários do sistema, sejam eles pessoas, unidades de software ou equipamento.
} 
de analisar as requisições e atividades das entidades sobre o sistema e detectar possíveis falhas na segurança.

\subsubsection{Autenticação}

A autenticação é um processo de identificação seguido de uma verificação de identidade. A autenticação exerce uma função primordial no controle de acesso (JOSHI, 2001). Através da autenticação, a identidade do requisitante pode ser garantida. Esta é uma condição necessária para a aplicação correta das regras de autorização.

\subsubsection{Autorização}

A autorização é a verificação da existência de uma permissão, ou a ausência de uma restrição, para um requisitante atuar sobre um objeto do sistema. O controle de acesso baseiase nas autorizações para conceder ou não o acesso para um requisitante. Uma regra de autorização incorretamente inserida pode acarretar sérios danos ao sistema de segurança, seja permitindo um acesso não autorizado, seja impedindo o acesso por uma entidade legítima (disponibilidade). Desta forma, a administração das autorizações deve ser conduzida sob requisitos rígidos de segurança.

\subsubsection{Auditoria}

A auditoria é o processo através do qual é possível rastrear uma ação no sistema. A auditoria requer o registro (logging) de todas as requisições e atividades realizadas para sua futura análise. O controle de auditoria pode ser útil tanto para inibir a violação da segurança por entidades legítimas quanto para analisar o comportamento das entidades e descobrir possíveis violações (SANDHU, 1994). Outra função importante da auditoria é auxiliar na determinação de possíveis falhas no sistema de segurança. 


\subsection{Principais Modelos}

Diversos modelos de controle de acesso são encontrados na literatura. Os mais tradicionais são chamados de modelos de controle de acesso discricionário e modelo de controle de acesso compulsório (SANDHU, 1994; JOSHI, 2001). Outros modelos surgiram posteriormente, como os modelos baseados em papéis e tarefas. Desses modelos surgiram variantes, que adicionam novas características de controle.

A política de controle de acesso não precisa seguir um modelo específico. Diferentes modelos podem ser combinados para fornecer a proteção adequada ao sistema. Os modelos apresentados a seguir servem de base para a definição de outros modelos, que atendam às necessidades específicas dos mais diversos sistemas.

\subsubsection{Modelo Discricionário}

Este é um dos modelos mais utilizados, devido à sua flexibilidade. O modelo de controle de acesso discricionário (CAD, ou DAC - Discretionary Access Control) controla o acesso das entidades baseado na identidade do requisitante e nas regras de autorização. As autorizações são definidas para cada entidade, ou grupo de entidades, sobre cada objeto do sistema que a entidade tem acesso (SANDHU, 1994). Cada requisição de acesso do requisitante é verificada sobre cada regra de autorização definida. Por exemplo, as autorizações são definidas em listas de controle de acesso (LCA), localizadas junto ao objeto protegido. Quando um requisitante solicita realizar uma operação sobre o objeto, a LCA é varrida, buscando por uma permissão para o requisitante realizar a operação solicitada. Se houver essa permissão, o requisitante é liberado para realizar a operação, caso contrário, a operação é bloqueada. 
Este tipo de modelo considera que o objeto protegido pertence a uma entidade do sistema, a qual tem direito de definir ou revogar autorizações para outras entidades, ou grupo de entidades (JOSHI, 2001).

O modelo CAD suporta autorizações positivas (permissões) ou negativas (restrições). Autorizações positivas definem permissões e autorizações negativas definem bloqueios. De acordo com a forma que autorizações positivas ou negativas são utilizadas, a política de controle de acesso discricionário pode ser classificada como fechada ou aberta (SANDHU, 1994). Modelos fechados são baseados em autorizações positivas explicitamente especificadas, caso nenhuma autorização explicita seja encontrada o acesso é bloqueado. Enquanto que modelos abertos são baseados em autorizações negativas explicitamente especificadas. O acesso é liberado se nenhum bloqueio foi especificado. Tanto para modelos fechados quanto para modelos abertos, as autorizações devem ser especificadas para cada entidade (ou grupo) e para cada objeto do sistema. O uso de autorização positiva ou negativa pode ser combinado, permitindo a especificação de permissão ou bloqueio. Neste caso, as interações entre autorizações positivas e negativas podem se tornar extremamente complicadas.

O CAD tem a desvantagem de dificultar a administração unificada da política, por exemplo, para saber os privilégios de uma entidade é preciso buscar a LCA em cada objeto do sistema. Da mesma forma, remover um privilégio pode envolver semelhante esforço. O problema se agrava quando se fala de sistemas distribuídos ou heterogêneos. Este problema ocorre devido à natureza do modelo, que vincula diretamente entidades, ou grupos de entidades, aos objetos através das autorizações. O modelo discricionário também tem a desvantagem de não fornecer garantia sobre o fluxo da informação em um sistema. Por exemplo, um usuário que possa ler uma informação, pode também passá-la a outros usuários não autorizados, ou seja, o modelo não impõe qualquer restrição sobre o uso da informação 
acessada. O modelo compulsório pode ser uma solução para sistemas que possuem este requisito.

A política de controle de acesso definida para o multidomínio, ou seja, para a composição dinâmica de domínios, não parece adequar-se ao modelo discricionário, pois num multidomínio os objetos e usuários estão altamente distribuídos e sob diferentes domínios administrativos. A aspiração por manter esse isolamento administrativo inviabiliza completamente a utilização direta de um modelo discricionário para o multidomínio.

\subsubsection{Modelo Compulsório}

O modelo de controle de acesso compulsório (CAC, ou MAC - Mandatory Access Control) tem sua origem na área militar e de segurança nacional, onde o fluxo de documentos confidenciais precisa ser controlado (SANDHU, 1996). O modelo CAC realiza o controle de acesso baseado na classificação de entidades e objetos no sistema (SANDHU, 1994; JOSHI, 2001). Um nível de segurança é atribuído a cada entidade e objeto no sistema. O nível atribuído para a entidade reflete a confiança de que a entidade não revelará informações confidenciais a entidades não autorizadas e o nível atribuído ao objeto reflete o quão crítica é a segurança da informação mantida pelo objeto.

O objetivo deste modelo é controlar o fluxo de informação, de forma a garantir a confidencialidade e integridade da informação. Suponha, quatro níveis de segurança: máxima (MA), média (ME), baixa (BA) e sem restrição (SR). Diz-se que um nível de segurança domina seu nível e todos os níveis abaixo na hierarquia (SANDHU, 1994). Para garantir a confidencialidade da informação o CAC pode usar um mecanismo de segurança em multiníveis, também conhecido como restrições de Bell-LaPadula (JOSHI, 2001). Este mecanismo utiliza regras de bloqueio de leitura para objetos com níveis de segurança acima do nível do requisitante e bloqueio de escrita para objetos com níveis de segurança abaixo do nível do 
requisitante. Por exemplo, um requisitante com nível de confiança ME não poderá ler dados de objetos de segurança MA, mas terá direito de escrever dados de objetos de segurança ME para objetos de segurança MA, pois esses dados serão acessíveis para entidades com maior nível de confiança. Essas restrições são inseridas para garantir que informações não fluam de um nível de segurança mais alto para um nível de segurança mais baixo.

Um aspecto importante relativo à aplicação das restrições acima está na possibilidade da entidade sobrescrever dados em objetos de nível mais elevado. Para evitar essa falha de segurança, alguns sistemas restringem a escrita para o mesmo nível do requisitante, outros proíbem a escrita direta, mas permitem que o dado seja enviado a uma entidade de nível mais alto para que seja escrita.

O nível de segurança atribuído ao objeto relativo à integridade está associado ao grau de confiança que pode ser depositado na informação armazenada, ou de outra forma, o potencial dano que poderia ser causado por uma modificação não autorizada (SANDHU, 1994). Para garantir o nível de integridade, as regras são formuladas para bloquear a leitura para níveis abaixo e bloquear a escrita para níveis acima. Por exemplo, suponha os níveis de integridade essencial (E), importante (I), desnecessária (D). Um requisitante de nível I não pode ler dados de objetos de nível D, mas pode escrever dados para objetos deste nível. Este mesmo requisitante pode ler dados de objetos de nível E, mas não pode escrever dados sobre objetos deste nível. O objetivo é não permitir o fluxo de informação de baixa garantia de integridade para objetos que precisam de alta garantia de integridade.

Para entender a aplicabilidade deste modelo é importante considerar que o principal objetivo não é proteger o sistema de atividades maliciosas executadas por entidades autênticas, mas sim proteger o sistema de atividades maliciosas que possam ser executadas pelas aplicações utilizadas por essas entidades. Por exemplo, impedir que um código malicioso copie informações de segurança MA para objetos de segurança SR, sob 
autenticação de um requisitante autenticado de nível de confiança MA, o que daria acesso à informação por entidades com confiança SR.

Até o momento não foi observado nenhum requisito de segurança para o multidomínio que exigisse características semelhantes às propostas pelo modelo de controle de acesso compulsório. Ao contrário, a necessidade de uma classificação uniformizada para os níveis de segurança seria um fator excludente para o modelo.

\subsubsection{Modelo Baseado em Papéis}

Políticas compulsórias, como CAC, surgem de ambientes rígidos, como o ambiente militar. Políticas discricionárias, como CAD, surgem de requisitos cooperativos ainda que autônomos, como os ambientes de pesquisa acadêmica. Mas nenhuma das duas políticas reflete adequadamente as necessidades de ambientes empresariais (SANDHU, 1994). O modelo de controle de acesso baseado em papéis (CABP, ou RBAC - Role-Based Access Control) fornece uma solução flexível que permite a especificação de autorizações de entidades sobre objetos, como em CAD, junto com a possibilidade de especificar restrições, como em CAC. Pode-se dizer que o CABP tem uma política neutra (SANDHU, 2001), no sentido que, usando papéis hierárquicos e restrições, uma ampla faixa de políticas de segurança pode ser expressa (JOSHI, 2001).

O CABP controla o acesso das entidades às informações com base nas atividades que a entidade precisa executar sobre o sistema para realizar suas funções dentro de uma organização. O modelo CABP mapeia entidades com papéis e papéis com autorizações. Um papel $^{9}$ pode ser definido, por exemplo, como um conjunto de ações e responsabilidades associadas com uma particular atividade de trabalho. O uso de papéis simplifica e organiza a

\footnotetext{
${ }^{9}$ Papel difere da definição de grupo. Grupo são simples coleções de entidades, enquanto papel define uma coleção de entidades de um lado e uma coleção de permissões do outro. Dependendo das responsabilidades assumidas pelo papel.
} 
administração de privilégios. Por exemplo, se um usuário sobe de cargo ou passa a ocupar outra função é suficiente trocar os papéis atribuídos ao usuário. Não sendo necessário alterar os privilégios deste usuário associados a cada objeto do sistema (JOSHI, 2001).

Uma entidade assumindo um papel pode executar todos os acessos para os quais o papel está autorizado. As opções de relacionamentos entre entidade e papel são bastante flexíveis. Em geral, uma entidade pode assumir diferentes papéis em diferentes ocasiões. Também o mesmo papel pode ser assumido por várias entidades, talvez simultaneamente. Algumas propostas para CABP permitem que uma entidade assuma múltiplos papéis ao mesmo tempo. Outras propostas limitam a entidade à somente um papel a cada instante, ou reconhece que alguns papéis podem ser juntamente exercidos enquanto outros são excludentes entre si.

Uma característica importante do CABP é o suporte a restrições de autorização, como, por exemplo, a separação de responsabilidade (SR). A SR restringe a atribuição ou ativação de papéis, definindo, por exemplo, que os papéis A e B não podem ser atribuídos a um mesmo usuário, ou que eles não podem ser ativados simultaneamente. A SR reduz o risco de fraude por não permitir que uma única entidade tenha totais poderes para realizar uma fraude. Outra importante consideração sobre CABP é a possibilidade de restrições temporais sobre os papéis. Um papel pode ser ativado por um parâmetro de tempo ou período de tempo, inclusive sendo ativado pela ativação de um outro papel (JOSHI, 2001).

A abordagem baseada em papéis possui várias vantagens, como:

- Gerenciamento da Autorização: a independência lógica entre a atribuição de papéis a entidades e de direitos de acesso a objetos do sistema simplifica muito o gerenciamento da segurança.

- Regras Hierárquicas: em muitos sistemas há uma hierarquia natural de papéis, baseado em princípios de especialização e generalização. Por exemplo, os papéis de engenheiro 
e engenheiro de software podem ter uma relação hierárquica, onde engenheiro é uma generalização de engenheiro de software. Neste caso, o engenheiro de software herdaria todos os privilégios atribuídos a engenheiro. A utilização de hierarquias pode, portanto, simplificar o gerenciamento da autorização.

- Mínimo Privilégio: o uso de papéis permite que sejam definidos somente os privilégios necessários para a execução daquele papel. Novos privilégios podem ser adquiridos à medida que novos papéis vão sendo assumidos.

- Separação de Responsabilidades: refere-se ao princípio de que não deveria ser dado a qualquer entidade privilégio suficiente para o mau uso do sistema em prejuízo do proprietário. Por exemplo, a pessoa autorizada a pagar cheques não deveria ser também autorizada a emiti-los. Outro exemplo ilustra a SR dinâmica, suponha que a liberação de pagamento precise ser feita por pelo menos dois gerentes. Através da separação de responsabilidade dinâmica poderia ser definido que qualquer usuário no papel de gerente pode iniciar esta atividade e que o segundo usuário a autorizar a liberação deveria ser diferente do primeiro.

(JOSHI, 2001) analisa os modelos para o controle de acesso CAD, CAC e CABP e algumas variações desses modelos quanto a sua adequação para aplicações baseadas na WEB. Em sua análise conclui que uma das características chave para a utilização do CABP é seu potencial suporte para ambientes multidomínio. O autor argumenta que o mapeamento de hierarquia de papéis entre dois domínios de política baseada em CABP poderia ser usado para definir uma meta-política para interoperação segura. Adicionalmente, o uso do CABP em conjunto com as facilidades de Infra-estrutura de Chaves Públicas (ICP, ou PKI - Public Key Infrastructure) [HOUSLEY, 1999; ADAMS, 1999] pode fornecer uma abordagem pragmática para o endereçamento de questões relacionadas à segurança de aplicações WEB distribuídas e workflows. 
(SANDHU, 1996) mostra que o modelo CABP pode ser utilizado para representar desde modelos muito simples até extremamente sofisticados, desta forma seria adequado representar o CABP não como um modelo simples, mas sim como uma família de modelos. Em seu trabalho Sandhu apresenta um conjunto de modelos CABP, os quais foram aceitos como o conjunto básico de modelos CABP pela comunidade (SANDHU, 2001).

Segundo (FERRAIOLO, 2001), embora os modelos CABP existentes sejam relativamente similares sobre os conceitos fundamentais do CABP, eles diferem em detalhes significantes. Os pontos de similaridades e diferenças não são óbvios porque muitos modelos utilizam diferentes terminologias para descrever o mesmo conceito. Para endereçar essas questões de escopo e terminologia, o NIST - National Institute of Standards and Technology do Estados Unidos propôs um modelo de referência padronizado para o CABP.

\subsection{O padrão CAPB proposto pelo NIST}

O padrão proposto pelo NIST para o CABP (FERRAIOLO, 2001), compreende um modelo de referência e um modelo funcional. O modelo de referência descreve o espaço de estado dos componentes do CABP, ou seja, os conjuntos de entidades, relacionamentos e restrições que constituem o modelo. O objetivo é definir um vocabulário comum de termos para especificar requisitos e definir o escopo das características do CABP incluídos no padrão.

A especificação funcional define os requisitos funcionais para as operações administrativas, funções de revisão e funções de suporte ao sistema. As operações administrativas envolvem a criação e manutenção do conjunto de elementos e relações, as funções de revisão desempenham consultas administrativas e as funções de suporte atuam sobre o gerenciamento de sessões do usuário e decisões sobre o controle de acesso. 
O CABP é definido em termos de quatro modelos componentes: Básico, Hierárquico, Separação de Responsabilidade Estática (SRE) e Separação de Responsabilidade Dinâmica (SRD). O CABP básico define um conjunto mínimo de elementos, conjuntos de elementos e relacionamentos para formar um CABP. O CABP hierárquico adiciona relacionamentos para suporte a hierarquias de papéis. O CABP com relação de SRE adiciona relações de exclusividade entre papéis com relação às atribuições do usuário, enquanto o CABP com relação de SRD define relações de exclusividade com relação aos papéis que estão ativos como parte da sessão do usuário.

O padrão define um modelo de referência e funcional para cada modelo componente. Nesta seção será apresentada uma visão geral desses modelos, com algumas informações adicionas para o modelo básico.

\subsubsection{CABP Básico}

O modelo de referência e modelo funcional do CABP básico é apresentado a seguir. O modelo de referência define os principais conceitos envolvidos no CABP e o modelo funcional apresenta os requisitos funcionais e administrativos do modelo.

\subsubsection{Modelo de Refência}

A figura 8 ilustra o modelo de referência do CABP básico. Cada modelo componente é definido pelos subcomponentes:

- um conjunto de conjuntos de elementos básicos,

- um conjunto de relacionamentos envolvendo aqueles conjuntos de elementos, e

- um conjunto de funções de mapeamento que retorna instâncias de membros de um conjunto de elementos para uma dada instância de um outro conjunto de elementos. 


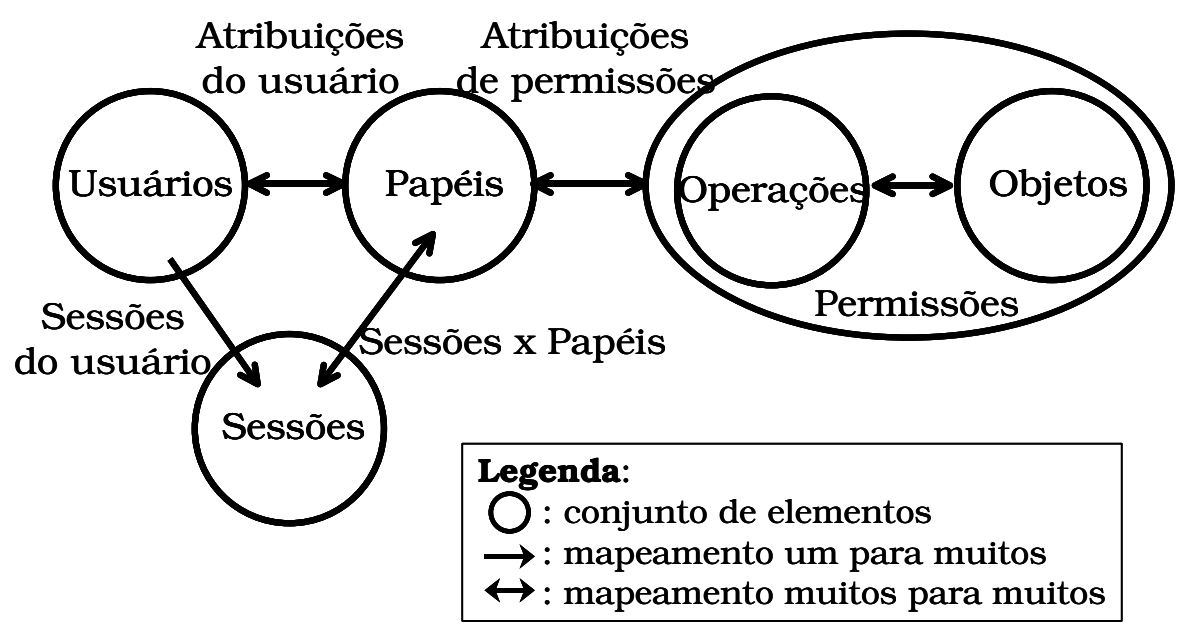

Figura 8 - CABP Básico

\section{Elementos básicos e conjunto desses elementos}

Usuário: um usuário pode ser um ser humano ou um agente autônomo que atua em benefício deste. Usuários é o conjunto de nomes que representam os usuários.

Objeto: um objeto é uma entidade que contém ou recebe informações através da execução de operações associadas. Objetos é o conjunto de nomes que representam os objetos protegidos.

Operação: uma operação é um código executável que, quando invocado, realiza alguma ação sobre um objeto em nome de um usuário. Operações é o conjunto de nomes que representam as operações.

Papel: um papel corresponde a uma função ou cargo numa organização, com atribuições bem definidas para as responsabilidades atribuídas ao detentor do cargo. Papéis é o conjunto dos nomes que representam os papéis.

Permissão: uma permissão é um consentimento para executar uma operação relacionada a um ou mais objetos do sistema. Uma autorização é sempre positiva (permissão) para o CABP do NIST, mas pode ser inserida autorização negativa (restrição) em suas extensões. Permissões é o conjunto de nomes que representam as permissões. 
Sessão: uma sessão corresponde a um momento particular, quando um usuário se conecta a um sistema para realizar alguma atividade que tem o acesso controlado através do CABP. Sessões é o conjunto de nomes que representam as sessões.

O modelo define que os conjuntos dos elementos apresentados acima são disjuntos, ou seja, usuários, papéis, sessões, operações e objetos não podem compartilhar o mesmo nome. [NOME] representa o espaço de nomes dos elementos do CABP.

\section{Definição de Relações e Funções de mapeamento}

(FERRAIOLO, 2001) especifica as funções e relações do modelo utilizando notação $Z^{10}$ (SPIVEY, 1998; JACKY, 2001). Z é uma notação para especificação formal baseada na teoria dos conjuntos e lógica de predicados de primeira ordem.

- Atribuições do Usuário (AU): representa um mapeamento muitos para muitos entre Usuários e Papéis. AU é um subconjunto dos possíveis mapeamentos de usuários para papéis.

$$
\text { AU } \subseteq \text { Usuários } \times \text { Papéis }
$$

- Usuários atribuídos: representa o mapeamento de um papel sobre um conjunto de usuários. O conjunto de usuários atribuídos a um papel é um subconjunto dos usuários, tal que o par (usuário, papel) pertence às Atribuições do Usuário.

$$
\text { UsuáriosAtribuídos(r) = }\{\mathrm{u} \in \text { Usuários } \mid(\mathrm{u}, \mathrm{r}) \in \mathrm{AU})
$$

- Atribuições de Permissão (AP): representa um mapeamento muitos para muitos entre Permissões e Papéis. AP é um subconjunto dos possíveis mapeamentos de permissões para papéis.

$$
\text { AP } \subseteq \text { Permissões } \times \text { Papéis }
$$

\footnotetext{
${ }^{10} \mathrm{Z}$ foi padronizada pela ISO em 2002, ISO/IEC 13568:2002.
} 
- Permissões atribuídas: representa o mapeamento de um papel sobre um conjunto de permissões. O conjunto de permissões atribuídas a um papel é um subconjunto das permissões, tal que o par (permissão, papel) pertence às atribuições de permissões.

$$
\text { PermissõesAtribuídas(r) }=\{\mathrm{p} \in \text { Permissões } \mid(\mathrm{p}, \mathrm{r}) \in \mathrm{AP})
$$

- Sessões do usuário: representa o mapeamento de um único usuário para um conjunto de sessões. Este conjunto de sessões tem mapeamento $(\rightarrow)$ para o conjunto potencial (“Power set ${ }^{11 »)}$ de Sessões $\left(2^{\text {Sessões }}\right)$.

$$
\text { SessõesUsuário(u: Usuários) } \rightarrow 2^{\text {Sessões }}
$$

- Papéis da Sessão: representa o mapeamento de uma sessão sobre um conjunto de papéis. O conjunto de papéis de uma sessão é um subconjunto dos papéis que estão atribuídos ao usuário da sessão.

$$
\text { PapéisSessão( } \left.\mathrm{s}_{\mathrm{i}}\right) \subseteq\left\{\mathrm{r} \in \text { Papéis } \mid\left(\text { UsuárioSessão( } \mathrm{s}_{\mathrm{i}}\right), \mathrm{r}\right) \in \mathrm{UA} \text { ) }
$$

- Permissões disponíveis de uma sessão: o conjunto de permissões disponíveis para um usuário em uma sessão, é a união dos conjuntos de permissões atribuídas aos papéis, quando o papel pertence ao conjunto de papéis da sessão.

$$
\bigcup_{r \in \text { Papéissessão(s) }} \text { PermissõesAtribuídas }(r)
$$

A figura 9 apresenta o modelo CABP básico através de um diagrama UML (SHIN, 2000) ${ }^{12}$. Este diagrama mostra o relacionamento entre os elementos do CABP.

\footnotetext{
11 "Power set": conjunto das partes de um conjunto, ou seja, conjunto de todos os possíveis subconjuntos de um conjunto. Ex.: o conjunto $\{1,2\}$ tem "power set” $\{\varnothing,\{1\},\{2\},\{1,2\}\}$. A representação em potência $\left(2^{\text {conjunto }}\right)$ é utilizada por representar o número de elementos do "Power set", outra notação utilizada é “P conjunto”.

${ }^{12}$ (SHIN, 2000) apresenta um diagrama UML do CABP incluindo restrições e tempo de sessão.
} 


\section{Relacionamentos}

- Um usuário pode ser atribuído para muitos papéis e um papel pode estar associado a muitos usuários.

- Um papel pode estar associado a muitas permissões e uma permissão pode ser atribuída a muitos papéis.

- Um usuário pode estabelecer uma ou mais sessões. Ao iniciar uma sessão o usuário escolhe, entre os papéis atribuídos a ele, os papéis que deseja ativar.

- Uma sessão pode ter ativado um ou mais papéis, entre os papéis atribuídos ao usuário que estabeleceu a sessão.

- Uma permissão concede o direito de execução de uma operação, que pode ser realizada sobre um ou mais objetos. Um objeto pode estar associado a muitas operações.

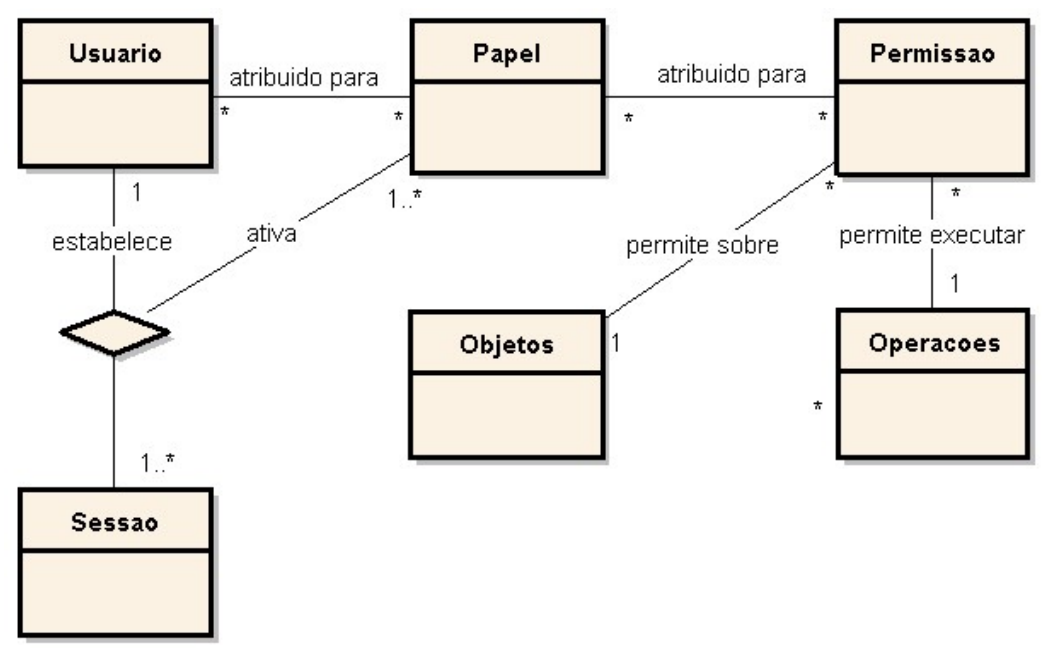

Figura 9 - Diagrama UML do CABP Básico

O CABP básico mostra os papéis como intermediários entre usuários e permissões. As permissões disponíveis para um usuário são as permissões associadas aos papéis ativos existentes em todas as sessões correntes iniciadas pelo usuário. A ativação de papéis não é especificada, mas a especificação requer a capacidade de ativação simultânea de múltiplos papéis. 


\subsubsection{Modelo Funcional}

A especificação funcional define os requisitos funcionais para a realização das operações administrativas e gerenciais do CABP, através da descrição da semântica das diversas funções que são necessárias para a criação e manutenção dos componentes do modelo CABP. O objetivo da especificação funcional é garantir a consistência do modelo após a realização de operações que alteram seu estado. Essas funções são divididas em três categorias:

- Funções administrativas: funções para a criação e manutenção dos conjuntos de elementos e relações para a construção dos vários modelos componentes.

o Funções sobre os conjuntos: adicionar e remover Usuários, adicionar e remover Papéis.

o Funções de relação: atribuir e remover atribuição de papel ao usuário (AU), atribuir e remover atribuição de permissão ao papel (AP).

- Funções de suporte ao sistema: funções que são necessárias para a implementação do CABP, envolvendo as interações com o usuário.

o Funções de sessão: criar e remover sessões, e adicionar e remover os papéis ativos de uma sessão.

o Função de acesso: verificar permissão de acesso.

- Funções de revisão: funções para a verificação dos resultados das ações criadas pelas funções administrativas. As funções UsuáriosAtribuídos e PapéisAtribuídos são consideradas obrigatórias pela especificação, as demais são opcionais.

o UsuáriosAtribuídos: retorna o conjunto de usuários atribuídos a um dado papel.

o PapeisAtribuidos: retorna o conjunto de papéis atribuídos a um dado usuário.

o PermissõesPapel: retorna o conjunto de permissões garantidas a um dado papel. 
o PermissõesUsuário: retorna as permissões que um dado usuário obtém através dos papéis a ele atribuídos.

o PapéisSessão: retorna os papéis ativos associados com uma dada sessão.

o PermissõesSessão: retorna as permissões de uma dada sessão, ou seja, as permissões atribuídas aos papéis ativos nesta sessão.

o OperaçõesPapelSobreObjeto: retorna o conjunto de operações que um dado papel é permitido desempenhar sobre um dado objeto.

o OperaçõesUsuárioSobreObjeto: retorna o conjunto de operações que um dado usuário é permitido desempenhar sobre um dado objeto.

A seguir é apresentado, como exemplo, duas funções definidas para o modelo funcional, usando notação Z. (FERRAIOLO, 2001, apêndice A) apresenta a especificação completa das funções do modelo funcional.

AdiçãoPapel
$\triangle$ CABP básico
papel? : NOME
papel? $\in$ Papéis
Papéis' = Papéis $\cup\{$ papel?\}
UsuáriosAtribuídos' = UsuáriosAtribuídos $\cup\{$ papel? $\mapsto \varnothing\}$
PermissõesAtribuídas' = PermissõesAtribuídas $\cup\{$ papel? $\mapsto \varnothing\}$

A função AdiçãoPapel está representada por um esquema em Z. O símbolo $\Delta$ indica que a função AdiçãoPapel altera o estado do CABP básico. NOME declara que "papel” pertence ao espaço de nomes [NOME]. “papel?” declara que papel é uma variável de entrada. A lista de predicados, no quadro inferior do esquema, define a função. Os predicados dizem que: a) o nome representado por “papel” pertence ao conjunto dos papéis, esta é uma pré-condição para a operação. b) O novo estado do conjunto de Papeis (Papéis') é a união do conjunto de Papéis atual (Papéis) com o conjunto unitário contendo o novo papel. c) O novo estado do conjunto UsuáriosAtribuídos é a união do estado atual deste conjunto com o conjunto unitário contendo o mapeamento do papel para um conjunto vazio. d) O novo estado do conjunto 
PermissõesAtribuídas é a união do estado atual deste conjunto com o conjunto unitário contendo o mapeamento do papel para um conjunto vazio.

O esquema para a função AdiçãoPapel, visa mostrar que o modelo CABP é especificado através de conjuntos e relações entre conjuntos e que a especificação funcional visa garantir a consistência desses conjuntos após uma alteração no estado do sistema, ou seja, quando algum elemento é adicionado ou removido, ou alguma relação é alterada. Um outro esquema, de exemplo, mostra a função de verificação de permissão de acesso.

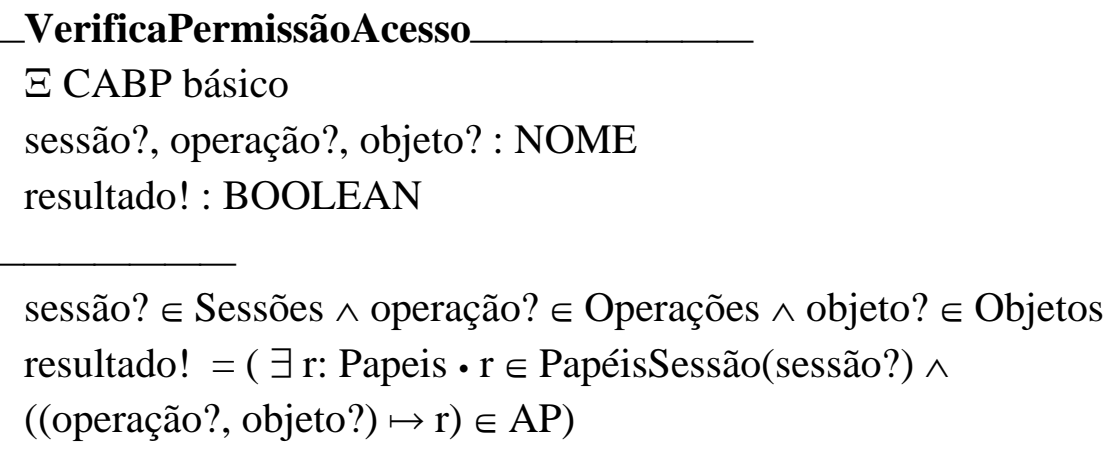

O símbolo $\Xi$ indica que a função VerificaPermissãoAcesso não altera o estado do CABP básico. “sessão?, operação? e objeto?” são entradas da função e “resultado!” representa a saída da função, que é do tipo verdadeiro ou falso (BOOLEAN). A primeira linha do predicado define a pré-condição para a função, que diz que a entrada sessão? deve pertencer ao conjunto Sessões, operação? deve pertencer ao conjunto Operações e objeto? deve pertencer ao conjunto Objetos. A permissão de acesso é dada, ou seja, a resposta da função é “verdadeiro”, se existe algum papel (r), tal que: este papel (r) esteja ativado para a sessão em questão (PapéisSessão(sessão?)), e o mapeamento $(\mapsto)$ do par (operação, objeto) para este papel (r) pertença ao conjunto de permissões atribuídas ao papel (AP).

\subsubsection{CABP Hierárquico}

Este modelo facilita a administração do CABP quando diversas autorizações são compartilhadas entre diversos papéis. Neste caso a utilização do CABP básico resultaria em 
ter que atribuir uma mesma autorização para diversos papéis e se uma autorização fosse revogada teria que desassociá-la de cada papel, com risco que privilégios residuais.

A hierarquia classifica as relações entre usuários e autorizações de acordo com a relação de responsabilidade existente entre os papéis. A figura 10 ilustra o CABP hierárquico e a figura 11 mostra um exemplo de hierarquia em árvore invertida. O modelo também suporta hierarquia em árvore e malha. No caso, as hierarquias em árvores são chamadas hierarquias restritas por não permitir mais que um ascendente, no caso de árvore invertida ou mais que um descendente no caso de árvore.

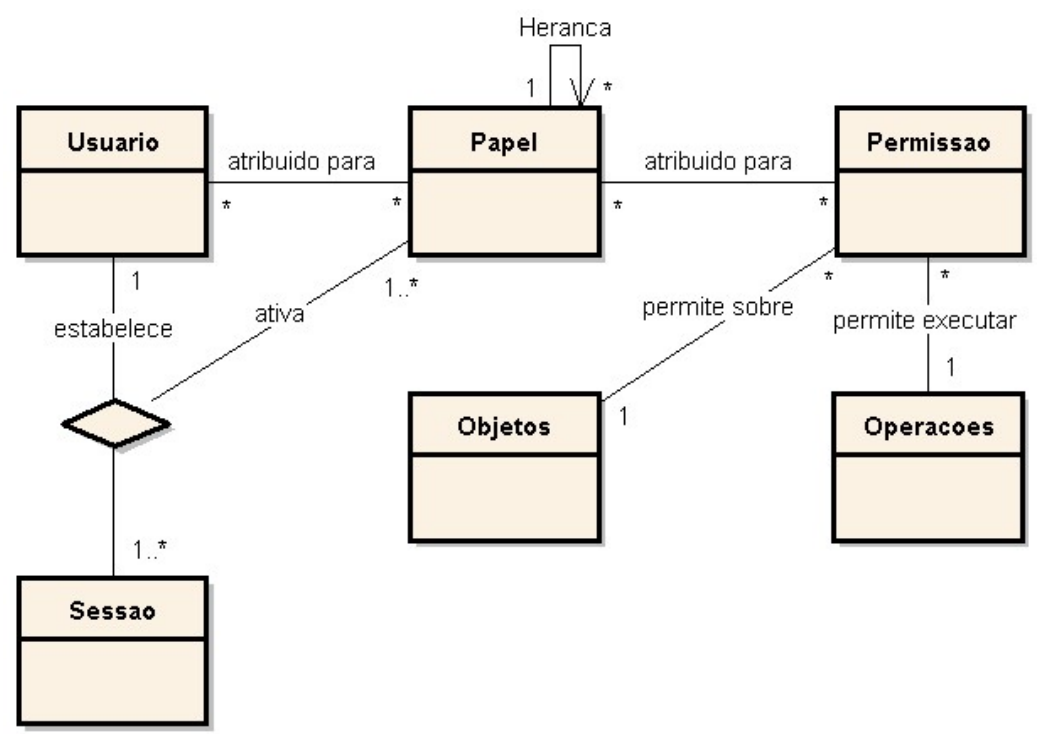

Figura 10 - Diagrama UML do CABP Hierárquico

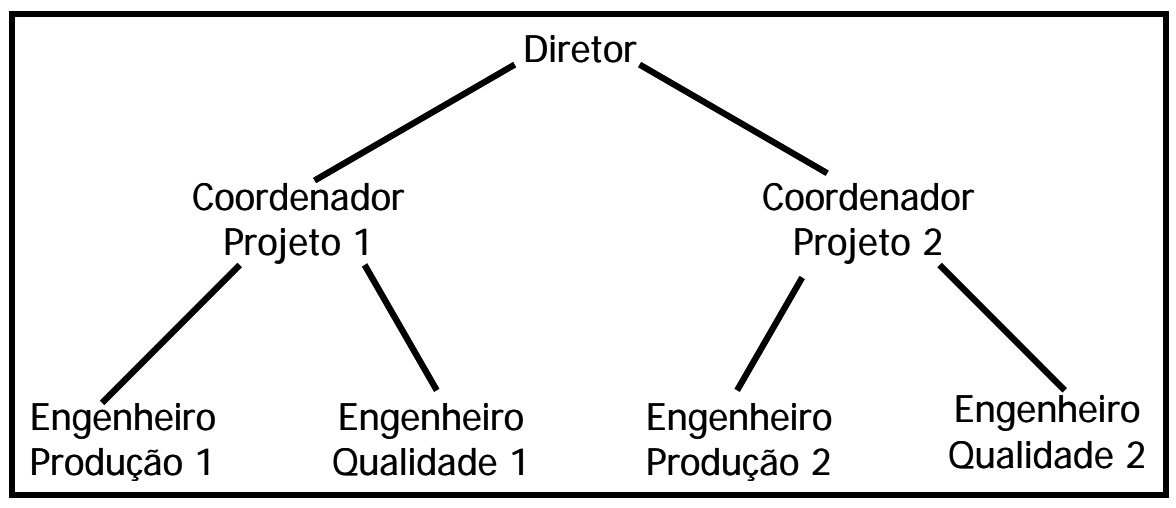

Figura 11 - Exemplo de Hierarquia em árvore invertida 
No caso da hierarquia da figura 11, as permissões são herdadas de baixo para cima. Por exemplo, o papel diretor herda as permissões atribuídas aos coordenadores de projeto 1 e 2 e o coordenador de projeto 1 por sua vez herda as permissões atribuídas aos engenheiros de produção e qualidade 1. Por outro lado, se um usuário é incorporado ao papel de coordenador de projeto 2, ele também está, automaticamente, sendo incorporado aos papeis de engenheiro de produção e qualidade 2. Ou seja, os usuários associados a um papel são os usuários diretamente associados ao papel mais os usuários diretamente associados aos papéis hierarquicamente superiores a ele. Por outro lado, as autorizações associadas a um papel são as autorizações diretamente associadas ao papel, mais as autorizações associadas aos papéis hierarquicamente inferiores a ele.

\subsubsection{CABP Restrito}

As restrições são um poderoso mecanismo para delinear a política de acesso numa organização. O CABP restrito introduz restrições por meio de relações de separação de responsabilidade (SR), que particionam de modo compulsório a responsabilidade e a autoridade para realizar uma ação por vários papéis mutuamente exclusivos.

A SR estática (SRE) impõe restrições na atribuição de papéis a usuários, através da definição de um conjunto de papéis conflitantes e um inteiro $n$ maior ou igual a 2. Isso significa que nenhum usuário pode estar associado a $n$ ou mais papéis deste conjunto. Por exemplo, suponha uma restrição para o conjunto de papéis \{administrador, usuário\} com $n=2$. Isto significa que um usuário não pode estar associado ao papel de administrador e usuário ao mesmo tempo. Outro exemplo: suponha uma restrição para o conjunto de papéis \{professor, administrador, coordenador com $n=3$. Significa que um usuário pode estar associado a até dois papéis do grupo, mas não aos três. Ele pode acumular as funções de professor e administrador ou professor e coordenador, mas não as três. 
A figura 12 mostra a relação de SRE como uma restrição. Esta restrição é aplicada sobre as atribuições de usuário e a papéis. A SRE pode ser aplicada ao CABP Hierárquico.

Há situações em que os conflitos de interesses potenciais ocorrem somente quando um usuário ativa simultaneamente dois ou mais papéis específicos. Os conflitos não existem se o usuário ativa esses papéis separadamente. Para esses casos existe a relação de SR dinâmica (SRD). Neste caso as restrições são aplicadas às sessões, ou seja, um usuário não pode ativar simultaneamente papéis conflitantes numa sessão. O CABP com relação de SRD pode ser estendido para impor a restrição ao conjunto de sessões do usuário.

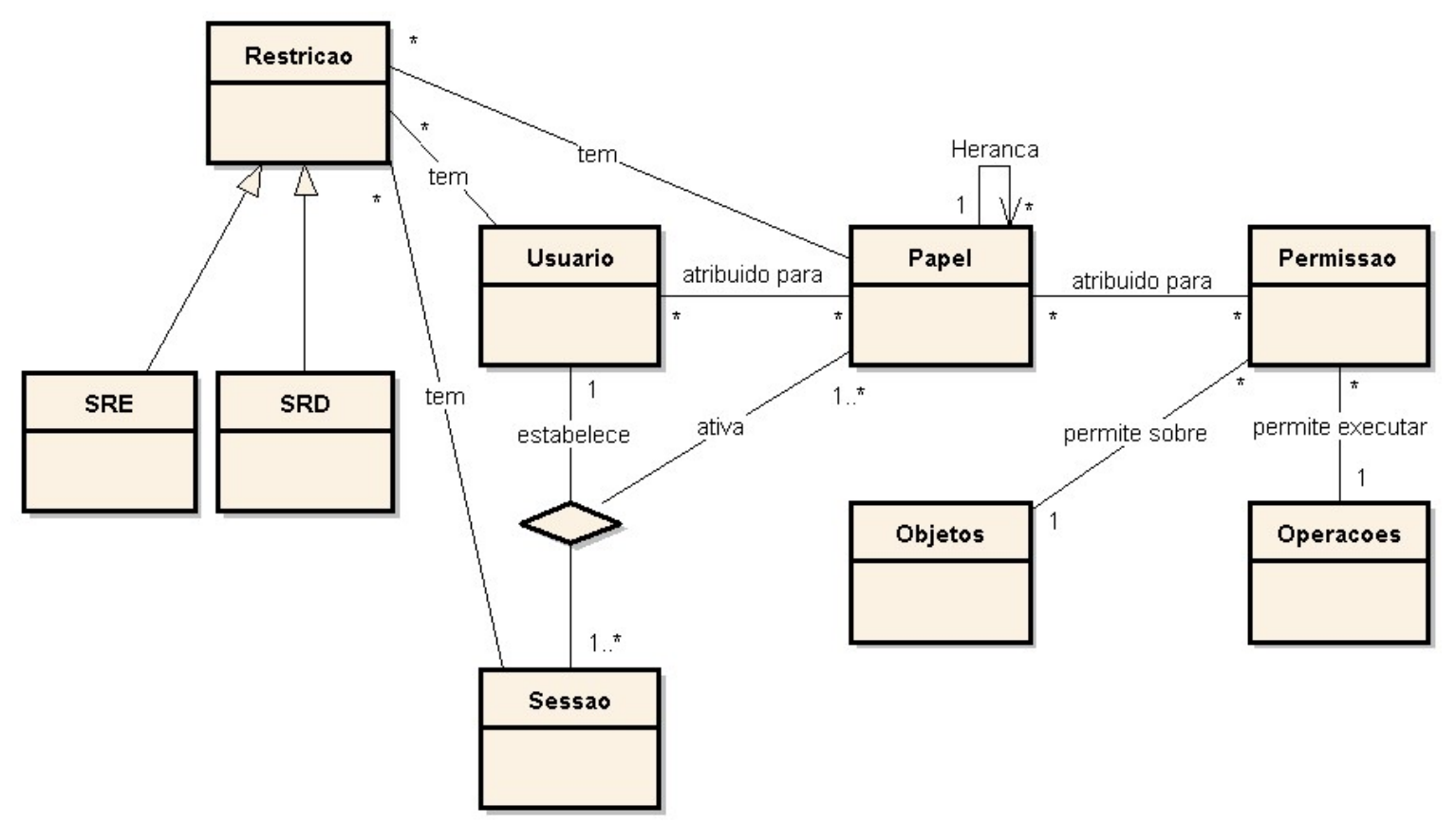

Figura 12 - Diagrama UML do CABP Restrito

O CABP restrito SRD é interessante no sentido que a ativação de um papel conflitante implica na desativação de outro, de modo que, a disponibilidade de autorizações sensíveis não persiste além do tempo necessário para a tarefa pretendida. 


\subsection{Trabalhos Relacionados ao Controle de Acesso em}

\section{Multidomínios}

Esta seção apresenta alguns trabalhos encontrados na literatura que propõe modelos de controle de acesso para aplicação em multidomínios. Esses trabalhos propõem novos modelos baseados nos modelos básicos apresentados acima.

\subsubsection{DRBAC - Distributed Role-Based Access Control}

O modelo dRBAC, apresentado em (FREUDENTHAL, 2002), foi desenvolvido pelo departamento de computação da Universidade de New York, Estados Unidos. O dRBAC foi motivado pelo problema de controlar o acesso a recursos em ambientes de coalizão. Um ambiente de coalizão poderia ser comercial, no qual corporações formam parcerias, ou governamental/militar, no qual várias nações trabalham juntas para atingir um objetivo comum.

O objetivo do modelo é permitir que múltiplas organizações possam cooperar e compartilhar um subconjunto de seus recursos protegidos, necessários para a coalizão, enquanto protegem seus recursos que não querem compartilhar. Ambientes de coalizão são altamente dinâmicos e devem suportar a autorização de recursos em vários níveis de acesso para refletir a estrutura natural das organizações e suas alianças. Adicionalmente, estas autorizações devem permitir delegação transitiva de autoridade, para suportar o acesso por usuários que são desconhecidos para os proprietários dos recursos.

(FREUDENTHAL, 2002), argumenta que as soluções existentes, como LCA (Lista de Controle de Acesso) e CABP (Controle de Acesso Baseado em Papéis) não atendem aos requisitos de ambientes de coalizão, pois recaem sobre uma administração centralizada e não 
escalam para um grande número de usuários mutuamente anônimos, que seria encontrado em ambientes de coalizão.

dRBAC propõe um modelo baseado na delegação de papéis para usuários. Os papéis indicam autorização de acesso. Basicamente o dRBAC autoriza acesso para recursos seguros por verificar se o principal requisitante (nome ou chave pública) tem atribuído a ele algum dos papéis que o recurso requer para ser acessado. Para facilitar a busca da cadeia de credenciais, as delegações possuem tags que ajudam a localizar as credenciais na cadeia. A solução basicamente acrescenta ao modelo RBAC a delegação de autoridade para a atribuição de papeis aos usuários.

O diferencial deste modelo está em não precisar manter o mapeamento de papéis entre domínios; isto é feito através das credenciais de delegação de autoridade, e permitir a delegação de autoridade entre domínios com espaço de nomes independente por domínio, eliminando a possibilidade de conflito de nomes entre domínios. Um acordo entre domínios é automaticamente estendido para seus usuários. Tem a desvantagem de usar equivalência de papéis para o controle de acesso, o que rompe o isolamento dos domínios por permitir que uma alteração na política interna altere a política externa.

\subsubsection{C-RBAC - Collaborative Role-Based Access Control}

O modelo C-RBAC (Collaborative Role-Based Access Control) foi desenvolvido pelo Departamento de Informação e Comunicação do Instituto de Ciência e Tecnologia de Gwangju e pela Universidade de Kyushu, ambos no Japão. O trabalho, apresentado em (KIM, 2005), propõe um modelo CABP colaborativo para sistemas distribuídos que permitem que os acessos ultrapassem os domínios do sistema. A abordagem dada no artigo é aplicada a TOS (Trusted Operation System), por isso foca sobre requisitos mais rígidos no estabelecimento das relações. 
A proposta tem como objetivo romper as barreiras administrativas para a cooperação entre TOS implementando diferentes políticas de segurança e sobre diferentes sistemas. Os autores fazem uma abordagem sobre a prevenção de conflitos de domínio, conflitos de regras e liberdade de políticas.

O modelo proposto permite a cooperação entre domínios, tal que uma tarefa possa acessar permissões além de seus limites de domínio, quando a condição de contexto de colaboração for satisfeita. O foco principal do modelo está sobre conflitos. O artigo apresenta um conjunto de possibilidades de mapeamento entre domínios e argumenta que esses mapeamentos são potenciais fontes de conflito. A argumentação é justificada com exemplos de situações relativas a TOS onde um conflito ocorre, mas é possível contra-argumentar que estes conflitos não são potenciais em diversos outros cenários com regras mais flexíveis, e também distribuídos e cooperativos.

Para exemplificar potenciais conflitos são apresentados quatro tipos de mapeamentos entre domínios: usuário-papel, papel-objeto, usuário-papel e papel-objeto, e papel-papel. No mapeamento usuário-papel, usuários de um domínio 1 são mapeados para papéis no seu domínio e em outro domínio 2. No mapeamento papel-objeto, objetos de um domínio 2 são mapeados para papeis em seu domínio e de um outro domínio 1. Usuário-papel e papel-objeto é um mapeamento duplo dos casos acima. Finalmente, no mapeamento papel-papel é considerado o mapeamento entre três domínios. Analisando os mapeamentos, os autores argumentam que o mapeamento usuário-papel tem potencial risco de conflito de interesses, pois um mesmo usuário pode ter responsabilidades em dois domínios de políticas concorrentes. O mesmo ocorre quando mais que um papel gerencia determinado objeto, pode haver conflito por múltiplos gerenciadores. Um conflito de responsabilidade pode ocorrer no mapeamento misto, quando um usuário pode ter direito de acesso a um objeto por dois papéis diferentes. Para justificar o conflito potencial no mapeamento papel-papel, são considerados 
dois casos. O primeiro caso considera um mapeamento transitivo, um papel do domínio 1 é mapeado para um papel do domínio 2, que por sua vez é mapeado para um papel no domínio 3. Se for considerado que, neste caso, o papel do domínio 1 está mapeado indiretamente para um papel do domínio 3, há um conflito por haver um estado alcançável sem que uma regra fosse explicitamente declarada. Um segundo caso ocorre quando há um laço entre os mapeamentos de três domínios, sendo que um papel 1 no domínio 2 acaba sendo indiretamente mapeado para um papel 2 hierarquicamente superior em seu próprio domínio. Neste caco, há um conflito de regra, através de uma promoção disfarçada.

Uma vez apresentado os possíveis potenciais conflitos nos mapeamentos diretos, o artigo apresenta um modelo baseado em meta-políticas, que são políticas sobre políticas. As meta-políticas coordenam o acesso entre domínios de políticas heterogêneas, gerando regras explícitas para todos os acessos interdomínios. As meta-políticas são estabelecidas através de papeis de cooperação, chamados de meta papéis. A responsabilidade de traduzir os papéis de cooperação é dada ao administrador de segurança de cada domínio.

A solução proposta pelo modelo cria papéis acordados entre os domínios, automaticamente ou extra sistema, e responsabiliza cada domínio a definir quais usuários assumirão os papéis de cooperação e quais entidades serão alocadas para esses papéis.

\subsubsection{X-RBAC - XML Role-Based Access Control}

O modelo X-RBAC (XML Role-Based Access Control) foi desenvolvido na Universidade de Purdue, nos EUA como parte de um projeto para desenvolvimento de um framework para gerenciamento de controle de acesso e segurança em ambientes multidomínios heterogêneos (GHAFOOR, 2003). Joshi et al. (2004) apresenta o modelo XRBAC, uma linguagem de especificação que tem como objetivo atender aos requisitos para especificação de políticas para ambientes multidomínio (AMD). 
O X-RBAC utiliza XML para abordar a solução de segurança em AMD. O desafio é apresentar um modelo de controle de acesso usando XML que garanta o acesso baseado no contexto ambiental, no conteúdo da informação, tipo de objeto e entidade, perfil ou qualificação e facilite a integração de múltiplas políticas de segurança.

O modelo proposto estende o modelo do NIST através da adição de restrições temporais, atributos de papéis, condições contextuais, noção de estados de papéis e precondições para a transição de estados, ainda apresenta suporte para o mapeamento em AMD.

X-RBAC utiliza documentos XML para representar usuários ${ }^{13}$, papéis, operações, objetos e os possíveis relacionamentos entre esses componentes. Os papéis são parametrizados e esses parâmetros são utilizados para adicionar pré-condições para a ativação de papéis pelo usuário, atribuição de papéis a usuários e atribuição de relacionamento entre autorizações e papéis. Ou seja, através da parametrização de papéis é possível impor restrições aos relacionamentos do modelo. A parametrização dos papéis pode ser baseada nos contextos de tempo, localização e conteúdo da informação. Por exemplo, uma pré-condição poderia envolver a verificação se o domínio de rede do usuário equivale a algum préespecificado nome de domínio. Adicionalmente, o conceito de estado é atribuído aos papéis. Um papel pode estar desabilitado, habilitado ou ativo. Um papel desabilitado não pode ser ativado em uma sessão, um papel habilitado indica que um usuário autorizado para o papel naquele instante pode requisitar sua ativação e um papel ativo significa que no mínimo um usuário está com o papel ativado.

A política X-RBAC considera que, durante uma interação, dois domínios podem estar fracamente ou fortemente acoplados. Um acoplamento fraco significa que cada domínio participa parcialmente no domínio acoplado e um acoplamento forte significa que um dos

\footnotetext{
${ }^{13}$ Usuário neste caso equivale à definição de usuário do modelo CABP do NIST.
} 
domínios assumirá o papel de mestre e será responsável por mediar acessos para os domínios individuais, através de uma política global. A criação desses ambientes multidomínio ocorre através do mapeamento de papéis. Associações com acoplamento fraco mapeiam papéis em um domínio, com papéis em outro domínio, por exemplo, o papel “professor doutor” em um domínio equivale ao papel "professor assistente” no outro domínio. Nas associações com acoplamento forte, novos papéis são criados e mapeados a um ou mais papéis nos domínios locais. Um novo papel pode ser mapeado para papeis em domínios locais distintos. Esses mapeamentos podem ser uni ou bidirecionais. O autor apresenta algumas possibilidades de conflito durante uma interação de domínios, como, por exemplo, quando as regras hierárquicas atribuídas aos papéis são quebradas. O autor considera que dois princípios devem ser mantidos para que não haja conflito após um mapeamento: autonomia e segurança. Autonomia significa que um acesso permitido dentro de um domínio deve ser mantido após uma interação. Segurança significa que um acesso negado dentro de um domínio deve continuar sendo negado após uma interação.

A linguagem de especificação proposta pelo X-RBAC parece atender a uma série de requisitos necessários para a especificação do modelo objetivo do trabalho, mas as diretrizes do modelo tendem para uma centralização além do aceitável para o multidomínio e a política de composição está direcionada para o mapeamento de papéis entre os domínios.

\subsubsection{ORBAC - Object-Oriented Role-Based Access Control}

O modelo ORBAC (Oriented-Object Role-Based Access Control) foi desenvolvido pelo Departamento de Ciência da Computação da Universidade de Regina, TRLabs, Canadá. (ZHANG, 2001) apresenta o modelo, que foi proposto como uma solução para o controle de acesso em ambientes distribuídos, quando recursos são compartilhados entre múltiplos domínios, numa abordagem orientada a objetos. 
O modelo proposto estende o RBAC através de dois gerenciadores. Um gerenciador local é utilizado para atender às requisições internas ao domínio. Um outro gerenciador externo é utilizado para atender às requisições de ou para outros domínios. Os gerenciadores externos se comunicam para obter autorizações de acesso para os usuários. Quando um usuário do domínio A deseja utilizar um serviço do domínio B, o usuário faz a requisição ao gerenciador externo de seu domínio (A). O gerenciador externo do domínio A se comunica com o gerenciador externo do domínio B e faz a requisição de acesso. A autorização, se bem sucedida, é retornada pelo gerenciador externo do domínio $B$, através de certificados de privilégios. Estes certificados são emitidos pelos gerenciadores externos e enviado para o usuário e servidor. O processo se repete para cada requisição de acesso.

A solução viabiliza a autorização entre domínios com isolamento entre a política interna (domínio) e externa (multidomínio), devendo existir uma relação de confiança préestabelecida entre os gerenciadores. A proposta tem a desvantagem de exigir uma entidade central (gerenciador) em cada domínio e do processo de autorização entre domínios exigir diversas trocas de mensagens.

\subsubsection{Credential-Based Access Control}

Este modelo foi proposto, em conjunto, pelo Instituto de Informática Aplicada e Métodos de Descrição Formal da Universidade de Karlsruhe, e pelo laboratório de Sistemas de Informação e Segurança da Universidade de Dortmund, ambos na Alemanha. (AGARWAL, 2004) apresenta o modelo de controle de acesso baseado em credenciais para aplicação em serviços Web Semântica. O ambiente Web semântica é um ambiente aberto, distribuído, descentralizado, dinâmico e interoperável, no qual serviços Web devem ser oferecidos e usados por qualquer um espontânea e dinamicamente, e os usuários não desejam revelar suas identidades. 
A proposta é construída sobre a idéia de garantia autônoma de direito de acesso e tomada de decisão baseado em estruturas de confiança independentes. Para isso, utiliza as técnicas de DAML-S (DARPA Agent Markup Language) e SPKI/SDSI (Simple Public-Key Infrastructure/Simple Distributed Security Infrastructure). O DAML-S é uma linguagem para a definição de ontologia e SPKI/SDSI define uma infra-estrutura de chaves públicas simples, com suporte a certificados de delegação de autoridade e possibilidade de utilizar um espaço de nomes independentes (não global) para certificados.

O modelo é definido com o uso de ontologia. Uma ontologia é uma especificação formal de termos em um domínio e as relações entre eles (GRUBER, 1993), estabelecendo uma linguagem comum para a troca de conhecimento. O modelo define uma ontologia para serviços, credenciais e listas de controle de acesso, sendo que, uma lista de controle de acesso está relacionada com credenciais através de uma “condição de controle de acesso”. O controle de acesso é tratado pelo modelo como uma pré-condição para disparar o processo para utilização de serviços.

Credenciais SPKI/SDSI são vinculadas à chave pública, não à identidade, permitindo a privacidade do usuário. Os servidores podem emitir credenciais e definir sua estrutura de confiança de forma independente. O controle de acesso é baseado em autorização e não em autenticação. Ou seja, a posse da credencial e seus atributos é que define os direitos de acesso, não a identidade do possuidor da credencial.

Por exemplo, uma entrada da lista de controle de acesso (LCA) é definida pelo conjunto de <Self, subject, authorization, delegation, validity>. "Self" é uma palavra reservada. Subject denota um conjunto de principais $^{14}$ para os quais será garantida a autorização. Authorization especifica as garantias de permissões. Delegation é um valor binário que, se definido, significa que as permissões garantidas em authorization podem ser

\footnotetext{
${ }^{14}$ Um principal pode ser uma chave pública, um apelido ou um nome.
} 
delegadas para outros principais. Validity denota o tempo de vida da entrada. Um certificado de delegação tem exatamente o mesmo formato, com a palavra reservada "Self” substituída pelo principal do emissor do certificado, que delega para o subject as authorization, pelo período de tempo definido em validity.

(AGARWAL, 2004) não apresenta um modelo completo e embora cite, não trata a política de composição e não define claramente o vínculo entre uma autorização e real objeto sendo controlado.

\subsubsection{Ontology-Based Policy}

O centro de pesquisa L3S e Universidade de Hannover, na Alemanha, em conjunto com o Departamento de Computação da Universidade de Illinois nos Estados Unidos, propõem, em (NEJDL, 2005), um mecanismo para a definição de política de controle de acesso baseado em ontologia. A ontologia é utilizada para simplificar a tarefa de especificação e administração da política. A solução é direcionada para aplicações Web Semântica, que fornecem um ambiente onde as partes podem fazer conexão e interagir sem terem se conhecido previamente.

A política de segurança em sistemas Web semântica normalmente é baseada em negociação de confiança. Negociação de confiança difere do controle de acesso tradicional, baseado em identidade, pelo controle ser estabelecido baseado nas propriedades das partes, obtida através de credenciais, e por duas partes estabelecerem confiança diretamente, sem envolver uma terceira parte, além do emissor de credenciais. Para tal, as partes utilizam softwares para automatizar o processo de, interativamente, estabelecer confiança bilateral, baseada na política de controle de acesso das partes, isto é, um software de negociação de confiança. 
As políticas descrevem as propriedades que as partes devem apresentar de forma a obter acesso a um recurso. Ao invés de autenticação e autorização em um único passo, a confiança é estabelecida incrementalmente, através de uma seqüência de descobrimentos de credenciais bilateral.

A ontologia é aplicada para definir credenciais, cujos atributos são utilizados pela política para restringir ou liberar o acesso. Por exemplo, uma regra de controle de acesso poderia ser definida sobre atributos de credenciais equivalentes à carteira de habilitação, emitidas pelos estados ou órgão militar. O tipo de emissor (estado ou órgão militar) e classe da habilitação poderia ser utilizado para restringir o acesso à informação. O conceito de política padrão e obrigatória é utilizado, onde política padrão é herdada de classes hierarquicamente superiores e podem ser sobrescritas, enquanto que política obrigatória não pode ser sobrescrita.

A autorização é baseada em política definida através de restrições aos atributos das entidades, contidos nas credenciais definidas segundo uma ontologia e emitidas por terceiros cofiáveis. Este tipo de política não permite a definição de regras não estáticas, como por exemplo, restrição de localização.

\subsubsection{Modelo Híbrido: Baseado em regras e em ontologia}

(TONINELLI, 2005) apresenta uma análise das tendências para especificação de políticas em ambientes baseados em contextos semanticamente ricos, como Web Semântica, salientando suas limitações, vantagens e desvantagens. A análise foi feita pela Universidade de Bologna, na Itália, pelo Instituto da Flórida para Percepção Homem e Máquina, nos Estados Unidos, e pelo MIT CSAIL, Estados Unidos.

O estudo propõe uma abordagem híbrida para a definição da política para sistemas multi-agentes em ambientes de computação pervasiva. Nestes ambientes os recursos não são 
pré-determinados e os agentes não são sempre conhecidos a priori. Se os agentes transitam entre diferentes redes, eles podem ter diferente visibilidade e disponibilidade de recursos, dependendo de sua localização e outras informações dependentes de contexto, tais como política de segurança local. A computação pervasiva tem o ‘contexto’ como sua principal qualidade, uma vez que a identificação ou os papéis de seus participantes (agentes) são muitas vezes desconhecidos. Então, ao invés de definir políticas baseadas na identidade ou papéis, definem-se condições para a disponibilidade dos recursos aos agentes, baseado no contexto.

O objetivo da política desses ambientes é controlar o comportamento dos agentes. Duas abordagens são normalmente utilizadas: uma baseada em ontologia, que recai sobre expressivas características de linguagem lógica de descrição, e outra abordagem baseada em regras, que codifica políticas como regras de lógica de programação.

A bordagem baseada em ontologia conta amplamente com as expressivas características das linguagens lógicas de descrição, tal como OWL (Web Ontology Language), para classificar contextos e políticas, habilitando então a realização de inferências dedutivas e resolução de conflito de política estática. Em contraste, a abordagem baseada em regras toma a perspectiva de lógica de programação para codificar regras de uma forma clara. Portanto, facilita o mapeamento direto da política para os mecanismos de execução de nível mais baixo, favorecendo sua sintaxe concisa e fácil de entender.

(TONINELLI, 2005) propõe que a abordagem baseada em ontologia seja utilizada para descrever contextos e políticas associadas em um alto nível de abstração, de forma que permita a classificação, comparação e resolução de conflito estático da política. Esta característica é essencial, por exemplo, de forma a detectar conflitos entre políticas antes delas serem executadas, então garantindo a interoperabilidade entre entidades pertencentes a diferentes domínios que adotam diferentes políticas. Enquanto que os benefícios da 
abordagem baseada em regras possam ser utilizados para a execução. O artigo utiliza como exemplo políticas para os frameworks KaoS (ontologia) e Rei (regras).

\subsubsection{PEACE}

O projeto PEACE (KEOH, 2004), desenvolvido no Imperial College London em Londres, desenvolveu um framework de segurança baseado em política. O trabalho foi especificado considerando uma rede ad hoc, que apresenta uma topologia dinâmica e não pode contar com conexão contínua a Internet. O principal desafio era propor uma solução que não recaísse sobre uma informação compartilhada pré-existentes.

A proposta está baseada na especificação de comunidade. Uma comunidade é regida por uma doutrina, a qual define os papéis dos participantes e as características que eles devem ter para estarem aptos a assumir um papel, assim como as políticas governando seus comportamentos dentro da comunidade. Comunidades são formadas, tipicamente, por dispositivos autônomos, em ambiente sem fio, que colaboram e compartilham recursos uns com os outros.

Uma doutrina, criada por um emissor, é definida pela tupla $\langle R, P, S, T K, \operatorname{Sig}\rangle$, onde $R$ define os tipos de papéis que os participantes podem assumir dentro da comunidade, $P$ define um conjunto de políticas que regulam o comportamento dos participantes assumindo os papéis, $S$ define as restrições da comunidade, $T K$ define a chave pública dos emissores de credenciais e Sig contém a assinatura do emissor da doutrina. O conjunto de políticas $P$ é composto por políticas de autorização, que associa permissões a papéis; políticas de obrigação, que são regras sobre eventos-condições-ações que facilitam o gerenciamento da adaptação; e segurança da comunidade. As restrições $S$ contêm restrições de separação de responsabilidade e cardinalidade, as quais devem ser preservadas durante as mudanças nos membros participantes da comunidade. A definição dos papéis vem acompanhada da política 
de associação de usuários a papéis, que estabelece as regras que regem quem pode participar da comunidade.

A formação de comunidades parte de dois princípios: o usuário confia no emissor da doutrina, ou seja, está apto a verificar a assinatura da doutrina, e a doutrina é obtida antes da formação da comunidade. Suponha uma doutrina criada para compartilhamento de música entre os usuários associados a provedores de música, como AOL e Napster. Essa doutrina poderia definir dois papéis: usuárioNormal e usuárioEspecial. A política para a associação de papéis a usuários (APU) poderia definir que para assumir o papel de usuárioNormal o usuário deveria ter credenciais de sócio para um dos provedores listados e para assumir o papel de usuárioEspecial deveria ter credenciais especiais de um desses provedores. A política de autorização poderia, por exemplo, definir que um usuárioNormal poderia escutar música e que um usuárioEspecial poderia escutar e copiar músicas. Adicionalmente, a política de obrigação poderia definir que um usuárioEspecial teria que desabilitar qualquer usuário que tentasse por três vezes copiar músicas sem autorização, assim como registrar (logging) o ocorrido e notificar os outros membros da comunidade. A doutrina também poderia colocar restrições quanto ao número de participantes ou separação de responsabilidade, como, por exemplo, que um usuário não poderia assumir os dois papéis simultaneamente. As chaves públicas dos provedores de música, ou seja, dos emissores das credenciais, deveria ser parte da doutrina para garantir que todos os participantes estariam aptos a validar as credenciais.

A comunidade se forma a partir de um usuário, que inicia o processo, por broadcast, e assume o papel de coordenador. Os usuários que têm essa doutrina habilitada para a associação automática, responderão à requisição fornecendo suas credencias e papel desejado. O coordenador então verifica se as credenciais são válidas, associa os usuários a papéis, emite a lista dos usuários da comunidade, assina e a retorna aos usuários. A partir deste ponto os usuários podem compartilhar músicas segundo a política especificada na doutrina. 
A adição de um novo membro ou remoção de um membro associado envolve a emissão de uma nova lista de membros pelo coordenador da comunidade e notificação aos demais membros, que atualizam sua lista. A remoção pode ocorrer por solicitação do membro ou por notificação de comportamento indevido (conforme definido na política de obrigação). A proposta trabalha com a presença contínua do coordenador e membros. Se um membro ficar ausente por determinador tempo ele é removido e se o coordenador ficar ausente por mais que um tempo é eleito um novo coordenador apto, ou seja, com recursos computacionais para isso. Se nenhum estiver apto, a comunidade se mantém, mas sem poder adicionar ou remover membros.

O modelo de controle de acesso proposto pelo PEACE atua, primeiro controlando o acesso à comunidade depois controlando o acesso aos recursos compartilhados. O controle de acesso à comunidade é feito através da validação de políticas previamente determinadas, no caso, validação de credenciais. O controle de acesso aos recursos compartilhados é feito pelos serviços, segundo a política definida para a comunidade, que autoriza o acesso baseado nos papéis assumidos pelos membros.

Este projeto tem dois pontos interessantes, primeiro por criar uma solução que permite a associação automática entre domínios (ou usuários de domínios), através de uma política previamente acordada. Segundo por utilizar uma política pré-definida, com regras gerais para o compartilhamento de recursos, que permite a interação segura entre seus membros. A utilização de papéis permitiu o isolamento entre usuário e autorização dentro da comunidade, ao mesmo tempo em que não interferiu nos papéis assumidos pelos usuários dentro de seus domínios.

Uma otimização do projeto foi apresentada em (KEOH, 2005), com o objetivo de reduzir o número de verificações de assinaturas e autenticações ocorridas para a utilização da 
arquitetura proposta. A otimização é possível através da utilização do protocolo de autenticação por broadcast TESLA (PERRIG, 2002).

\subsection{Considerações}

(JOSHI, 2004) propõem o uso de mapeamento de papéis para estabelecer equivalência de direitos de acesso em sistemas com modelos de controle de acesso baseado em papéis. Ou seja, considerando que os domínios compondo o multidomínio estabelecem suas autorizações de acesso para os usuários internos ao domínio através de papéis, cada domínio mapeia os papéis de outros domínios para papéis equivalentes em seu domínio. Desta forma, se um papel X do domínio A é mapeado para o papel Y pelo domínio B, um usuário do domínio A que assume o papel $\mathrm{X}$, quando acessando recursos do domínio $\mathrm{B}$, terá os mesmos direitos de acesso que um usuário interno ao domínio B que assume o papel Y. Esta solução tem a desvantagem de exigir um alto grau de integração entre os domínios. Variações desta solução definem papéis específicos para o multidomínio, que são mapeados para um ou mais papéis nos domínios individuais (ZHANG, 2001; JOSHI, 2004; KIM, 2005). Esta abordagem reduz a integração entre domínios e permite simplificar o mapeamento de papéis, o que a torna mais flexível e escalável. (FREUDENTHAL, 2002) propõe uma outra abordagem para a equivalência de papéis, baseado em credenciais de atribuição de papéis e credenciais de delegação de autoridade. A equivalência de papéis é estabelecida através de uma cadeia de credenciais. Esta abordagem facilita o gerenciamento, mas a delegação transitiva sem restrição de profundidade pode dificultar a controle sobre as autorizações de acesso (YIN, 2004).

Uma outra abordagem propõe o uso de modelos de controle de acesso baseado em políticas (AGARWAL, 2004; NEJDL, 2005). Esses modelos baseiam-se na relação de confiança entre domínios e a política de controle de acesso é definida através de restrições 
sobre propriedades das partes. Uma regra de controle de acesso poderia ser: usuários que possuem credenciais do tipo X (restrição), emitidas pelos domínios A e B (relação de confiança para validação das credenciais), cujas propriedades obedecem à condição Y (restrição), têm autorização para acessar o recurso Z. Ou seja, não há uma regra explícita para cada usuário ou papel, mas sim uma política que define os critérios de autorização. As soluções acima foram propostas para aplicação a sistemas baseados em Web Semântica, que são sistemas abertos, distribuídos, descentralizados, dinâmicos e interoperáveis (AGARWAL, 2004). Esses sistemas utilizam ontologias para descrever serviços com semântica interpretável por máquina. De forma equivalente, as propostas acima propõem o uso de ontologia de credenciais para viabilizar a definição de regras baseadas em restrições sobre atributos destas credenciais. Estas soluções têm a vantagem de permitir a definição de regras de controle de acesso genéricas, baseado apenas em informações contextuais descritivas, como tipos de credenciais, atributos cujos possíveis valores são previamente definidos e domínios confiáveis. Isto pode simplificar o gerenciamento da política, mas a definição de regras de controle de acesso somente sobre valores descritivos, como no caso de ontologias, pode não ser adequada em cenários que exijam regras mais expressivas (TONINELLI, 2005).

(TONINELLI, 2005) propõe uma abordagem híbrida para a definição da política de controle de acesso em sistemas multi-agentes em ambientes de computação pervasiva. Nestes ambientes os recursos não são pré-determinados, e os usuários (agentes) não são sempre conhecidos a priori, dependem do contexto em que os agentes atuam. (TONINELLI, 2005) sugere uma abordagem integrada que explora o melhor das abordagens baseada em regras e baseada em ontologias. A proposta é utilizar a abordagem baseada em ontologias para obter a política num alto grau de abstração, tal que possa ser verificada a compatibilidade entre políticas, garantindo a interoperabilidade entre entidades pertencentes a diferentes domínios e que adotam diferentes políticas. A abordagem baseada em ontologia facilita a interpretação e 
negociação da política. Ao mesmo tempo, a proposta sugere o uso da abordagem baseada em regras em um nível mais operacional, para a efetiva execução, o que permite a definição de regras de forma mais clara e expressiva. (TONINELLI, 2005) não apresenta um novo modelo ou solução para o controle de acesso, mas faz uma análise das duas vertentes, baseado em regras e em ontologia, salientando suas limitações, vantagens e desvantagens.

(KEOH, 2004) propõe a utilização de políticas fixas, definidas por terceiros confiáveis, para a formação de comunidades ad hoc para fins específicos. Esta proposta permite a formação dinâmica e automática de multidomínios (comunidades), mas tem a desvantagem de ser pouco flexível e depender de terceiros.

Este trabalho busca unir as características dos trabalhos acima, extraindo suas idéias e abstraindo sua aplicação específica para definir um modelo de controle de acesso que atenda aos requisitos dos multidomínios. De $(\mathrm{KEOH}, 2004)$, extrai-se a idéia de um modelo de multidomínio que possa ser pré-definido e dinamicamente entendido/interpretado por diferentes domínios, e que, devido a estas características, têm a simplicidade necessária para formações ad hoc e domínios pessoais. Dos modelos (AGARWAL, 2004; NEJDL, 2005) extrai-se a técnica do uso da ontologia, que permite a definição de conceitos e relações entre conceitos para a troca de conhecimento entre diferentes domínios. De (TONINELLI, 2005) extrai-se a idéia de uma abordagem híbrida, utilizando a abordagem baseada em ontologias para obter a política num alto grau de abstração, tal que possa ser verificada a compatibilidade entre políticas, garantindo a interoperabilidade entre entidades pertencentes a diferentes domínios e que adotam diferentes políticas. E utilizando a abordagem baseada em regras em um nível mais operacional. Dos modelos baseados em papéis (ZHANG, 2001; JOSHI, 2004; KIM, 2005, FREUDENTHAL, 2002) extrai-se a técnica do modelo de controle de acesso baseado em papéis. Finalmente, de (FREUDENTHAL, 2002; AGARWAL, 2004) extrai-se a idéia do uso de credenciais e delegação de autoridade. 
O modelo definido neste trabalho inova na composição e integração de idéias isoladas propondo a definição de multidomínios utilizando ontologia, tal que modelos pré-definidos possam ser dinamicamente entendidos/interpretados por diferentes domínios, ao mesmo tempo em que permite que novos modelos possam ser facilmente especializados a partir desta ontologia. O modelo de controle de acesso adotado é baseado no CABP, sendo que, o modelo de controle de acesso é definido em dois níveis, um abstrato e outro concreto. O modelo concreto é baseado em regras e é adotado para a execução da política do multidomínio nos domínios individuais. O modelo abstrato é baseado em ontologia e é utilizado para a negociação da política do multidomínio e resolução de alguns conflitos estáticos e de interesses. O modelo abstrato representa o modelo concreto num alto grau de abstração. Finalmente, a atribuição de papéis aos usuários ocorre através das credenciais, com suporte a delegação de autoridade. 


\section{Capítulo 5 - Modelo Ontológico de Segurança}

Este capítulo descreve a contribuição principal desta tese, a qual se caracteriza pela proposta de um Modelo Ontológico de Segurança (MOS) para viabilizar a negociação de uma política de segurança para o controle de acesso em ambientes multidomínio. O MOS é um modelo de segurança para a definição de uma política de controle de acesso distribuída e compartilhada entre diferentes domínios de segurança. Distribuída porque é definida, gerenciada e executada por todos os domínios, não existe uma entidade central responsável pela política. Compartilhada porque os domínios têm conhecimento da política geral, composta pelas políticas dos domínios. O MOS busca permitir que redes ou sistemas sob diferentes domínios administrativos de segurança possam compartilhar seus recursos segundo uma política de segurança negociada e conhecida por todos.

A política de controle de acesso definida pelo MOS é formada pela composição das políticas de controle de acesso individuais, definidas pelos domínios que participam da associação. A proposta de um modelo ontológico é justificada pela necessidade de estabelecer uma linguagem semântica que possa ser dinamicamente interpretada pelos domínios participantes, sem a necessidade de um conhecimento prévio entre os domínios.

\subsection{Visão Geral}

Uma política de segurança é um conjunto de regras e procedimentos que caracterizam os objetivos de segurança para um sistema. Ela define como um sistema deveria se comportar de forma a manter a aderência a estes objetivos. Uma política particular tem efeito sobre um certo domínio. Este domínio descreve quando a política particular é relevante (HOAGLAND, 1998). A política de segurança de um multidomínio tem o objetivo de garantir a segurança da 
comunicação e da informação dos membros participantes. O MOS é um modelo para a definição desta política quanto à segurança da informação, sendo relevante para a proteção dos recursos disponíveis contra acesso não autorizado.

Segundo (FERRAIOLO, 2001), o propósito de um mecanismo de controle de acesso é proteger os recursos do sistema. No entanto, em qualquer aplicação CABP em sistemas de computação, fala-se em proteger objetos. (FERRAIOLO, 2001) define um objeto como uma entidade que contém ou recebe informações. Esses objetos podem representar repositórios de informação (por exemplo, arquivos e diretórios em sistemas operacionais; colunas, linhas, tabelas ou visões dentro de base de dados) ou recursos esgotáveis, tais como impressoras, espaço em disco e ciclos de CPU.

Essa visão sobre os “recursos protegidos do sistema”, tem a perspectiva de um sistema centralizado, que recebe toda e qualquer requisição de acesso aos recursos (chamados objetos, no modelo) sob seu controle, e precisa decidir sobre permitir ou não o acesso ao recurso baseado na política previamente definida.

Considere agora, a política de controle de acesso sob uma outra perspectiva, a visão do usuário. Adicionalmente, considere que os recursos estão distribuídos, como é o caso do multidomínio. A figura 13 ilustra essas perspectivas.

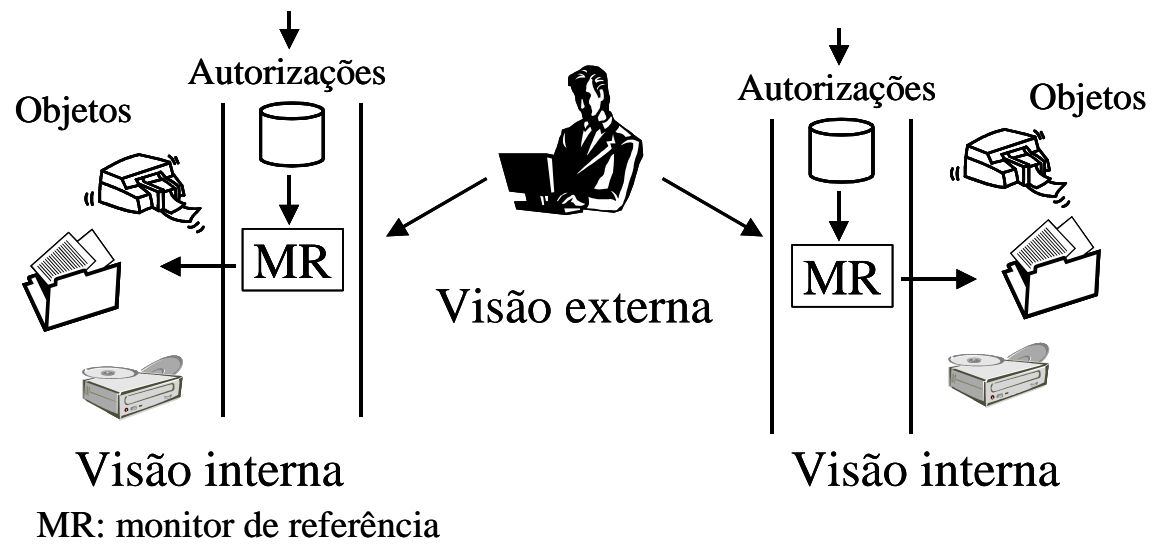

Figura 13 - A política de controle de acesso sob a perspectiva do usuário 
A figura 13 mostra que, em ambientes multidomínio, com formação ad hoc, onde os recursos estão distribuídos em sistemas distintos, cada domínio "vê” a política de controle de acesso de outros domínios sob o ponto de vista do conjunto funcional que caracteriza os serviços ofertados (visão externa). Ao mesmo tempo, "vê” sua política sob a ótica da garantia de segurança sobre seus recursos oferecidos (visão interna). Ou seja, o modelo de controle de acesso deve ser flexível para permitir o grau de abstração necessário para cada ponto de vista.

Durante a negociação, cada domínio contribui com sua política parcial, como mostra a figura 14, para a formação da política composta. Neste caso, a política está sob a visão interna, de quem exporta seus recursos sob regras de controle de acesso. Por outro lado, um domínio toma a decisão sobre sua participação ou não no multidomínio sob a visão externa que ele tem da política composta, ou seja, se a política atende ou não às suas necessidades, do ponto de vista de quem importa recursos. Logo, o modelo deve refletir a política sob as duas perspectivas.

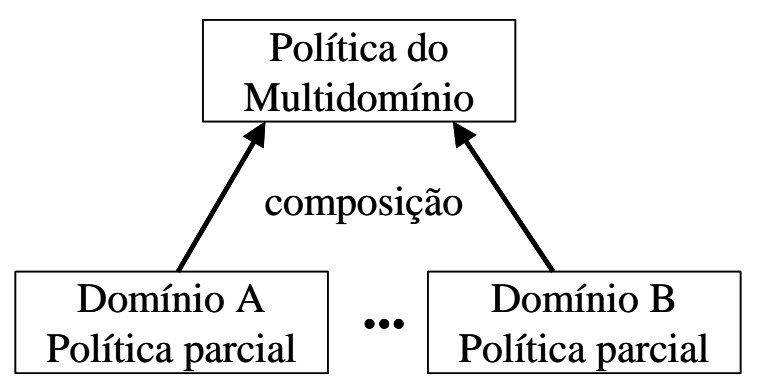

Figura 14 - Política do multidomínio

Como visto no capítulo 3, uma das dificuldades em definir a política de controle de acesso em multidomínios ad hoc está no desconhecimento, a priori, dos membros que participarão do multidomínio. A utilização de modelos baseado em papéis permite a definição das regras de controle de acesso (atribuição de permissões a papéis) em momentos distintos da associação de membros como participantes do multidomínio (atribuição de papéis aos usuários) e uma mudança nos membros participantes não altera, necessariamente, as regras e vice-versa. A abordagem utilizada para a definição da política de controle de acesso do MOS 
é o modelo básico de controle de acesso baseado em papéis (CABP), proposto pelo NIST. Mas acreditamos que o MOS possa, futuramente, ser generalizado para outros modelos de controle de acesso também baseados em papéis.

O modelo de CABP, introduzido na seção 4.3 e figura 8, é centrado no conjunto de papéis definidos para o sistema. Dado um conjunto de operações que podem ser executadas sobre um conjunto de objetos do sistema, pode ser definido um conjunto de possíveis permissões. Permissões refletem direitos para realizar operações sobre objetos. Pode-se dizer que, para o modelo básico, a política de controle de acesso é definida pelas atribuições de permissão e atribuições do usuário (FERRAIOLO, 2001). Para, efetivamente, obter permissão, o usuário inicia uma (ou mais) sessão e ativa os papéis que estará assumindo naquela sessão. Mas observe que, no modelo básico ${ }^{15}$, a componente "sessão” do modelo é considerada para a execução da política, não sendo considerada durante a definição das atribuições de permissões e atribuições do usuário.

Em um multidomínio, recursos são compartilhados pelos domínios, resultando em um conjunto de possíveis permissões (inicialmente não atribuídas). Cada domínio possui um ou mais membros que participam da associação. Logo, o conjunto de possíveis permissões e usuários (participantes) são conhecidos parcialmente pelos domínios. A figura 15 ilustra, na parte superior, o modelo CABP de um domínio sem a componente sessão, e na parte inferior da figura, sua contribuição parcial para a política do multidomínio. Ou seja, o conjunto de permissões (operações, objetos) compartilhadas em um multidomínio é um subconjunto das permissões do próprio domínio. Da mesma forma, nem todos os membros do domínio participam do multidomínio. Adicionalmente, um espaço de nomes é reservado para os papéis do multidomínio, tal que não haja conflito de nomes entre papéis internos (atribuídos a

\footnotetext{
${ }^{15}$ Modelos estendidos, como o CABP com Separação de Responsabilidade Dinâmica, podem impor restrições para a ativação de papéis, o que significa que a definição da política envolve a componente “sessão”.
} 
membros do domínio) e externos (atribuídos aos participantes do multidomínio). O conflito pode ser evitado, por exemplo, através da utilização de espaço de nomes hierárquicos e reservando um ramo da árvore hierárquica de nomes para os papéis externos.

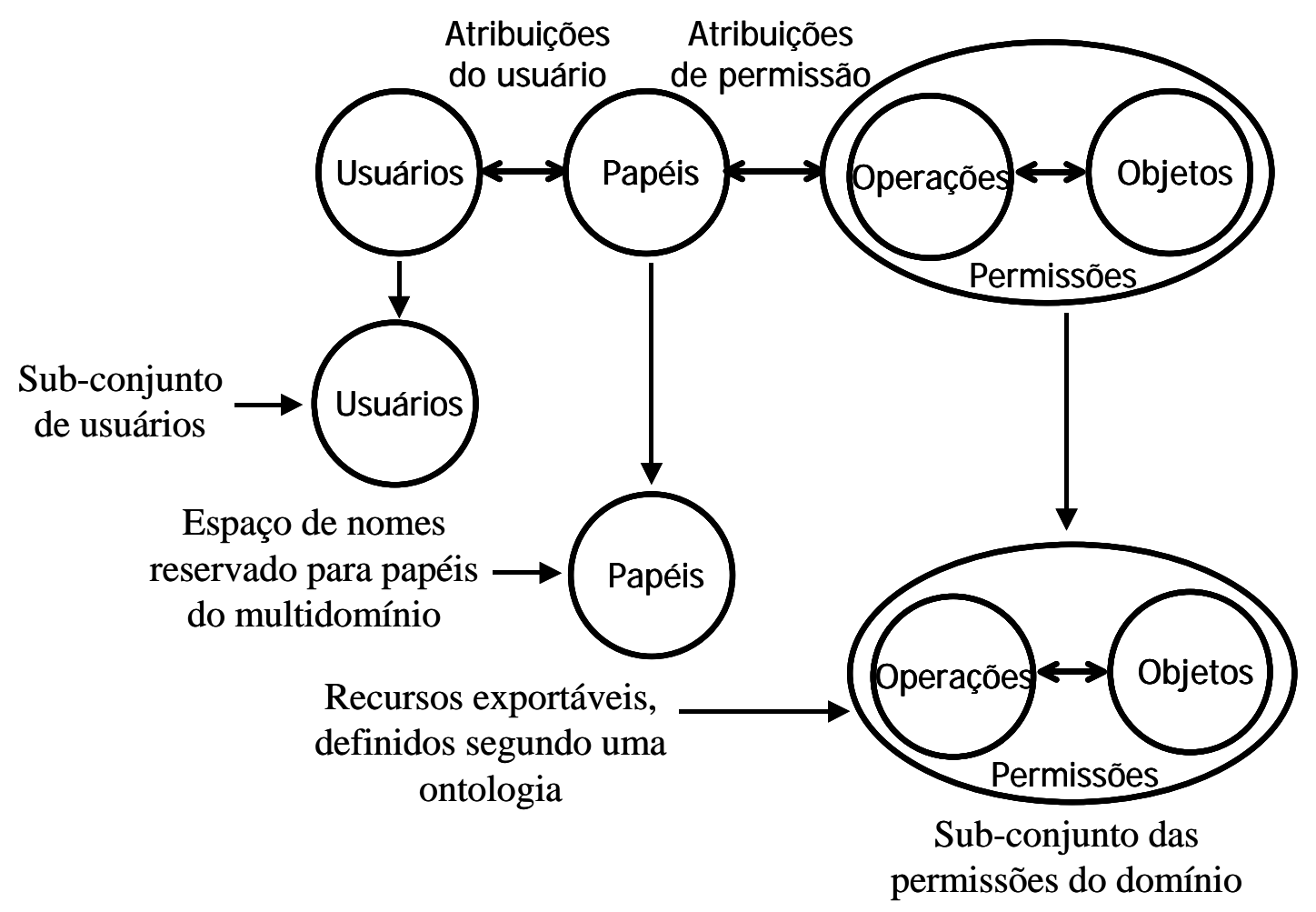

Figura 15 - CABP para multidomínios.

Para concluir a definição da política do multidomínio, segundo o modelo CABP básico, é necessário escolher um conjunto de papéis e estabelecer as atribuições usuário-papel e papel-permissão. O ponto principal a ser observado sobre multidomínios é que, ao mesmo tempo que eles podem ser formados para as mais diversas motivações, cada formação possui um objetivo específico e bem definido, por exemplo:

- Domínios pessoais podem associar-se para o compartilhamento de músicas.

- Domínios educacionais podem associar-se para a realização de trabalho colaborativo durante a execução de um projeto.

- Domínios corporativos podem associar-se para a realização de parcerias com objetivos específicos. 
- Domínios de tipos distintos podem associar-se para uma reunião.

- Domínios de provedores de acesso sem fio podem associar-se para ampliar sua cobertura (semelhante ao que ocorre com a telefonia celular).

O objetivo para o qual um multidomínio se forma pode definir um conjunto de papéis adequados para seu propósito. Para evitar um procedimento de negociação dos papéis do multidomínio e possíveis conflitos de nomes, o conjunto de papéis do multidomínio é definido pela ontologia de multidomínio, definida pelo MOS. Ou seja, o multidomínio é descrito por uma ontologia que define, entre outras coisa, os papéis passíveis de serem assumidos pelos usuários do multidomínio. Por exemplo, um multidomínio para projetos de pesquisa e desenvolvimento poderia suportar os papéis de pesquisador, desenvolvedor, testador e coordenador.

As atribuições de usuários e atribuições de permissões são definidas através da negociação da política, auxiliada pelo modelo ontológico de segurança. A negociação e composição da política do multidomínio ocorrem através da política de exportação e importação definida pelos domínios indiidualmente.

O conjunto de operações e suas respectivas permissões de cada domínio (figura 15), quando associado aos papéis do multidomínio, define a política do domínio como provedor de recursos, e é chamada de Política de Exportação. O conjunto de papéis que um domínio deseja assumir define sua política como consumidor de recursos, e é chamada Política de Importação.

\subsection{Ontologia}

O MOS é um modelo definido segundo uma ontologia. Uma ontologia é uma especificação de uma conceitualização (GRUBER, 1993). A ontologia fornece um 
vocabulário para a representação e comunicação do conhecimento sobre algum tópico e um conjunto de relacionamentos entre os termos daquele vocabulário. Ontologias são muitas vezes consideradas hierarquias taxonômicas de classes, ou seja, definições de classes e subclasses relacionadas, mas uma ontologia não precisa ser limitada a esta definição. Ontologias também não são limitadas a definições no sentido lógico tradicional, que somente introduzem uma terminologia e não adicionam qualquer conhecimento sobre o mundo ${ }^{16}$. Para especificar uma conceitualização é preciso declarar axiomas que façam restrições às possíveis interpretações para os termos. A interpretação de uma ontologia depende do domínio do discurso sobre o qual a ontologia foi definida, ou seja, depende do objetivo e escopo (domínio do problema, ou discurso).

O desenvolvimento de uma ontologia é um processo iterativo (NOY, 2001). Uma vez especificada a ontologia, ela é revisada e refinada. O primeiro passo para a definição de uma ontologia é definir o domínio do discurso, ou domínio do problema. Algumas questões podem ajudar a definir o domínio da ontologia (NOY, 2001):

- Qual é o domínio que a ontologia cobrirá?

- Para que a ontologia será utilizada?

- Para que tipo de questões as informações na ontologia deveria fornecer respostas?

- Quem usará e manterá a ontologia?

As respostas a estas questões ajudam a definir um conjunto de conceitos, os termos mais adequados para estes conceitos no contexto da aplicação da ontologia e seus usuários e a delimitar o escopo da ontologia.

(GRÜNINGER, 1995) propõe formular uma lista de questões que a ontologia deveria estar apta a responder, o que chamou de “questões de competência informal”. Esta lista serviria para definir o escopo da ontologia.

\footnotetext{
${ }^{16}$ Extraído de KSL - Knowledge System, AI Laboratory em http://www-ksl.stanford.edu.
} 
A ontologia especificada para a aplicação no MOS atende ao domínio do conhecimento envolvido na negociação, composição (definição) e manutenção da política de controle de acesso de multidomínio. Esta ontologia é capaz de responder às questões relativas ao controle de acesso tanto sob o ponto de vista do sistema protegido (interno) quanto do usuário (externo), de forma a viabilizar a negociação de uma política de segurança para um multidomínio. Através do modelo ontológico é possível obter respostas equivalentes às especificadas para o CABP básico.

Desta forma, a ontologia especificada para o MOS define um vocabulário para a representação das entidades envolvidas na definição da política de controle de acesso de um multidomínio, assim como o relacionamento entre estas entidades e as restrições sobre a interpretação dos termos e relacionamentos.

\subsubsection{Nomenclatura e Representação}

O objetivo desta seção é introduzir uma nomenclatura básica utilizada para definição de ontologia e sua relação com o diagrama UML. A figura 16 mostra um exemplo de representação de ontologia através de diagrama UML. As classes do diagrama representam os conceitos no domínio do discurso, os atributos das classes representam as propriedades dos conceitos (chamados slots na nomenclatura da ontologia) e os relacionamentos entre classes representam os relacionamentos entre os conceitos (relacionamentos também são slots). Atributos e relacionamentos podem ter restrições, que são chamadas facets na nomenclatura da ontologia ${ }^{17}$.

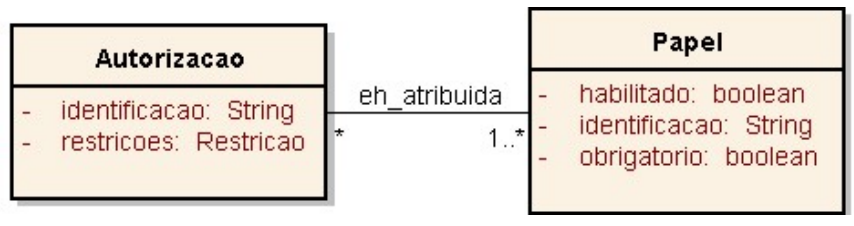

Figura 16 - Exemplo de representação de ontologia em UML

\footnotetext{
${ }^{17}$ Slots são menos comumente chamados de roles ou properties, e facets de role restrictions.
} 
Existem algumas restrições comuns definidas para atributos e relacionamentos, por exemplo: cardinalidade, tipo do valor, domínio, etc. Por exemplo, o atributo “identificação” do conceito “Autorização”, possui restrição de tipo de valor = String e cardinalidade mínima = 1 e máxima $=1$. Significa que o atributo “identificação” suporta um único valor do tipo String e que este valor TEM que ser definido (mínimo = 1), caso contrário uma restrição da ontologia não foi cumprida. Um relacionamento pode ter restrição de tipo de valor = classe ou instância de classe, definindo um relacionamento entre classes ou instâncias. É possível definir uma restrição para o alcance (range) do relacionamento. Por exemplo, o conceito Autorização possui associado um relacionamento “eh_atribuida” que aceita instâncias do tipo “Papel”, que é o alcance do relacionamento. Todo relacionamento associado a uma classe possui um domínio, que é a própria classe que o relacionamento está associado. Por exemplo, o relacionamento “eh_atribuida” tem domínio “Autorização” e alcance “Papel”. Um atributo ou relacionamento é independente e pode não estar associado a uma classe.

Uma ontologia, junto com um conjunto de instâncias individuais de classes constitui uma base de conhecimento. Segundo (NOY, 2001), na verdade, existe uma fina linha onde a ontologia termina e a base do conhecimento se inicia.

\subsection{O Modelo}

O Modelo Ontológico de Segurança (MOS) é especificado sobre a ontologia apresentada no diagrama UML da figura 17. O MOS é um modelo de controle de acesso baseado no CABP, onde os elementos do modelo são definidos por uma ontologia. Os recursos protegidos, papéis, operações e autorizações do modelo são descritos pela ontologia, permitindo uma linguagem semântica de comunicação entre os domínios. 
Os conceitos representados pela ontologia sofreram algumas alterações em relação à definição original do CABP. Algumas necessárias, outras apenas por melhor representar o conhecimento sobre a política para sua aplicação. Segue a definição dos conceitos e sua comparação com o CABP.

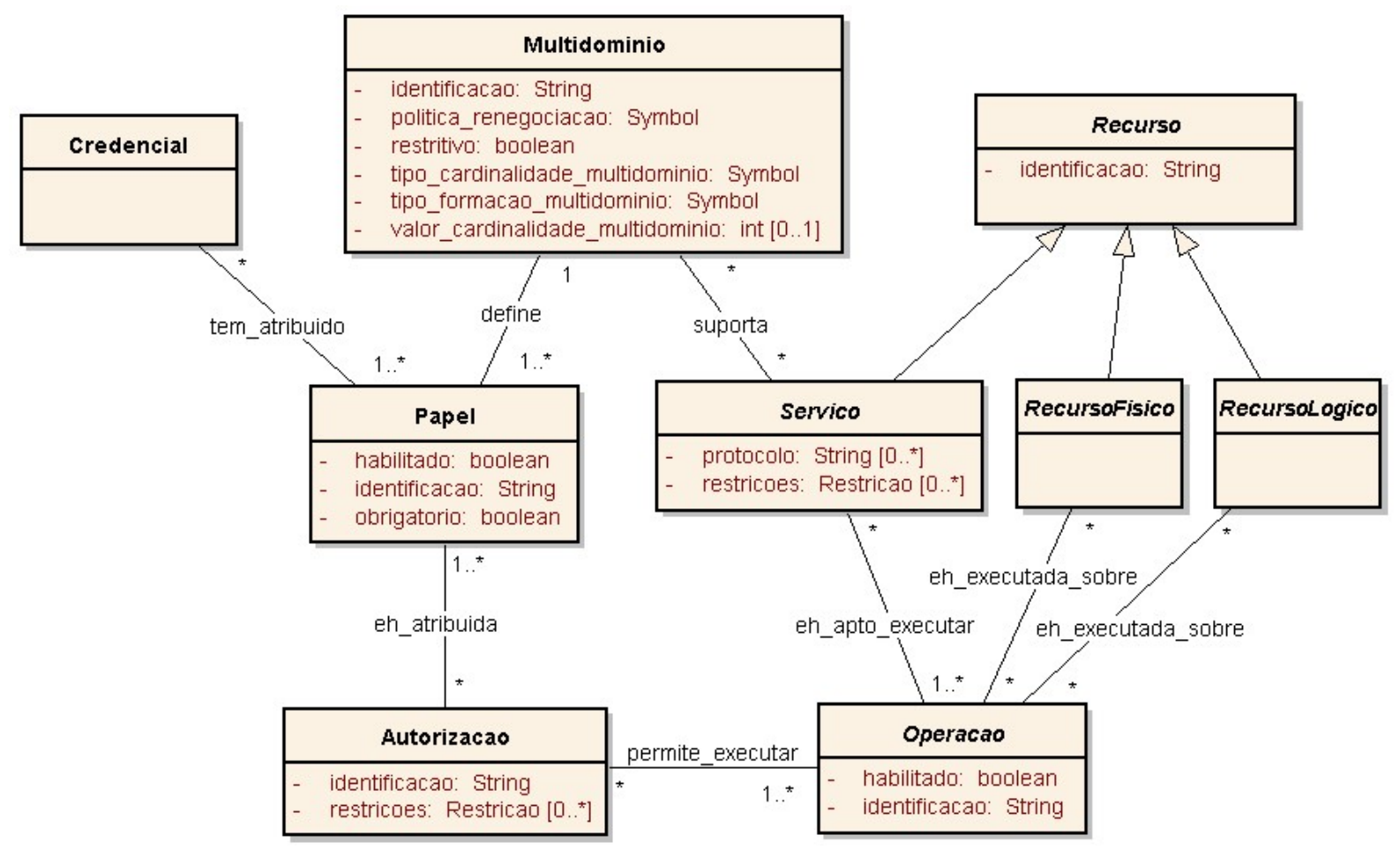

Figura 17 - Diagrama UML do Modelo Ontológico de Segurança

\subsubsection{Definição dos Conceitos}

Na ontologia, para especificar uma conceitualização é preciso declarar axiomas que façam restrições às possíveis interpretações para os termos definidos. Alguns atributos declarados para os conceitos representam restrições sobre o conceito, portanto têm axiomas associados a eles. Esses axiomas são apresentados no apêndice A.

\section{a) Papel}

Um papel é uma função de um usuário dentro do contexto de formação do multidomínio. Um papel tem associado uma semântica relativa à autoridade e responsabilidade conferida ao usuário (participantes) que assume o papel. O significado de 
um papel pode mudar dependendo do contexto em que ele é aplicado, ou seja, dependendo do objetivo do multidomínio. O conjunto de todas as instâncias de Papel representa o conjunto Papéis do CABP.

Foram especificados três atributos para o conceito Papel: identificação, habilitado e obrigatório. A identificação representa o Papel no espaço de nomes do modelo de controle de acesso CABP. O atributo habilitado é uma restrição estática sobre as atribuições do usuário. Se o valor for falso, indica que o papel não pode ser atribuído a qualquer usuário. O atributo obrigatório é uma restrição estática sobre as atribuições do usuário. Se o valor for verdadeiro, indica que é um papel essencial para o objetivo do multidomínio, ou seja, algum usuário TEM que assumir este papel, caso contrário, a política do multidomínio não será consistente com seus interesses.

\section{b) Autorização}

Uma autorização representa uma aprovação para um papel desempenhar uma ou mais operações. Mais precisamente, uma autorização representa um conjunto de operações permitidas, que sob determinadas restrições, são mapeadas a papéis. Uma autorização atribui direitos de acesso aos papéis para realizar operações em um multidomínio. O conceito de Autorização define as atribuições de permissões do CABP, quando mapeia Papel para Operações permitidas que por sua vez são mapeadas para Objetos (representados pelos recursos físicos e lógicos). No entanto, o mapeamento de Operações para Objetos no CABP é uma Permissão. Logo, uma Autorização na ontologia envolve os conceitos de Permissão e

\section{atribuições de permissões.}

O conceito de Autorização possui dois atributos: identificação e restrição. A identificação é o nome da regra de autorização. O atributo restrições visa representar restrições que não podem ser tratadas pela ontologia. A ontologia permite a verificação apenas de restrições estáticas, ou seja, restrições aplicadas sobre a base do conhecimento. Este 
atributo tem um objetivo informativo durante a negociação, ele representa uma restrição que será aplicada no momento da execução da política. Por exemplo, uma restrição poderia definir que o papel “Aluno” tem permissão para "Imprimir” sobre o recurso físico "Impressora”, apenas quando o papel "ProfessorResponsável” estiver ativado. Uma ontologia de restrições seria necessária para que este atributo pudesse ser interpretado pelos domínios.

\section{c) Operação}

Uma operação é um código executável de um programa, o qual sob invocação executa uma função. Essa definição equivale à definição do CABP, no entanto, na ontologia, o programa responsável por responder à invocação e executar a operação é deixado explícito, através do recurso Serviço. O conceito de Serviço foi adicionado ao modelo de controle de acesso para permitir uma melhor representação da política do ponto de vista do usuário, conforme apresentado em 5.1. O conjunto de todas as instâncias de operações representa o conjunto Operações do CABP.

O conceito operação possui dois atributos: identificação e habilitado. A identificação representa a Operação no espaço de nomes do CABP. O atributo habilitado é uma restrição sobre a criação de uma autorização para executar a operação. Se habilitado é falso, esta operação não pode ser permitida por nenhuma autorização.

\section{d) Credencial}

O conceito credencial foi inserido na ontologia para abstrair o conceito de usuário. Uma credencial representa um requisitante autenticado com um conjunto de papéis atribuídos.

\section{e) Recurso}

O conceito genérico de Recurso refere-se a qualquer objeto físico ou lógico que possa ser compartilhado, e, portanto, estará sujeito às regras de controle de acesso definidas pelo modelo ontológico de segurança. O conceito Recurso foi classificado em três tipos: Servico, RecursoFisico e RecursoLogico. Inicialmente, Recurso havia sido classificado como 
RecursoAtivo e RecursoPassivo, sendo que Serviço seria um recurso ativo, e RecursoFisico e RecursoLogico seriam recursos passivos. Mas consideramos que esta subclassificação nada acrescentaria a nossa ontologia e sob outros pontos de vista um RecursoFisico poderia ser classificado como um recurso ativo. Desta forma, optamos por uma classificação mais simples, mas mantivemos todos sob o mesmo conceito de Recurso.

O conceito Serviço representa um recurso capaz de receber requisições e executar pelo menos uma operação sobre os recursos lógicos e/ou físicos ${ }^{18}$. O conceito RecursoFisico representa um objeto palpável do mundo real, como impressoras, projetores multimídia, scanners, modem, etc. O conceito RecursoLogico representa uma informação, que pode estar disponível em determinado formato de armazenamento (ex. arquivos, programas, etc.), ou diretamente na memória.

RecursoLogico e RecursoFisico são referidos como objetos no CABP. Optamos por subclassificar e atribuir estes nomes por considerá-los mais expressivos. Para um recurso físico é normalmente relevante o local onde este recurso se encontra, enquanto que, para um recurso lógico, esta informação pode ser irrelevante. Por exemplo, um “serviço de impressão” pode executar a operação de “imprimir” sobre a “Impressora X”. Um usuário é atribuído a um papel que permite executar a operação de “imprimir” sobre a "Impressora X”. Se o objetivo do usuário é ter posse do objeto impresso, é relevante saber se a “Impressora X” está localizada nas suas proximidades. Por outro lado, o usuário pode querer imprimir sobre uma impressora remota em um local específico justamente para enviar o documento para o outro destino. Do ponto de vista de regra de controle de acesso, pode ser interessante criar uma restrição sobre autorizações, tal que operações sobre "RecursoFisico" só podem ser autorizadas se o usuário estiver no mesmo local (ou rede local) que o recurso físico.

${ }^{18}$ Do ponto de vista do multidomínio, um Serviço compartilhado é um membro do multidomínio, recursos físicos e lógicos não, pois não são entidades ativas. 
O conceito Recurso possui apenas um atributo: identificação. As subclasses de Recurso herdam este atributo. A identificação em RecursoLogico e RecursoFisico representa o nome do objeto no espaço de nomes do CABP. No caso de Serviço, a identificação representa o nome conferido pelo usuário ao compartilhar o recurso.

Serviço possui outros dois atributos: protocolo e restrições. O atributo protocolo define uma lista de nomes que representa os protocolos que podem ser utilizados para fazer requisições de operações para aquele serviço, auxiliando na verificação de compatibilidade dos recursos.

O atributo restrições visa representar restrições que não podem ser tratadas pela ontologia. A ontologia permite a verificação apenas de restrições estáticas, ou seja, restrições aplicadas sobre a base do conhecimento. Este atributo tem um objetivo informativo durante a negociação, ele representa uma restrição que será aplicada no momento da execução da política. Por exemplo, uma restrição que define que o serviço permite apenas dois acessos simultâneos. Uma ontologia de restrições seria necessária para que este atributo pudesse ser interpretado pelos domínios.

\section{f) Multidomínio}

O conceito Multidomínio especifica as regras gerais para a negociação, composição e gerenciamento da política de controle de acesso de um multidomínio. Um multidomínio é formado com um objetivo específico, o que define um conjunto de papéis para os quais as permissões de acesso devem ser atribuídas. Dado o objetivo do multidomínio, podem ser especificados os tipos de serviços que este domínio suporta. O Multidomíno possui diversos atributos que visam definir a política do multidomínio (regras gerais).

\section{f.1) Identificação}

A identificação representa o nome do multidomínio. 


\section{f.2) Restritivo}

Este atributo define se as restrições sobre o conjunto de papéis e serviços suportados, especificados para o Multidomínio, podem ser complementados pelos domínios. Ou seja, se este atributo for verdadeiro, nenhum papel pode ser adicionado e nenhum serviço de tipo diferente dos listados pode ser compartilhado, dentro da política do multidomínio. Este atributo apenas significa que, a menos que um domínio explicitamente crie uma regra de autorização fora do controle do MOS, nenhuma autorização será permitida fora das restrições definidas pelo multidomínio.

\section{f.3) tipo_formacao_multidomínio}

Este atributo informa sobre o tipo de multidomínio quanto à negociação da política. O atributo tem valor do tipo Symbol, que permite a seleção sobre um conjunto de opções, no caso: \{CENTRALIZADA, DISTRIBUIDA\}. Uma formação centralizada indica que existe um mediador da política, para o qual deve ser enviada a política parcial para a composição e verificação de restrições (conflitos). Numa formação distribuída, a negociação pode envolver todos os domínios.

\section{f.4) tipo_cardinalidade_multidomínio}

Este atributo define o tipo de cardinalidade relativo ao número de domínios participantes do multidomínio. O atributo tem valor do tipo Symbol, com valores permitidos: \{FIXA, MUTAVEL\}. Cardinalidade FIXA indica que, a política do multidomínio só é definida (através da composição) após a adição de um número fixo de domínios (definido pelo atributo valor_cardinalidade_multidomínio), e que, após a composição da política, nenhum outro domínio pode ser adicionado ou removido sem que todo o processo se repita. Uma cardinalidade MUTÁVEL indica que domínios podem ser adicionados ou removidos do multidomínio a qualquer momento, sem que obrigatoriamente a política seja redefinida. 


\section{f.5) valor_cardinalidade_multidomínio}

Este atributo está vinculado ao atributo tipo_cardinalidade_multidomínio. Se a cardinalidade for FIXA, este atributo deve conter o número de domínios participantes do multidomínio. Se for MUTÁVEL, este valor não é utilizado.

\section{f.6) politica_renegociação}

Este atributo define a necessidade de uma renegociação da política quando ocorre alguma mudança na política; seja através da adição ou remoção de um domínio, seja por alteração na política parcial de um domínio. O atributo tem valor do tipo Symbol, com valores suportados: \{OBRIGATORIA, OPCIONAL, DESNECESSARIA\}.

OBRIGATORIA: qualquer alteração na política parcial ou alteração nos domínios associados deve disparar um processo de renegociação da política. Exemplo: quando existe política obrigatória para papéis ou operações, ou seja, um papel TEM que ser atribuído, ou determinada operação TEM que ser disponibilizada.

OPCIONAL: a decisão sobre disparar ou não o processo de renegociação, quando uma alteração na política parcial ou nos domínios associados ocorre, fica a cargo da implementação ou do usuário. Exemplo: multidomínios onde a necessidade de renegociação depende do tipo de alteração e isto pode ser verificado pelo próprio domínio.

DESNECESSARIA: uma alteração na política parcial ou nos domínios associados não implica em mudanças sobre a visão macro da política composta. Exemplo: multidomínio para compartilhamento de MP3 entre amigos com mesma política para todos os domínios.

\subsubsection{Relacionamentos}

- Um Multidomínio define um ou mais Papéis e um Papel é definido por um Multidomínio. Um Multidomínio pode suportar diversos Serviços e um Serviço pode ser suportado por diversos Multidomínios 
- Um Papel pode ser atribuído a diversas Credencias e uma Credencial tem atribuído um ou mais Papéis. Uma credencial está associada a um usuário, logo, a atribuição de um papel a uma credencial significa atribuir este papel a um usuário.Um papel pode ter atribuído diversas Autorizações e uma Autorização é atribuída a um ou mais Papéis.

- Uma Autorização permite executar uma ou mais Operações e uma Operação pode ser permitida por diversas Autorizações.

- Um Serviço está apto a executar uma ou mais Operações e uma Operação pode ser executada por diversos Serviços.

- Uma Operação pode ser executada sobre diversos RecursosFisicos ou RecursosLógicos. RecursosFísicos e RecursoLógicos podem sofrer a execução de diversas Operações.

- Serviços, RecursosFísicos e RecursosLógicos são Recursos.

\subsubsection{Definições Relacionadas ao CABP}

- Atribuições do Usuário (AU) no CABP é um subconjunto dos possíveis mapeamentos de usuários para papéis. Este conjunto é equivalente ao conjunto dos mapeamentos entre credenciais e papeis no MOS, ou seja, o relacionamento tem_atribuído.

$$
\mathrm{AU} \Leftrightarrow \text { tem_atribuido }
$$

- Usuários atribuídos: representa o mapeamento de um papel sobre um conjunto de usuários no CABP. O MOS abstrai usuários pelo conceito credencial:

$$
\text { UsuáriosAtribuídos(r) }=\{\mathrm{u} \in \text { Credencial } \mid(\mathrm{u}, \mathrm{r}) \in \text { tem_atribuido) }
$$

- Atribuições de Permissão (AP) é um subconjunto dos possíveis mapeamentos de permissões para papéis no CABP. O conjunto de permissões no CABP é equivalente ao conjunto dos mapeamentos entre operações e (RecursosLogicos $\cup$ RecursosFisicos) no MOS, ou seja, o relacionamento eh_executada_sobre. 


$$
\begin{aligned}
& \text { AP } \subseteq \text { eh_executada_sobre } \times \text { Papel } \\
& \text { eh_executada_sobre } \Leftrightarrow \text { Permissões }
\end{aligned}
$$

- Permissões atribuídas: representa o mapeamento de um papel sobre um conjunto de permissões no CABP. O conjunto das permissões atribuídas a um papel para o MOS é um subconjunto dos mapeamentos de operações para recursos lógicos ou físicos (eh_executada_sobre), tal que a operação do mapeamento seja uma operação permitida de uma das autorizações associadas ao papel.

$$
\begin{gathered}
\text { PermissõesAtribuídas(r) }=\{(\text { op, ob) } \in \text { eh_executada_sobre } \mid \\
\exists \mathrm{a}: \text { Autorização } \bullet \mathrm{a} \in \text { AutorizaçõesPapel(r) } \wedge \text { op } \in \text { OperaçõesPermitidas(a) }\} \\
\text { OperaçõesPermitidas(a) }=\{\text { op } \in \text { Operações } \mid(\mathrm{a}, \mathrm{op}) \in \text { permite_executar }\} \\
\text { AutorizaçõesPapel }(\mathrm{r})=\{\mathrm{a} \in \text { Autorizações } \mid(\mathrm{a}, \mathrm{r}) \in \text { eh_atribuida }\}
\end{gathered}
$$

\subsubsection{Negociação e Composição da Política}

A política de controle de acesso do multidomínio é formada pela composição da política de exportação e importação dos domínios, cujas informações são descritas pela ontologia definida pelo MOS. O MOS não define mensagens de protocolo para a negociação da política, mas é responsabilidade do MOS garantir a consistência da política resultante.

O MOS pode ser utilizado tanto por multidomínios que buscam um acordo automatizado, quanto em procedimentos que exigem maior interação com os responsáveis (usuários ou administradores) pelos domínios. O processo de negociação e composição corresponde à formação da base do conhecimento sobre o qual o controle de acesso opera, a qual é definida com a colaboração de todos os domínios.

A criação da base do conhecimento consiste em criar as instâncias das classes definidas pela ontologia, obtendo uma descrição de todos os elementos envolvidos no controle 
de acesso: recursos, operações, papéis, autorizações e credenciais, assim como seus relacionamentos. Multidomínio e domínios dividem esta responsabilidade, como segue:

- O conjunto de papéis é definido pelo multidomínio.

- Os recursos compartilhados (serviços, recursos lógicos e físicos) são definidos pelos domínios.

- O conjunto de possíveis operações é definido pelos serviços compartilhados.

- A definição dos recursos físicos e lógicos, pelo menos para a fase de negociação, não é obrigatória (relação zero ou mais), depende do grau de abstração considerado suficiente para a negociação.

- A atribuição de permissões para papéis ocorre através do conceito de autorização. O multidomínio define, através da autorização, o conjunto de operações passíveis de serem permitidas a cada papel, de acordo com a autoridade e responsabilidade conferida ao usuário que assume determinado papel no multidomínio. Mas uma permissão só se torna efetiva quando domínios compartilham serviços que disponibilizam as operações associadas às autorizações. Portanto, a atribuição de permissões aos papéis envolve definições e atribuições do multidomínio e dos domínios.

- Um programa de raciocínio sobre a política é capaz de inferir sobre as permissões disponíveis para atribuição a um papel, baseado no conjunto de possíveis operações, definido pelos serviços compartilhados, e no conjunto de operações passíveis de serem assumidas em cada papel, definido pelas autorizações.

- A adição de recursos, operações e a associação destas operações aos papéis através de autorizações, ocorrem separadamente em cada domínio, e define a política de exportação de cada domínio. 
- Uma credencial representa um único usuário associado a um ou mais papéis. Esta credencial pode ser uma representação abstrata de uma lista, definida em cada domínio, que mapeia a identificação de usuários aos papéis a ele atribuídos. Ou pode ser uma representação abstrata de um certificado de autorização sobre o papel atribuído, vinculado a um nome ou uma chave pública. O MOS não define restrições para a atribuição de papéis aos usuários, representados pelas credenciais.

- A política de importação é definida por instâncias de credenciais, criadas pelos domínios, associadas aos papéis desejados. Esta associação de credenciais a papéis não se torna efetiva se não for aceita pelos domínios, depois de finalizada a negociação. O MOS define apenas que os domínios devem manifestar seus interesses em assumir papéis através de uma política de importação.

- A política composta corresponde à inclusão das políticas parciais de exportação e importação, sobre a política, também parcial, definida pelo multidomínio. A política composta deve ser consistente, ou seja, todas as restrições devem ser cumpridas. Caso a política composta não resulte em um modelo consistente, um programa de raciocínio sobre a ontologia pode, num processo automatizado, tentar resolver os conflitos. Caso conflitos não possam ser automaticamente resolvidos, a política resultante deve ser devolvida aos domínios para renegociação.

\subsubsection{Regras de Negociação}

As seguintes regras são propostas para serem seguidas durante a negociação para garantir a consistência do modelo.

- A política definida pelo conceito Multidomínio, envolvendo a definição de papéis, serviços suportados e autorizações para os papéis, só é alterada pelo criador do multidomínio. 
- A política de importação e exportação definida pelos domínios adiciona conhecimentos e relacionamentos à política, mas nunca remove ou altera conhecimentos ou relacionamentos pré-existentes.

- As políticas de exportação e importação devem representar um modelo consistente, a menos das restrições impostas pelo atributo obrigação, que só se aplicam à política composta. Os conceitos Papel e Operação possuem este atributo (5.3.1).

- A composição da política ocorre pela adição dos conhecimentos e relacionamentos, definidos pela política de importação e exportação de cada domínio, à política originalmente definida pelo criador do multidomínio. Eventuais alterações que os domínios tenham feito nesta política são descartadas.

A composição pode resultar em um modelo inconsistente, pela existência de conflitos sobre as restrições do modelo ou conflitos de interesses. Alguns conflitos comuns na negociação podem ser automaticamente resolvidos durante a composição. Conflitos não resolvidos exigem uma renegociação.

\subsubsection{Detecção e Resolução de Conflitos}

Os possíveis conflitos nesta fase são classificados em três tipos: conflitos de negociação, conflitos de interesse e conflitos do modelo. Um conflito de negociação ocorre quando qualquer restrição definida para a negociação não é cumprida. Conflito de interesses corresponde a conflitos entre as políticas de importação e exportação. Enquanto conflitos de modelo ocorrem quando qualquer das restrições definidas pelo modelo, MOS ou especialização dele, não são cumpridas.

Todos os conflitos, independente de serem automaticamente resolvidos ou não, são registrados e enviados aos domínios juntamente com a política consolidada. O modelo propõe que as verificações de conflitos e a aplicação da regra de resolução de conflito sigam a seqüência numérica abaixo. 


\section{Regras de resolução de conflitos de negociação:}

1. Conflito sobre o atributo restritivo: qualquer papel ou serviço fora do conjunto definido para o multidomínio não é importado para a base do conhecimento do multidomínio, é descartado.

2. Conflito sobre operações: qualquer operação sem um serviço que se habilite a executálo é desabilitado.

3. Conflito de papéis: qualquer papel sem permissão para executar pelo menos uma operação habilitada é desabilitado.

4. Conflito sobre o atributo obrigatório: este conflito ocorre se existir um papel obrigatório desabilitado ou existir, em qualquer autorização, operações obrigatórias que estão desabilitadas ou não estão associadas às operações permitidas. Esse tipo de conflito não é tratável por processo automatizado. O conflito deve ser registrado para uma renegociação, mas o processo de composição não é interrompido.

\section{Regras de resolução de conflitos de interesses}

5. Conflito de exportação: qualquer papel para o qual são providos recursos, através de autorizações, mas não há manifestação de interesse em assumir este papel, é desabilitado.

6. Conflito de importação: qualquer papel desabilitado que esteja inserido na política de importação é removido desta política. Caso contrário ocorreria um conflito de modelo.

\section{Regras de resolução de conflitos de modelo}

7. Os conflitos de modelo não são tratáveis por processo automatizado. O conflito deve ser registrado para uma renegociação, mas o processo de composição não é interrompido. 
a) Conflito de nomes: o conflito de nomes pode ser evitado usando nomes hierárquicos para a identificação dos elementos da ontologia. Por exemplo, o serviço de impressão do domínio 1 teria nome: Domínio1.Impressão.

b) Conflito de papéis: papéis desabilitados não podem ser atribuídos às credenciais. Papéis obrigatórios têm que estar atribuídos a pelo menos uma credencial e possuir pelo menos uma permissão atribuída.

c) Conflito de operações: operações obrigatórias têm que estar habilitadas e devem estar permitidas para as autorizações correspondentes.

Se nenhum conflito não tratável for detectado no final do processo, a negociação segue para a efetiva atribuição de papéis. Caso contrário, é disparado um processo de renegociação. Em qualquer dos casos a relação de conflitos é enviada aos domínios.

\subsubsection{Aplicação do MOS}

A aplicação do MOS para o controle de acesso em multidomínios ocorre em dois níveis, um abstrato e outro concreto. O modelo abstrato representa a política de controle de acesso num alto grau de abstração. O modelo abstrato baseia-se no conhecimento extraído da ontologia, utiliza uma linguagem descritiva, e é adotado para a negociação da política e resolução de conflitos estáticos. Já o modelo concreto atua sobre os objetos reais, utiliza uma linguagem baseada em regras, e é adotado para a implementação da política de controle de acesso. O modelo abstrato é mapeado/traduzido para o modelo concreto, interno de cada domínio, para sua execução.

A utilização dos dois modelos é justificada pelo fato de modelos baseados somente em ontologia não permitirem a definição de regras de controle de acesso com a variedade de restrições contextuais que podem ser necessárias em domínios mais complexos, como restrições temporais, ambientais, separação de responsabilidade dinâmica, etc. (TONINELLI, 
2005). Por outro lado, um modelo baseado somente em regras não permite a interoperabilidade viabilizada pela ontologia.

O modelo concreto é baseado no modelo básico do CABP do NIST, e o modelo abstrato utiliza ontologias para extrair os conceitos relativos ao controle de acesso que são relevantes para a negociação de uma política comum, distribuída e compartilhada. Através da ontologia é possível a utilização de uma linguagem comum para a negociação e composição desta política.

\subsection{Considerações}

Este capítulo apresentou um modelo ontológico de segurança que representa os elementos essenciais para a negociação e composição de uma política de controle de acesso em multidomínios. A definição do modelo baseado em ontologia permite a utilização de uma linguagem comum e padronizada, viabilizando sua interpretação por diferentes domínios durante a negociação. O uso de ontologia também permite a inserção de restrições que delimitam as interpretações sobre os conceitos e ajudam a garantir a consistência do modelo nas fases de negociação (definição das políticas de exportação e importação), composição e possível renegociação.

A utilização do modelo baseado em papéis permite que a política do multidomínio seja negociada através das políticas de importação e exportação, que podem ser diretamente relacionadas, através dos papéis, para a verificação de conflito de interesses. Adicionalmente, o modelo permite a negociação da política com abstração sobre os reais recursos disponibilizados e a política resultante é totalmente independente da política interna dos domínios. Isto permite manter a autonomia e isolamento dos domínios. O próximo capítulo apresenta um modelo concreto do MOS através de um exemplo de sua aplicação em domínios pessoais. 


\section{Capítulo 6 - O MOS em Multidomínios Pessoais}

Este capítulo visa mostrar a aplicabilidade do MOS em multidomínios pessoais, através de uma especialização da ontologia proposta pelo MOS para esta finalidade. Essa ontologia especializada propõe uma hierarquia de recursos e operações, define instâncias da ontologia de multidomínio e propõe o uso de delegação de autoridade para as atribuições de papéis.

A seção 6.1 apresenta uma visão geral da especialização do MOS e alguns comentários sobre a metodologia utilizada para a validação, ou seja, para a análise de viabilidade da aplicação do MOS. As sessões 6.2 a 6.5 apresentam o MOS especializado e um exemplo utilizado para sua validação. A seção 6.6 apresenta os resultados da negociação para o exemplo definido. Finalmente, a seção 6.7 expõe algumas considerações sobre a aplicação do modelo.

\subsection{Visão Geral}

O MOS foi dividido em três submodelos para simplificar a apresentação. Os submodelos são referidos como Modelo Ontológico para a Associação de Domínios (MOAD), Modelo Ontológico de Controle de Acesso (MOCA) e Modelo Ontológico de Delegação de Autoridade (MODA). A figura 18 apresenta a divisão do MOS em submodelos, tendo o papel como o elemento comum entre todos eles. As sessões seguintes apresentam estes submodelos, sendo a ontologia de recursos e operações apresentadas separadamente.

A ontologia utilizada para a validação do modelo foi especificada com a ferramenta Protégé. Protégé é um editor de ontologias e um framework para base do conhecimento, desenvolvido pela Universidade de Stanford, nos Estados Unidos da América. Esta ferramenta 
é um software livre desenvolvido em linguagem Java e possui uma API que pode ser utilizada por aplicações externas à ferramenta.

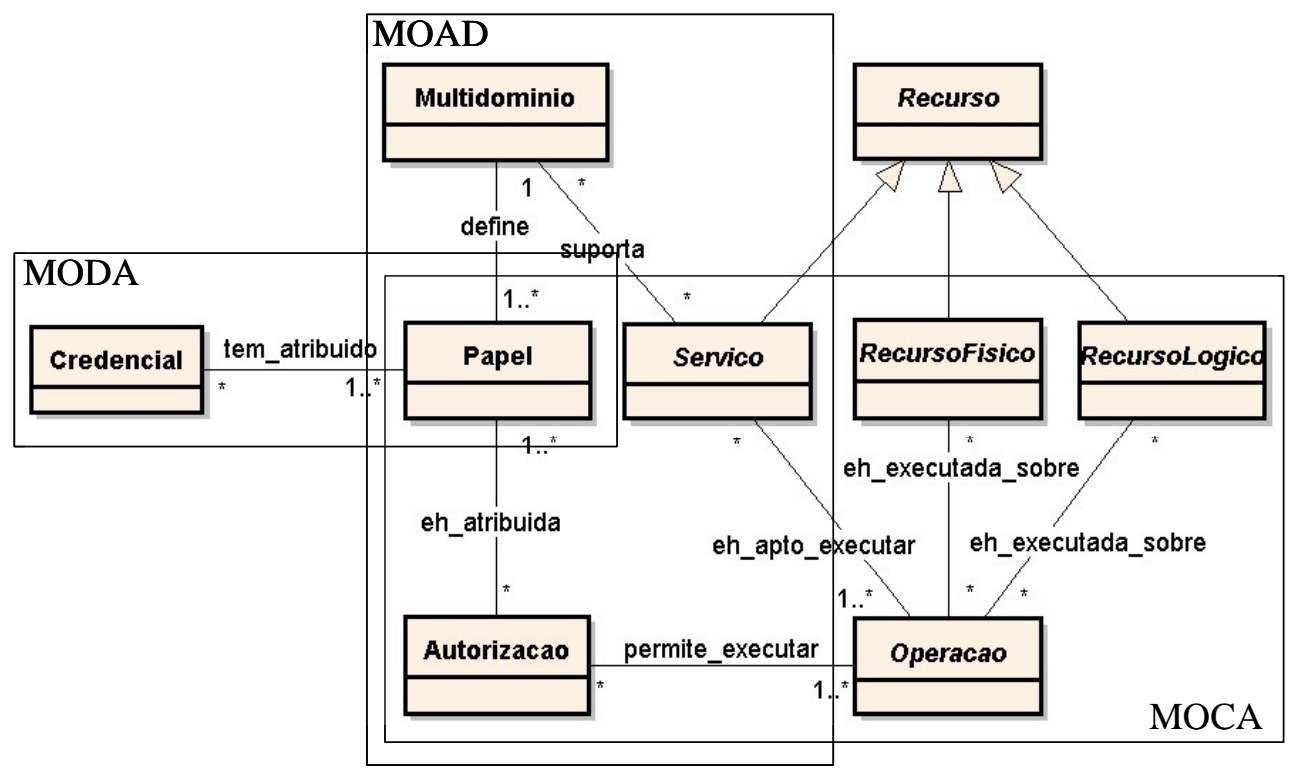

Figura 18 - Submodelos do MOS

A validação do modelo foi feita por simulação utilizando a ferramenta Protégé para as fases de edição e obtenção de informações da ontologia. Essas informações são obtidas através de perguntas e respostas feitas sobre a ontologia. Todos os procedimentos utilizados durante a simulação podem ser acessíveis através da API disponível pelo Protégé, o que viabiliza sua integração ao projeto MPSD, também desenvolvido em linguagem Java.

Algumas alterações foram feitas no projeto original do MPSD para adequar-se ao modelo de controle de acesso baseado em papéis e viabilizar sua integração com o MOS.

\subsection{Ontologia de Recursos e Operações}

A figura 19 e figura 20 ilustram a ontologia de recursos e operações respectivamente. Essas ontologias definem uma hierarquia de recursos e operações e a relação entre elas. 


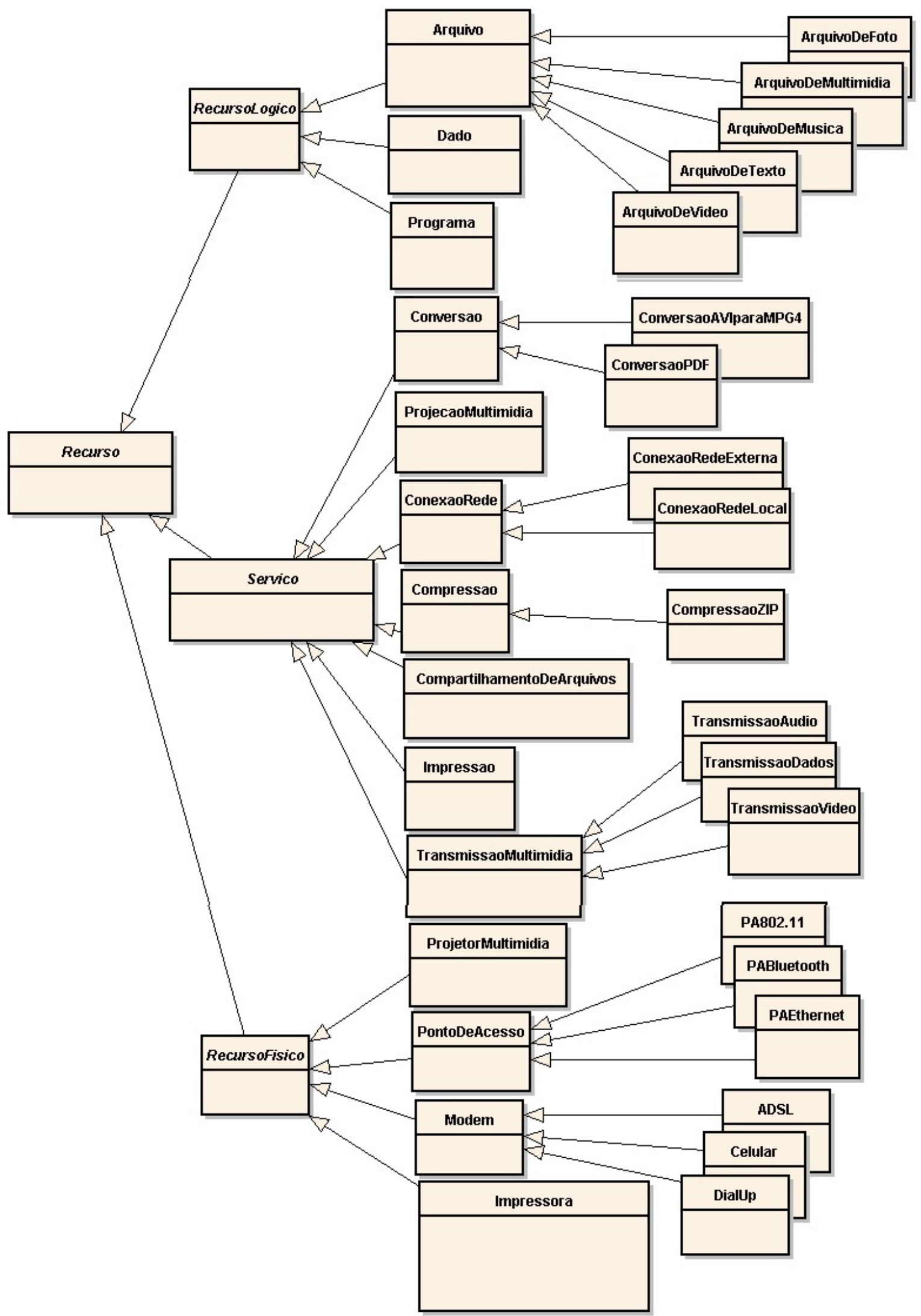

Figura 19 - Ontologia de Recursos 


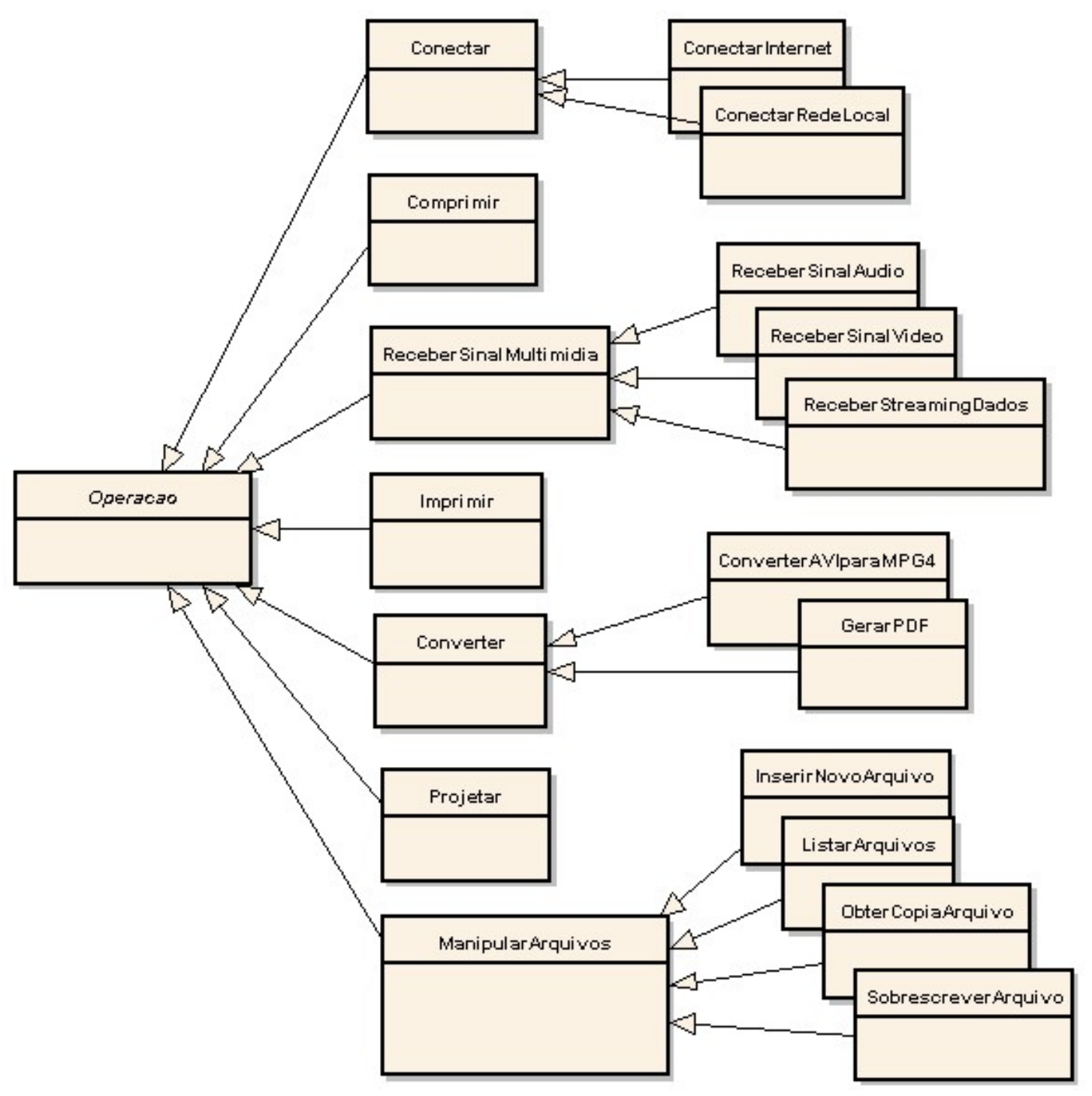

Figura 20 - Ontologia de Operações

Os relacionamentos entre os conceitos apresentados nestas figuras são relacionamentos de herança. Herança é um relacionamento do tipo “é um”. Por exemplo, na figura 19, ArquivoDeVideo “é um” Arquivo que “é um” RecursoLógico que “é um” Recurso.

A hierarquia de recursos e operações proposta pela ontologia contém operações, serviços, recursos físicos e recursos lógicos comuns em pequenos domínios. O objetivo é definir uma ontologia que, embora com pouca maturidade, permita mostrar a aplicabilidade do MOS em domínios pessoais.

Num relacionamento de herança, o conceito hierarquicamente inferior (conceito filho) herda os atributos e relacionamentos do conceito superior (conceito pai). Por exemplo, o 
conceito ManipularArquivos herda os atributos e relacionamentos do conceito Operação. Na ontologia, é possível impor restrições aos relacionamentos herdados pelos conceitos filhos (figura 21). O conceito filho pode sobrescrever um relacionamento herdado, desde que este relacionamento seja mais restritivo que o do conceito pai. Por exemplo, todos os conceitos do tipo Serviço herdam o relacionamento eh_apto_executar com o conceito Operação. Os conceitos filhos de Serviço podem restringir seu relacionamento apenas a alguns tipos de Operações. A figura 21 ilustra uma restrição aplicada ao relacionamento entre os conceitos Serviço, Operação e RecursoLógico. Neste caso, o serviço de CompartilhamentoDeArquivos está apto a executar apenas operações do tipo ManipularArquivos, e esta operação, por sua vez é executada apenas sobre recursos do tipo Arquivo.

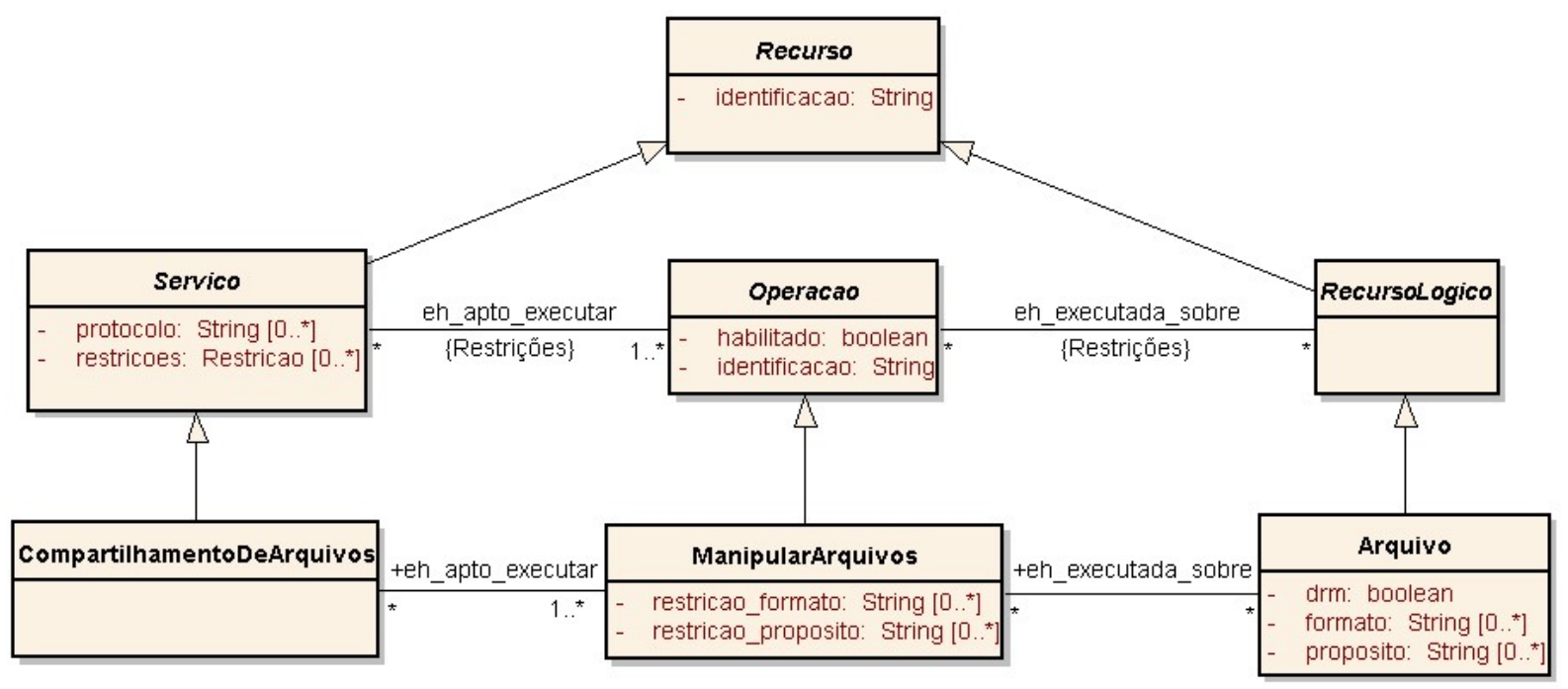

Figura 21 - Restrições sobre relacionamentos: Compartilhamento de Arquivos

Um serviço de compartilhamento de arquivos é bastante genérico e pode ser aplicado com fins específicos. Por exemplo, um serviço de compartilhamento de arquivos pode ser utilizado para compartilhar MP3 em um multidomínio de Músicas, e ao mesmo tempo para compartilhar documentos de tipos diversos em um multidomínio de Pesquisa. Com o objetivo de permitir a atribuição flexível de permissões a este tipo de serviço, a operação do tipo ManipularArquivos suporta dois novos atributos: restrição_formato e restrição_propósito. A 
restrição de formato limita a extensão do arquivo (atributo formato em Arquivo) sobre o qual a operação pode ser executada. A restrição de propósito limita a operação a ser executada sobre arquivos definidos com mesmo propósito (atributo propósito em Arquivo). Por exemplo, um multidomínio de pesquisa pode definir autorizações para operar sobre arquivos, sendo que desenvolvedores operam com direito de escrita sobre arquivos com o propósito de desenvolvimento, pesquisadores operam com direito de escrita sobre arquivos com o propósito de pesquisa e todos operam com direito de leitura sobre quaisquer dos propósitos do grupo.

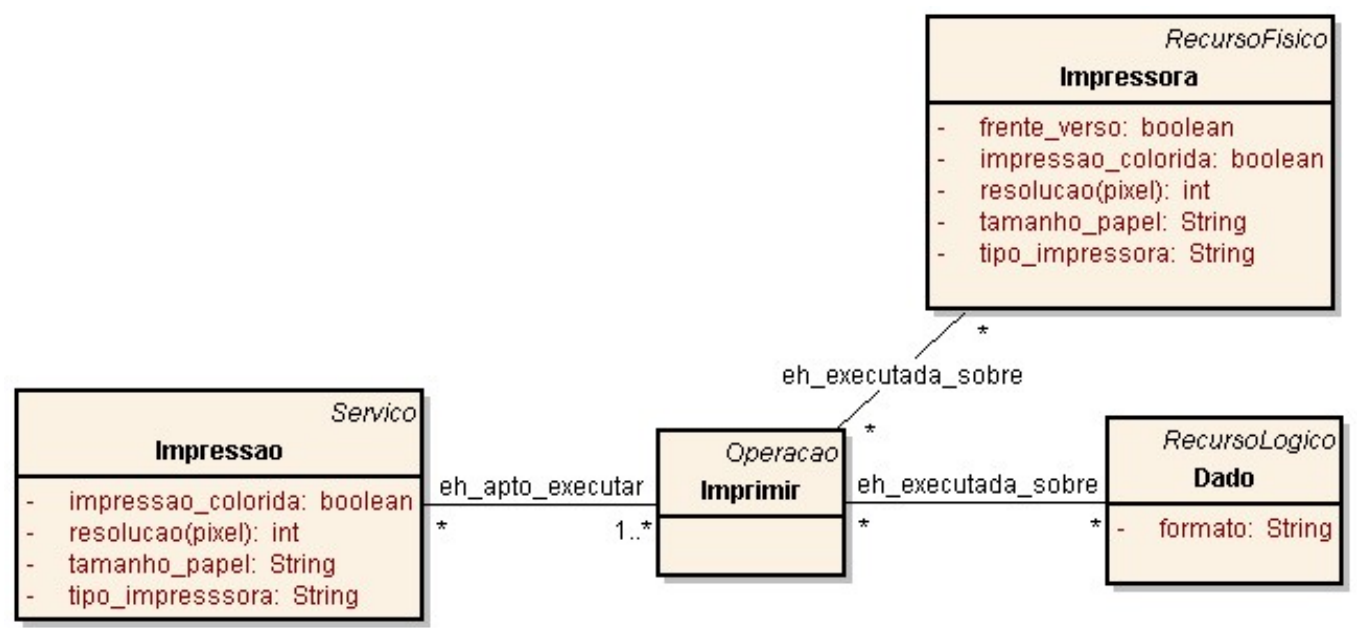

Figura 22- Restrição sobre relacionamentos: Serviço de Impressão

A figura 22 representa a parte da ontologia relativa ao serviço de impressão. O diagrama mostra que o serviço de Impressão está apto a executar a operação de Imprimir, que é executada sobre um recurso físico Impressora e um recurso lógico Dado. O recurso lógico Dado representa uma informação na memória, normalmente uma informação recebida do requisitante para processamento. Este relacionamento mostra que para realizar uma operação pode ser necessária a atuação sobre mais que um recurso físico ou lógico. 


\subsection{Modelo Ontológico para a Associação de Domínios}

Esta seção apresenta, como exemplo, um multidomínio para Projeto de Pesquisa, com o objetivo mostrar a aplicabilidade do modelo proposto. O MOAD - Modelo Ontológico para a Associação de Domínios é responsável pela primeira fase da definição da política de controle de acesso, quando os conceitos de Multidomínio, Papel, Serviço e Autorização são definidos.

No exemplo, um projeto de pesquisa possui os atributos apresentados na tabela 1, que mostra que o multidomínio é restritivo. Em um multidomínio restritivo apenas os papéis definidos e serviços suportados pelo multidomínio podem ser utilizados.

Tabela 1 - Multidomínio para Projeto de Pesquisa

\begin{tabular}{|l|l|}
\hline \multicolumn{1}{|c|}{ Atributo e Relacionamentos } & \multicolumn{1}{|c|}{ Valor } \\
\hline identificação & Projeto LARC \\
\hline tipo_formação_multidomínio & CENTRALIZADA \\
\hline tipo_cardinalidade_multidomínio & MUTÁVEL \\
\hline valor_cardinalidade_multidomínio & <não definido> \\
\hline política_renegociação & OPCIONAL \\
\hline restritivo & Sim \\
\hline Papéis definidos & Coordenador \\
& Pesquisador \\
& Desenvolvedor \\
& Testador \\
& Secretária \\
& Colaborador \\
\hline Serviços suportados & Impressão \\
& ConversãoPDF \\
& ProjeçãoMultimídia \\
& CompartilhamentoDeArquivos \\
\hline
\end{tabular}

A tabela 2 apresenta o conjunto de autorizações e respectivas operações permitidas. A tabela 3 apresenta as atribuições das autorizações aos papéis. As operações permitidas aos papéis, através das autorizações, servem de orientação para os domínios sobre as atribuições de cada papel. Basicamente, cada papel tem direito às autorizações gerais, direito de escrita sobre os arquivos relativos a sua função e direito de leitura sobre os arquivos das demais funções, com exceção dos papéis de Secretária e Colaborador que possuem permissões 
específicas. Um colaborador possui apenas direito de leitura sobre arquivos do projeto sobre o qual colabora.

Tabela 2 - Lista de Autorizações do Projeto de Pesquisa

\begin{tabular}{|c|c|c|}
\hline Autorização & Operação & Atributos de Operação \\
\hline \multirow{5}{*}{ AutorizacaoGeral } & Imprimir & \\
\hline & Projetar & \\
\hline & GerarPDF & \\
\hline & ListarArquivos & $\begin{array}{l}\text { propósito }=\{\text { adm, pesq, } \operatorname{dev} \text {, } \\
\text { teste, col }\}\end{array}$ \\
\hline & ObterCopiaArquivo & $\begin{array}{l}\text { propósito }=\{\text { adm, pesq, } \operatorname{dev} \text {, } \\
\text { teste, col }\}\end{array}$ \\
\hline \multirow[t]{2}{*}{ AutorizacaoCoordenador } & InserirArquivosAdm & propósito=adm \\
\hline & SobrescreverArquivosAdm & propósito=adm \\
\hline \multirow[t]{2}{*}{ AutorizacaoPesquisador } & InserirArquivosPesq & propósito=pesq \\
\hline & SobrescreverArquivosPesq & propósito=pesq \\
\hline \multirow[t]{2}{*}{ AutorizacaoDesenvolvedor } & InserirArquivosDev & propósito=dev \\
\hline & SobrescreverArquivosDev & propósito=dev \\
\hline \multirow[t]{2}{*}{ AutorizacaoTestador } & InserirArquivosTeste & propósito=teste \\
\hline & SobrescreverArquivosTeste & propósito=teste \\
\hline \multirow{3}{*}{ AutorizacaoSecretária } & ListarArquivosAdm & propósito=adm \\
\hline & ObterCopiaArquivosAdm & propósito=adm \\
\hline & Imprimir & \\
\hline \multirow{3}{*}{ AutorizacaoColaborador } & ListarArquivosCol & propósito=col \\
\hline & ObterCopiaArquivosCol & propósito=col \\
\hline & Projetar & \\
\hline
\end{tabular}

Tabela 3 - Atribuições a Papéis para Projeto de Pesquisa

\begin{tabular}{|c|l|}
\hline \multicolumn{1}{|c|}{ Papel } & \multicolumn{1}{|c|}{ Autorizações } \\
\hline Coordenador & AutorizacaoGeral \\
& AutorizacaoCoordenador \\
\hline Pesquisador & AutorizacaoGeral \\
& AutorizacaoPesquisador \\
\hline Desenvolvedor & AutorizacaoGeral \\
& AutorizacaoDesenvolvedor \\
\hline Testador & AutorizacaoGeral \\
& AutorizacaoTestador \\
\hline Secretária & AutorizacaoSecretaria \\
\hline Colaborador & AutorizacaoColaborador \\
\hline
\end{tabular}

O MOAD envolve os conceitos necessários para a criação da política inicial para a negociação, ou seja, a política de controle de acesso parcial sobre a qual as políticas de importação e exportação serão aplicadas. A negociação e composição da política de controle de acesso do multidomínio utilizam o MOCA. 


\subsection{Modelo Ontológico de Controle de Acesso}

O MOCA envolve todos os conceitos essenciais para a definição da política de controle de acesso, ou seja, para a definição das políticas de importação e exportação, negociação, composição e renegociação em caso de conflito. Durante a formação do multidomínio, os domínios recebem do criador do multidomínio a política definida pelo MOAD. A negociação ocorre seguindo as regras definidas em 5.3.4.1.

A seguir é apresentado um exemplo de definição da política de exportação e importação, negociação e composição para o projeto de pesquisa, utilizando o MOCA.

\subsubsection{Política de Exportação e Importação}

Como exemplo de definição de política de exportação e importação são considerados quatro domínios participantes do multidomínio. Cada domínio possui um conjunto de serviços para compartilhamento e associa a estes serviços um conjunto de operações para as quais o serviço está apto a executar e deseja compartilhar. Um exemplo de adição de serviços e relacionamentos para formar a política de exportação e importação para o projeto de pesquisa é mostrado nas tabela 4 e tabela 5 .

Tabela 4 - Exemplo de Política de Exportação

\begin{tabular}{|l|l|l|}
\hline \multicolumn{1}{|c|}{ Domínio } & \multicolumn{1}{|c|}{ Serviços } & \multicolumn{1}{c|}{ Operações } \\
\hline \multirow{4}{*}{ Domínio1 } & Impressão & Imprimir \\
\cline { 2 - 3 } & ProjeçãoMultimidia & Projetar \\
\cline { 3 - 3 } & CompartilhamentoDeArquivos & $\begin{array}{l}\text { ListarArquivos } \\
\text { ObterCopiaArquivo } \\
\text { InserirArquivosPesq } \\
\text { SobrescreverArquivosPesq } \\
\text { InserirArquivosDev } \\
\text { SobrescreverArquivosDev }\end{array}$ \\
\hline \multirow{2}{*}{ Domínio2 } & CompartilhamentoDeArquivos & $\begin{array}{l}\text { ListarArquivos } \\
\text { ObterCopiaArquivo } \\
\text { InserirArquivosPesq } \\
\text { SobrescreverArquivosPesq } \\
\text { InserirArquivosTeste } \\
\text { SobrescreverArquivosTeste }\end{array}$ \\
\hline
\end{tabular}




\begin{tabular}{|l|l|l|}
\hline & CompartilhamentoDeArquivos & $\begin{array}{l}\text { ListarArquivos } \\
\text { ObterCopiaArquivo } \\
\text { InserirArquivosAdm } \\
\text { SobrescreverArquivosAdm } \\
\text { Domínio3 }\end{array}$ \\
& & $\begin{array}{l}\text { InserirArquivosPesq } \\
\text { SobrescreverArquivosPesq } \\
\text { InserirArquivosDev } \\
\text { SobrescreverArquivosDev } \\
\text { InserirArquivosTeste } \\
\text { SobrescreverArquivosTeste } \\
\text { ListarArquivosAdm } \\
\text { ObterCopiaArquivoAdm } \\
\text { ListarArquivosCol } \\
\text { ObterCopiaArquivoCol }\end{array}$ \\
\hline Domínio4 & \\
\hline & & \\
\hline
\end{tabular}

Tabela 5 - Exemplo de Política de Importação

\begin{tabular}{|l|l|}
\hline \multicolumn{1}{|c|}{ Domínio } & \multicolumn{1}{c|}{ Papéis } \\
\hline Domínio1 & Pesquisador \\
& Desenvolvedor \\
\hline Domínio2 & Pesquisador \\
& Testador \\
\hline Domínio3 & Coordenador \\
& Pesquisador \\
\hline Domínio4 & Colaborador \\
\hline
\end{tabular}

A política de exportação é composta pelos serviços que cada domínio está compartilhando e os relacionamentos desses serviços com as operações que eles estão aptos a executar. As operações, por sua vez, estão associadas aos papéis através das autorizações definidas pelo MOAD. A política de exportação assume a forma de um conhecimento adicionado à base de conhecimento definida pelo MOAD. O relacionamento dos serviços compartilhados às operações pode ser criado por processo automatizado ${ }^{19}$. Neste caso, são criados relacionamentos para todas as operações que o serviço está apto a executar. Este é o caso do domínio 3. Nos domínios 1 e 2 as operações de manipulação de arquivos foram parcialmente compartilhadas (mapeadas ao serviço compartilhado). Neste caso, o responsável

19 Num processo automatizado, as operações a serem mapeadas para um serviço pertencem ao subconjunto resultante da intersecção do conjunto das operações disponíveis, com o conjunto das operações que o serviço está apto a executar. 
pelo domínio manualmente selecionou as operações permitidas de serem executadas pelo serviço compartilhado.

A política de importação é representada por uma credencial contendo a lista de papéis que o domínio deseja assumir (tabela 5). A atribuição real de papéis para credenciais ocorre através do MODA.

\subsubsection{Negociação e Composição da Política}

Uma vez definida a política de exportação e importação, o sistema verifica possíveis conflitos com a política definida pelo MOAD. Como, por exemplo, a adição de serviços não suportados em um multidomínio restritivo ou conflito de nomes quando novas operações são adicionadas. Depois de resolvidos eventuais conflitos as políticas de exportação e importação são enviadas ao mediador da negociação.

O mediador, depois de receber todas as políticas dos domínios, importa os elementos da ontologia adicionados em cada domínio para a política definida inicialmente. No caso, os serviços, seus mapeamentos para operações, as credenciais e seus mapeamentos para papéis são importados. O processo de importação corresponde à composição da política do multidomínio, no entanto, a política resultante pode ser inconsistente com o modelo, com a política de negociação ou com os interesses dos domínios participantes. Alguns desses conflitos são previstos pelo modelo e podem ser automaticamente resolvidos pela política de resolução de conflitos apresentada em 5.3.4.2.

Se nenhum conflito não tratável for detectado no final do processo, a negociação segue para a efetiva atribuição de papéis, através do MODA. Caso contrário, é disparado um processo de renegociação. Em qualquer dos casos a relação de conflitos é enviada aos domínios. 


\subsection{Modelo Ontológico de Delegação de Autoridade}

O processo de delegação de autoridade ocorre após a obtenção de uma política composta e livre de conflitos. O MOCA consolidado possui um conjunto de papéis exportados, ou indiretamente recursos exportados, enquanto que o MODA utiliza a política de importação para, efetivamente, atribuir os papéis aos usuários.

A ontologia de credenciais foi especializada para a aplicação em multidomínios através da definição de credenciais de atribuição e credenciais de delegação. A figura 23 apresenta a ontologia de credenciais para multidomínios.

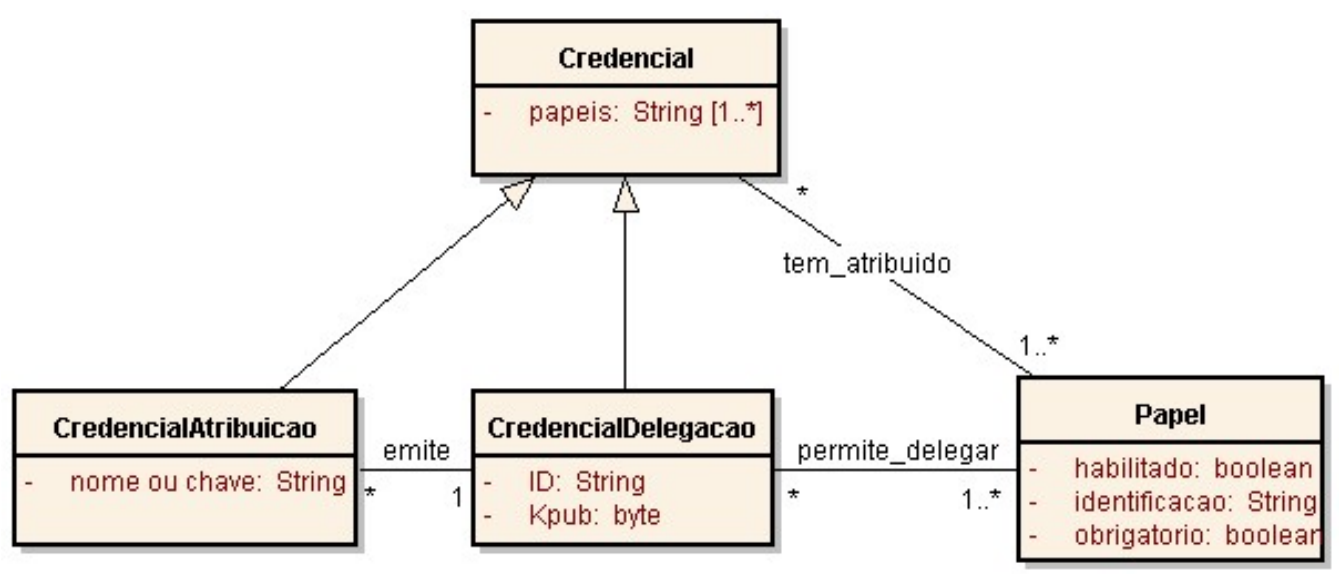

Figura 23 - Ontologia de Credenciais

Uma credencial de delegação tem atribuído um conjunto de papéis, os quais pode assumir para acesso aos recursos. A atribuição de papéis a este tipo de credencial tem implícito o relacionamento "permite_delegar”, o que significa que o proprietário desta credencial tem o direito de atribuir seus papéis para outros usuários. Na prática, uma credencial de delegação pode emitir credenciais de atribuição, atribuindo um ou mais de seus papéis a outros usuários.

No modelo especializado, a política de importação é definida na forma de credenciais auto-assinadas, contendo a identificação do domínio, a chave pública do domínio correspondente e um conjunto de papéis de interesse como atributo. Essas credenciais são 
assinadas pelos outros domínios, assumindo o formato de credencial de delegação. A emissão de credenciais de delegação e a distribuição destas credenciais aos seus proprietários finalizam o processo de negociação da política.

Porém, após a negociação de credenciais, pode novamente haver conflito de interesse, quando um papel não é autorizado para algum domínio. Portanto, pode ser necessário utilizar o mediador para a resolução do conflito.

\subsubsection{Atribuição de Papéis aos Usuários}

Os domínios recebem, após a negociação, as credenciais de delegação, as quais são usadas para atribuir usuários aos papéis. Esta atribuição é feita através de credenciais de atribuição, que podem ser utilizadas pelos usuários para obter acesso aos recursos do multidomínio. As credencias possuem validade e podem ser emitidas para curtos períodos de tempo.

Credenciais de atribuição associam papéis a um nome ou a uma chave pública, para fins de privacidade, enquanto que credenciais de delegação associam papéis à identidade do domínio proprietário.

\subsection{Resultados}

Seguindo as regras definidas para a negociação em 5.3.4.1, as políticas de exportação e importação apenas adicionam conhecimentos e relacionamentos à política. Desta forma, a política composta para o exemplo de projeto de pesquisa, corresponde à união das informações constantes nas tabelas 1 a 5 . Mas essas informações podem levar a uma política inconsistente, o que é verificado através das regras de detecção e resolução de conflitos definidas em 5.3.4.2. Os seguintes conflitos foram detectados e resolvidos: 
- Conflito sobre operação: não há um serviço habilitado para a operação GerarPDF. Tratamento: a operação GerarPDF é desabilitada.

- Conflito de exportação: existem recursos providos para o papel Secretária, mas não há interesse em assumi-lo na política de importação. Tratamento: o papel Secretária é desabilitado.

A figura 24 ilustra o multidomínio para o projeto de pesquisa do ponto de vista da política de exportação, representando os serviços compartilhados pelos domínios.

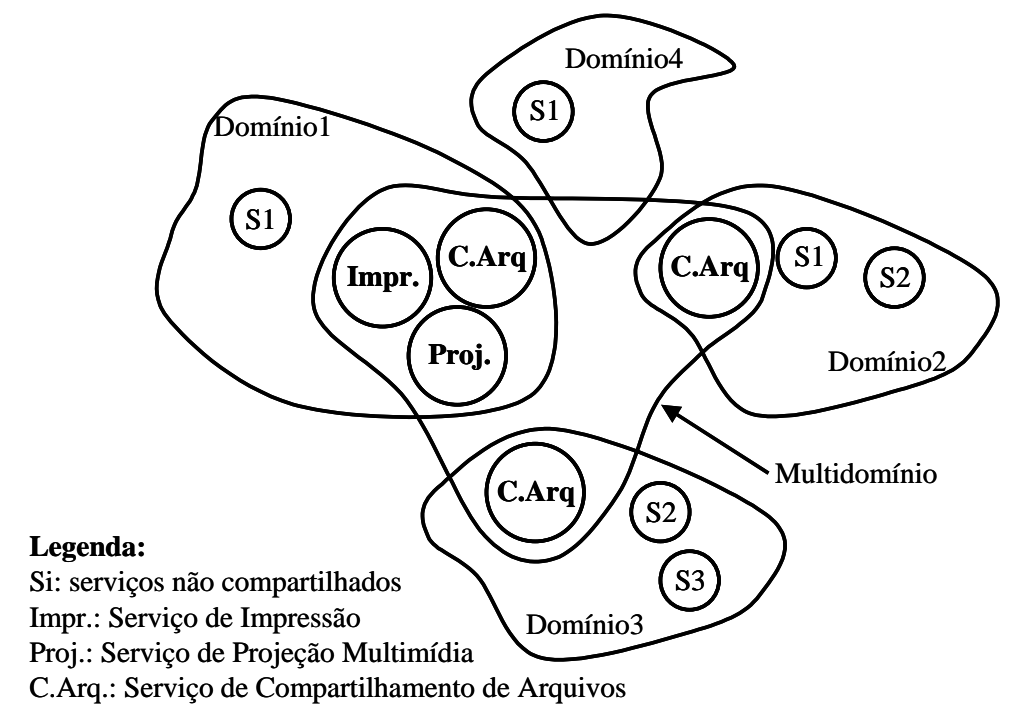

Figura 24 - Recursos Exportados para o Projeto de Pesquisa

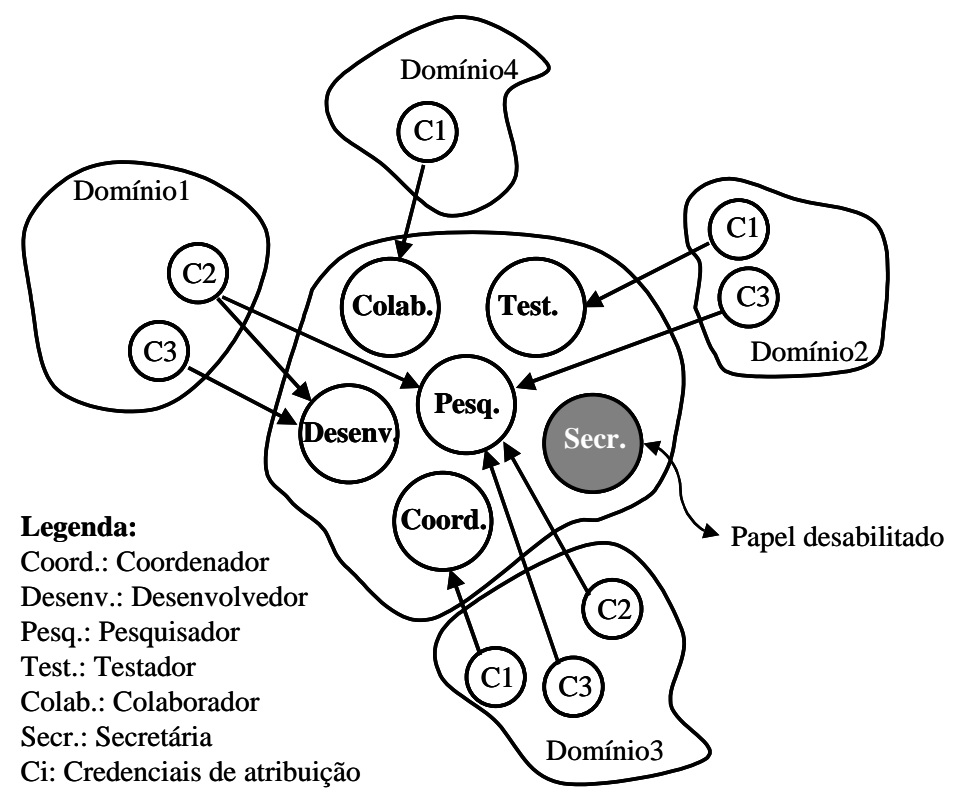

Figura 25 - Papeis Importados para o Projeto de Pesquisa 
A figura 25 ilustra o multidomínio para o projeto de pesquisa do ponto de vista da política de importação, representando os papéis importados pelos domínios e atribuídos aos usuários através de credenciais de atribuição.

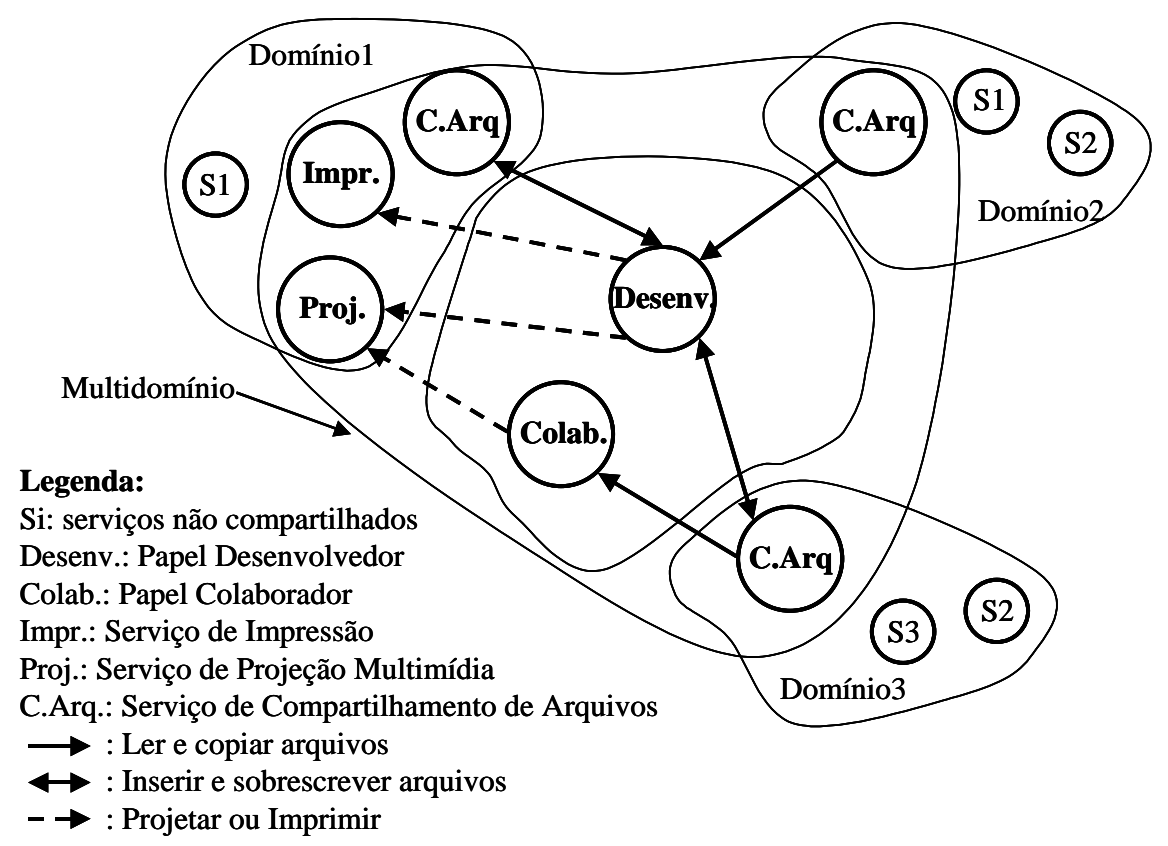

Figura 26 - Exemplo da Política Composta para o Projeto de Pesquisa

A figura 26 ilustra a política de controle de acesso do multidomínio para os papéis Colaborador e Desenvolvedor. A figura mostra que um usuário assumindo o papel de colaborador tem apenas os direitos de utilizar o serviço de projeção do domínio 1, e ler e copiar arquivos do serviço de compartilhamento de arquivos provido pelo domínio 3 . Um usuário assumindo o papel de desenvolvedor tem direito de utilizar o serviço de impressão e projeção do domínio 1, ler/copiar/inserir/sobrescrever arquivos no serviço de compartilhamento de arquivos provido pelos domínios 1 e 3, e apenas ler e copiar arquivos do serviço de compartilhamento de arquivos provido pelo domínio 2. 


\subsection{Considerações}

Este capítulo apresentou um exemplo concreto do modelo ontológico de segurança proposto no capítulo 5, mostrando sua aplicabilidade em multidomínios pessoais. O modelo concreto especializou o MOS através da proposta de uma hierarquia para a ontologia de recursos, operações e credenciais.

A especialização da ontologia viabilizou uma melhor representação conceitual dos recursos e operações envolvidos na política de controle de acesso em multidomínios, definindo um vocabulário para comunicação entre os seus domínios. A ontologia básica, através da definição dos elementos essenciais, de seus relacionamentos e das restrições sobre sua interpretação, foram fundamentais para a verificação da consistência do modelo durante a negociação e composição da política de segurança. As regras definidas pelo MOS para a negociação da política de segurança contribuíram para evitar conflitos e conduzir a negociação, de forma a convergir para um modelo coerente com os objetivos definidos para o multidomínio. As regras para a resolução de conflitos contribuíram para minimizar a necessidade de renegociações e obter um modelo composto consistente e coerente com os objetivos definidos pelo multidomínio. Adicionalmente, a delegação de autoridade contribuiu por evitar que a adição de usuários aos domínios exigisse a renegociação da política do multidomínio, uma vez que é delegada ao próprio domínio a autorização para emitir credenciais aos seus usuários. A utilização de delegação de autoridade também contribuiu para a autonomia dos domínios, quando permite que os papéis atribuídos a um domínio possam ser delegados aos usuários deste domínio.

Desta forma, a definição de um modelo concreto e a simulação da negociação e composição da política de controle de acesso, através de um exemplo de multidomínio de 
projeto de pesquisa, mostraram que o MOS permite a definição de um procedimento automatizável para a criação da política de controle de acesso de multidomínios. 


\section{Capítulo 7 - O MOS em EaD}

O modelo de controle de acesso proposto é aplicável em ambientes colaborativos, formados por múltiplos domínios que podem estar sob administração independente. Ambientes colaborativos são criados com objetivos específicos, ou seja, com o objetivo de realizar algum tipo de atividade envolvendo diversos participantes que interagem para a realização de trabalho conjunto. A área de Ensino a Distância (EaD) fornece um cenário rico para a aplicação do modelo, pois envolve diversas atividades interativas que são realizadas através de acesso remoto dos participantes. A seguir é apresentado um exemplo de aplicação do MOS em ambientes colaborativos de EaD.

\subsection{Modelo de Ensino a Distância}

A seguir são apresentados quem são os participantes deste tipo de ambiente, alguns exemplos de multidomínios, ferramentas, operações e papéis.

\subsubsection{Usuários}

Os usuários são representados pelos participantes das atividades de EaD. Usuários podem ser indivíduos, grupos ou sistemas. Um sistema está, diretamente ou indiretamente, associado a um indivíduo, que é o responsável por sua administração.

O MOS abstrai o conceito de usuário através do conceito de credencial. Uma credencial contém informações para a autenticação do participante e um ou mais papéis que esta credencial atribui a este participante. 


\subsubsection{Multidomínios: Atividades colaborativas}

O processo de aprendizagem pode ser composto por diversos tipos de atividades interativas, envolvendo diferentes participantes. Neste processo, os diversos participantes colaboram para atingir um objetivo pedagógico. A realização desta atividade colaborativa possui um objetivo específico, a partir do qual pode ser extraído um conjunto de recursos e operações necessárias para a realização da atividade didática. Os participantes envolvidos em uma atividade didática desempenham papéis específicos no processo de aprendizagem.

Uma atividade colaborativa aplicada ao EaD pode ser realizada através da formação de um multidomínio, onde os domínios dos participantes ${ }^{20}$ se associam para a realização da atividade. A seguir são apresentados alguns exemplos de atividades comuns em ambientes de EaD.

\section{Aula}

Objetivo: Apresentar um conceito/tema, sob diversos formatos de mídia, em tempo real ou não. Conduzir o processo de aprendizagem com perguntas e respostas.

\section{Discussão (Fórum)}

Objetivo: Apresentar um tema ou conceito sobre um tema que instigue o questionamento. Conduzir o processo de discussão através da emissão de opinião ou indagação sobre o tema, assim como responder às indagações.

\section{Reuniões de trabalho}

Objetivo: Apresentar uma ou mais questões a serem discutidas ou tarefas a serem executadas, com o objetivo de obter uma resposta ou solução consensual. Discutir as possíveis soluções, votar alternativas e fechar uma resposta ou solução através de um documento aceito pelos participantes.

\footnotetext{
${ }^{20}$ O domínio do professor pode ser o domínio da própria instituição de ensino, composto pelos recursos sob sua responsabilidade.
} 


\section{Projeto}

Objetivos: A realização de um projeto corresponde à execução de uma seqüência de tarefas ordenadas e distribuídas entre os participantes com um objetivo comum.

\section{Dúvidas}

Objetivo: Fazer perguntas sobre um tema específico e obter respostas de um profissional especializado.

\section{Chat}

Objetivo: Troca de informação entre um grupo sobre um assunto específico em tempo real.

\subsubsection{Recursos: Ferramentas e operações}

Ambientes de EaD são formados por diversas ferramentas que auxiliam no processo de aprendizagem e na realização de atividades colaborativas. As ferramentas colaborativas, disponíveis em multidomínios de EaD, podem ser vistas como serviços compartilhados entre os participantes de uma atividade pedagógica. Um serviço, para o MOS, é um recurso ativo que recebe solicitações para a realização de operações sobre os recursos físicos ou lógicos. Os recursos lógicos são, portanto, os materiais de ensino disponibilizados através destas ferramentas ou produzidos por elas. Material de ensino pode ser um conteúdo didático disponível sob algum formato de mídia ou o produto (documento, dado ou programa) resultante da atividade colaborativa.

\section{Exemplos de ferramentas de EaD:}

Ferramenta de Aula Virtual

Fórum de discussão

Chat

Áudio-conferência 
Vídeo-conferência

Ferramenta de Votação

Lousa eletrônica virtual

Agenda de tarefas

\section{Exemplos de recursos lógicos:}

Tarefa

Documento

Dado

As operações apresentadas abaixo são operações típicas deste tipo de ambiente. Essas operações correspondem a ações específicas dependendo do contexto em que são aplicadas, ou seja, dependendo da ferramenta que a executa.

Observar: acessar as informações do ambiente colaborativo sem atuar sobre os recursos físicos ou lógicos disponíveis de forma a alterar seu estado. São exemplos deste tipo de operação: ler um documento, assistir a um vídeo, ouvir uma palestra, observar uma discussão, etc.

Contribuir: atuar ativamente sobre a atividade colaborativa, alterando o estado dos recursos lógicos ou físicos. Contribuir diretamente para o produto resultante da colaboração. São exemplos deste tipo de operação: editar um documento, proferir uma palestra, atuar sobre a configuração de um equipamento parte de um experimento, votar sobre uma decisão, etc.

Participar: participar passivamente da atividade, não alterando o estado dos recursos lógicos ou físicos. Contribuir indiretamente para o produto resultante da atividade colaborativa sem tomar parte ativa na conclusão do trabalho. São exemplos deste tipo de operação: submeter material de consulta, submeter comentários, participar de uma discussão sem se envolver diretamente na conclusão, etc. 
Coordenar: atuar sobre os recursos de forma a alterar ou gerenciar a política de uso. São exemplos deste tipo de operação: iniciar e encerrar uma atividade, gerenciar a utilização de um recurso durante a realização de uma atividade, etc.

Copiar: obter cópia de dados, informação ou documento didático disponível ou do produto resultante de atividade colaborativa.

Configurar: alterar o estado de participação na atividade. São exemplos deste tipo de operação: ser ouvido/mudo, ativo/ausente/ocupado, etc.

Avaliar: emitir um julgamento sobre o resultado obtido.

\subsubsection{Operações por Serviço}

Dentro do contexto dos serviços implementados pelas ferramentas existentes nestes ambientes, as operações ilustradas podem ter significados específicos, como se descreve a seguir:

\section{Ferramenta de Aula Virtual}

Coordenar: iniciar, selecionar tarefa, autorizar, encerrar.

Observar: assistir, ouvir, ler.

Contribuir: falar, escrever, responder, executar.

Participar: submeter material, inserir (upload): documentos, mídias, etc.

Copiar: obter material didático (download).

\section{Fórum de discussão}

Coordenar: iniciar, selecionar tema, mediar, autorizar, encerrar.

Observar: ler perguntas e respostas.

Contribuir: submeter perguntas e respostas, contribuir na conclusão.

Participar: inserir comentário, observar a discussão.

Copiar: obter cópia do histórico total ou parcial da discussão. 


\section{Ferramenta de Votação}

Coordenar: iniciar, contabilizar, divulgar resultado, encerrar.

Observar: ler conteúdo a ser votado ou resultado da votação.

Contribuir: votar.

Participar: submeter comentários defendendo um ponto de vista sobre o conteúdo votado ou submeter conteúdo auxiliar para a tomada de decisão, sem votar.

\section{Áudio-conferência e vídeo-conferência}

Coordenar: autorizar, mediar e tomar a palavra.

Contribuir: falar, participar na conclusão.

Observar: ouvir / ver.

Participar: pedir a palavra, falar sem participar da conclusão.

Configurar: ser ouvido / mudo, ser visto / invisível.

\section{Lousa eletrônica virtual}

Observar: ver.

Contribuir: escrever, modificar.

Copiar: salvar conteúdo da lousa eletrônica.

Participar: submeter conteúdo acessível aos participantes.

Coordenar: autorizar e tomar o “pincel” para escrita.

\section{Agenda de Tarefas}

Coordenar: criar, remover e alterar o estado das tarefas.

Observar: ter acesso ao estado atual de execução tarefa.

Contribuir: alterar o estado atual de execução da tarefa, participar de sua execução e conclusão.

Participar: submeter comentários, não altera o estado de execução da tarefa. 


\section{Compartilhamento de Arquivos e armazenamento}

Coordenar: alterar direitos sobre arquivos e repositórios.

Observar: ler, ver, ouvir arquivo existente.

Participar: criar um novo arquivo.

Contribuir: alterar arquivo existente.

Copiar: obter cópia de arquivo.

\subsubsection{Papéis}

O ambiente de EaD sugere a existência de alguns papéis, que podem ter direitos distintos dependendo do contexto de aprendizagem em que estão inseridos, ou seja, dependendo do multidomínio que estão participando. Segue um conjunto de papéis que podem ser utilizados na aplicação do MOS.

- Professor: profissional responsável pela atividade didática.

- Especialista: profissional habilitado no contexto didático.

- Aluno: usuário alvo do processo de aprendizagem.

- Líder de Equipe: membro de uma equipe com responsabilidade especial.

- Monitor: usuário que auxilia atividades didáticas.

- Moderador: coordenador de atividade interativa.

- Proprietário: usuário proprietário/responsável por objetos específicos.

- Administrador: usuário com direitos especiais.

\subsection{Multidomínio Aula}

As ferramentas utilizadas em uma aula dependem das atividades definidas para a aula. Suponha uma aula para apresentação de um projeto a ser desenvolvido. Nesta aula o projeto é 
apresentado, alunos e professor discutem sobre os detalhes do projeto. Esta atividade de aula resulta no agendamento de tarefas que devem ser realizadas pelos grupos de projeto. Os resultados de cada fase do projeto são remetidos ao professor através de um repositório para upload. A cada fase do projeto é formada uma nova aula (multidomínio) com os recursos adequados àquela aula. As equipes também formam multidomínios para a realização do projeto, podendo ter fóruns de discussão, compartilhamento e outras ferramentas para o desenvolvimento do projeto em cooperação.

Tabela 6 - Multidomínio Aula

\begin{tabular}{|l|l|}
\hline \multicolumn{1}{|c|}{ Atributo e Relacionamentos } & \multicolumn{1}{c|}{ Valor } \\
\hline identificação & Aula \\
\hline tipo_formação_multidomínio & CENTRALIZADA \\
\hline tipo_cardinalidade_multidomínio & MUTÁVEL \\
\hline valor_cardinalidade_multidomínio & <não definido> \\
\hline política_renegociação & OPCIONAL \\
\hline restritivo & não \\
\hline Papéis definidos & Professor \\
& Aluno \\
& Monitor \\
& Especialista \\
& Líder de equipe \\
\hline Serviços suportados & Chat \\
& Fórum de discussão \\
& Ferramenta de aula virtual \\
& Áudio-conferência \\
& Vídeo-Conferência \\
& Agenda de tarefas \\
& Compartilhamento de arquivos e repositório \\
& Votação \\
\hline
\end{tabular}

Observação: A atribuição de papéis aos usuários no Multidomínio Aula, assim como permitir ou não a utilização de recursos, é responsabilidade do professor, portanto o multidomínio tem formação centralizada, com o domínio do professor como criador e responsável pelo multidomínio.

No processo de associação de domínios para a formação do multidomínio Aula, os domínios recebem a política do multidomínio com os papéis definidos e os serviços suportados. A tabela 6 mostra os atributos do multidomínio, sendo não restritivo. Isto 
significa que os demais domínios podem compartilhar serviços diferentes daqueles suportados inicialmente pelo multidomínio. A tabela 7 mostra as autorizações associadas aos papéis. Cada papel tem definido alguns tipos de operações que seriam autorizadas. Os domínios compartilham os recursos apresentados na tabela 8. Considere que os recursos são providos pelos dispositivos pertencentes ao participante do multidomínio ou podem ser sublocados de provedores de serviços, estando sob responsabilidade do participante.

Tabela 7 - Atribuições de autorização

\begin{tabular}{|l|l|}
\hline \multicolumn{1}{|c|}{ Papel } & \multicolumn{1}{|c|}{ Autorização } \\
\hline Professor & Coordenar \\
& Observar \\
& Participar \\
& Avaliar \\
& Configurar \\
\hline Aluno & Observar \\
& Contribuir \\
& Copiar \\
\hline Especialista & Participar \\
& Observar \\
Contribuir \\
\hline Monitor & Participar \\
& Observar \\
& Contribuir \\
\hline Líder de equipe & Participar \\
\hline
\end{tabular}

Tabela 8 - Recursos compartilhados pelos domínios

\begin{tabular}{|l|l|l|}
\hline \multicolumn{1}{|c|}{ Domínio } & \multicolumn{1}{|c|}{ Ferramenta } & \multicolumn{1}{c|}{ Operação } \\
\hline $\begin{array}{l}\text { Consultor: Domínio do } \\
\text { especialista consultor }\end{array}$ & Fórum & $\begin{array}{l}\text { Observar } \\
\text { Contribuir }\end{array}$ \\
\hline $\begin{array}{l}\text { Redes: Domínio da disciplina } \\
\text { ministrada }\end{array}$ & Ferramenta de aula virtual & $\begin{array}{l}\text { Coordenar } \\
\text { Participar } \\
\text { Observar } \\
\text { Copiar }\end{array}$ \\
\cline { 2 - 3 } & $\begin{array}{l}\text { Compartilhamento de } \\
\text { arquivos e repositório }\end{array}$ & $\begin{array}{l}\text { Observar } \\
\text { Participar }\end{array}$ \\
\cline { 2 - 3 } & Fórum & $\begin{array}{l}\text { Coordenar } \\
\text { Observar } \\
\text { Contribuir }\end{array}$ \\
\hline $\begin{array}{l}\text { EquipeX: Domínio do líder } \\
\text { de equipe de projeto }\end{array}$ & Agenda de tarefas & $\begin{array}{l}\text { Coordenar } \\
\text { Observar } \\
\text { Contribuir } \\
\text { Participar }\end{array}$ \\
\hline
\end{tabular}


Cada domínio define sua política de exportação e importação baseada nas informações sobre o multidomínio, recebidas durante a associação, e os recursos compartilhados (ferramentas). Num processo automatizado, todas as operações compartilhadas (instâncias) que são do mesmo tipo das operações autorizadas aos papéis pela política do multidomínio (tabela 6 e tabela 7), são mapeadas para esses papéis. A política de exportação e importação de cada domínio são apresentadas da tabela 9 a tabela 14 .

Tabela 9 - Política de Exportação do Domínio Consultor

\begin{tabular}{|l|l|l|}
\hline \multicolumn{1}{|c|}{ Papel } & \multicolumn{1}{|c|}{ Autorização } & \multicolumn{1}{c|}{ Operações } \\
\hline Professor & Observar & Consultor.Fórum.Observar \\
\hline \multirow{2}{*}{ Aluno } & Observar & Consultor.Fórum.Observar \\
\cline { 2 - 3 } & Contribuir & Consultor.Fórum.Contribuir \\
\hline \multirow{2}{*}{ Especialista } & Observar & Consultor.Fórum.Observar \\
\cline { 2 - 3 } & Contribuir & Consultor.Fórum.Contribuir \\
\hline \multirow{2}{*}{ Monitor } & Observar & Consultor.Fórum.Observar \\
\cline { 2 - 3 } & Contribuir & Consultor.Fórum.Contribuir \\
\hline Líder de equipe & & \\
\hline
\end{tabular}

Tabela 10 - Política de Importação do Domínio Consultor

\begin{tabular}{|l|l|}
\hline \multicolumn{1}{|c|}{ Credencial em nome de } & Papel \\
\hline José M. Pedroso & Especialista \\
\hline
\end{tabular}

Tabela 11 - Política de Exportação do Domínio Redes

\begin{tabular}{|l|l|l|}
\hline \multicolumn{1}{|c|}{ Papel } & \multicolumn{1}{|c|}{ Autorização } & \multicolumn{1}{c|}{ Operações } \\
\hline \multirow{4}{*}{ Professor } & Observar & $\begin{array}{l}\text { Redes.Ferramenta de aula virtual.Observar } \\
\text { Redes.CompArquivosRepositório.Observar } \\
\text { Redes.Fórum.Observar }\end{array}$ \\
\cline { 2 - 3 } & Coordenar & $\begin{array}{l}\text { Redes.Ferramenta de aula virtual.Coordenar } \\
\text { Redes.Fórum.Coordenar }\end{array}$ \\
\cline { 2 - 3 } & Participar & $\begin{array}{l}\text { Redes.Ferramenta de aula virtual.Participar } \\
\text { Redes.CompArquivosRepositório.Participar }\end{array}$ \\
\hline \multirow{3}{*}{ Aluno } & Observar & $\begin{array}{l}\text { Redes.Ferramenta de aula virtual.Observar } \\
\text { Redes.CompArquivosRepositório.Observar } \\
\text { Redes.Fórum.Observar }\end{array}$ \\
\cline { 2 - 3 } & Contribuir & Redes.Fórum.Contribuir \\
\cline { 2 - 3 } & Copiar & Redes.Ferramenta de aula virtual.Copiar \\
\hline
\end{tabular}




\begin{tabular}{|c|c|c|}
\hline \multirow{3}{*}{ Especialista } & Participar & $\begin{array}{l}\text { Redes.Ferramenta de aula virtual.Participar } \\
\text { Redes.CompArquivosRepositório.Participar }\end{array}$ \\
\hline & Observação & $\begin{array}{l}\text { Redes.Ferramenta de aula virtual.Observar } \\
\text { Redes.CompArquivosRepositório.Observar } \\
\text { Redes.Fórum.Observar }\end{array}$ \\
\hline & Contribuir & Redes.Fórum.Contribuir \\
\hline \multirow{3}{*}{ Monitor } & Participar & $\begin{array}{l}\text { Redes.Ferramenta de aula virtual.Participar } \\
\text { Redes.CompArquivosRepositório.Participar }\end{array}$ \\
\hline & Observar & $\begin{array}{l}\text { Redes.Ferramenta de aula virtual.Observar } \\
\text { Redes.CompArquivosRepositório.Observar } \\
\text { Redes.Fórum.Observar }\end{array}$ \\
\hline & Contribuir & Redes.Fórum.Contribuir \\
\hline Líder de equipe & Participar & $\begin{array}{l}\text { Redes.Ferramenta de aula virtual.Participar } \\
\text { Redes.CompArquivosRepositório.Participar }\end{array}$ \\
\hline
\end{tabular}

Tabela 12 - Política de Importação do Domínio Redes

\begin{tabular}{|l|l|}
\hline \multicolumn{1}{|c|}{ Credencial em nome de } & Papel \\
\hline Maria Cristina Moura & Professor \\
\hline
\end{tabular}

Tabela 13 - Política de Exportação do Domínio EquipeX

\begin{tabular}{|l|l|l|}
\hline \multicolumn{1}{|c|}{ Papel } & \multicolumn{1}{|c|}{ Autorização } & \multicolumn{1}{c|}{ Operações } \\
\hline \multirow{4}{*}{ Professor } & Observar & EquipeX.Agenda de tarefas.Observar \\
\cline { 2 - 3 } & Coordenar & EquipeX.Agenda de tarefas.Coordenar \\
\cline { 2 - 3 } & Participar & EquipeX.Agenda de tarefas.Participar \\
\hline Aluno & Observar & EquipeX.Agenda de tarefas.Observar \\
\cline { 2 - 3 } & Contribuir & EquipeX.Agenda de tarefas.Contribuir \\
\hline \multirow{3}{*}{ Especialista } & Participar & EquipeX.Agenda de tarefas.Participar \\
\cline { 2 - 3 } & Observar & EquipeX.Agenda de tarefas.Observar \\
\cline { 2 - 3 } & Contribuir & EquipeX.Agenda de tarefas.Contribuir \\
\hline \multirow{3}{*}{ Monitor } & Participar & EquipeX.Agenda de tarefas.Participar \\
\cline { 2 - 3 } & Observar & EquipeX.Agenda de tarefas.Observar \\
\cline { 2 - 3 } & Contribuir & EquipeX.Agenda de tarefas.Contribuir \\
\hline Líder de equipe & Participar & EquipeX.Agenda de tarefas.Participar \\
\hline
\end{tabular}

Tabela 14 - Política de Importação da EquipeX

\begin{tabular}{|l|l|}
\hline \multicolumn{1}{|c|}{ Credencial em nome de } & \multicolumn{1}{c|}{ Papel } \\
\hline Pedro Vidal & Aluno, Líder de equipe \\
\hline
\end{tabular}

Tabela 15 - Política de Importação de Outros Domínios que não Compartilham Recursos.

\begin{tabular}{|c|l|}
\hline \multicolumn{1}{|c|}{ Credencial em nome de } & \multicolumn{1}{c|}{ Papel } \\
\hline [Nome do aluno] & Aluno \\
\hline
\end{tabular}




\subsection{Resultados}

A tabela 16 ilustra o resultado da associação quanto às atribuições de permissão, ou seja, a união das políticas de exportação dos domínios à política definida para o multidomínio. Enquanto a tabela 17, ilustra o resultado da associação quanto às atribuições do usuário. Essas tabelas ilustram a política antes da resolução de conflitos. Por exemplo, existe conflito de interesse, pois recursos foram compartilhados para o papel monitor, mas nenhum domínio teve interesse em assumir este papel. Há também conflito de negociação, pois o papel professor está autorizado a realizar as operações de Avaliar e Configurar, mas nenhum serviço foi habilitado para executá-las. A tabela 18 ilustra a política composta, após resolução de conflitos.

Tabela 16 - Política Resultante antes da Resolução de Conflitos: atribuição de permissões

\begin{tabular}{|c|c|c|}
\hline Papel & Autorização & Operações \\
\hline \multirow{5}{*}{ Professor } & Avaliar & \\
\hline & Configurar & \\
\hline & Observar & $\begin{array}{l}\text { Consultor.Fórum.Observar } \\
\text { Redes.Ferramenta de aula virtual.Observar } \\
\text { Redes.CompArquivosRepositório.Observar } \\
\text { Redes.Fórum.Observar } \\
\text { EquipeX.Agenda de tarefas.Observar }\end{array}$ \\
\hline & Coordenar & $\begin{array}{l}\text { Redes.Ferramenta de aula virtual.Coordenar } \\
\text { Redes.Fórum.Coordenar } \\
\text { EquipeX.Agenda de tarefas.Coordenar }\end{array}$ \\
\hline & Participar & $\begin{array}{l}\text { Redes.Ferramenta de aula virtual.Participar } \\
\text { Redes.CompArquivosRepositório.Participar } \\
\text { EquipeX.Agenda de tarefas.Participar }\end{array}$ \\
\hline \multirow{3}{*}{ Aluno } & Observar & $\begin{array}{l}\text { Consultor.Fórum.Observar } \\
\text { Redes.Ferramenta de aula virtual.Observar } \\
\text { Redes.CompArquivosRepositório.Observar } \\
\text { Redes.Fórum.Observar } \\
\text { EquipeX.Agenda de tarefas.Observar }\end{array}$ \\
\hline & Contribuir & $\begin{array}{l}\text { Consultor.Fórum.Contribuir } \\
\text { Redes.Fórum.Contribuir } \\
\text { EquipeX.Agenda de tarefas.Contribuir }\end{array}$ \\
\hline & Copiar & Redes.Ferramenta de aula virtual.Copiar \\
\hline
\end{tabular}




\begin{tabular}{|c|c|c|}
\hline \multirow{3}{*}{ Especialista } & Participar & $\begin{array}{l}\text { Redes.Ferramenta de aula virtual.Participar } \\
\text { Redes.CompArquivosRepositório.Participar } \\
\text { EquipeX.Agenda de tarefas.Participar }\end{array}$ \\
\hline & Observar & $\begin{array}{l}\text { Consultor.Fórum.Observar } \\
\text { Redes.Ferramenta de aula virtual.Observar } \\
\text { Redes.CompArquivosRepositório.Observar } \\
\text { Redes.Fórum.Observar } \\
\text { EquipeX.Agenda de tarefas.Observar }\end{array}$ \\
\hline & Contribuir & $\begin{array}{l}\text { Consultor.Fórum.Contribuir } \\
\text { Redes.Fórum.Contribuir } \\
\text { EquipeX.Agenda de tarefas.Contribuir }\end{array}$ \\
\hline \multirow{3}{*}{ Monitor } & Participar & $\begin{array}{l}\text { Redes.Ferramenta de aula virtual.Participar } \\
\text { Redes.CompArquivosRepositório.Participar } \\
\text { EquipeX.Agenda de tarefas.Participar }\end{array}$ \\
\hline & Observar & $\begin{array}{l}\text { Consultor.Fórum.Observar } \\
\text { Redes.Ferramenta de aula virtual.Observar } \\
\text { Redes.CompArquivosRepositório.Observar } \\
\text { Redes.Fórum.Observar } \\
\text { EquipeX.Agenda de tarefas.Observar }\end{array}$ \\
\hline & Contribuir & $\begin{array}{l}\text { Consultor.Fórum.Contribuir } \\
\text { Redes.Fórum.Contribuir } \\
\text { EquipeX.Agenda de tarefas.Contribuir }\end{array}$ \\
\hline $\begin{array}{l}\text { Líder de } \\
\text { equipe }\end{array}$ & Participar & $\begin{array}{l}\text { Redes.Ferramenta de aula virtual.Participar } \\
\text { Redes.CompArquivosRepositório.Participar } \\
\text { EquipeX.Agenda de tarefas.Participar }\end{array}$ \\
\hline
\end{tabular}

Tabela 17 - Política Resultante antes da Resolução de Conflitos: atribuições do usuário

\begin{tabular}{|l|l|}
\hline \multicolumn{1}{|c|}{ Credencial em nome de } & \multicolumn{1}{c|}{ Papel } \\
\hline José M. Pedroso (domínio Consultor) & Especialista \\
\hline Maria Cristina Moura (domínio Redes) & Professor \\
\hline Pedro Vidal (domínio EquipeX) & Aluno, Líder de equipe \\
\hline & Monitor \\
\hline
\end{tabular}

Tabela 18 - Política Composta: atribuições de permissões

\begin{tabular}{|c|c|c|}
\hline Papel & Autorização & Operações \\
\hline \multirow[t]{3}{*}{ Professor } & Observar & $\begin{array}{l}\text { Consultor.Fórum.Observar } \\
\text { Redes.Ferramenta de aula virtual.Observar } \\
\text { Redes.CompArquivosRepositório.Observar } \\
\text { Redes.Fórum.Observar } \\
\text { EquipeX.Agenda de tarefas.Observar }\end{array}$ \\
\hline & Coordenar & $\begin{array}{l}\text { Redes.Ferramenta de aula virtual.Coordenar } \\
\text { Redes.Fórum.Coordenar } \\
\text { EquipeX.Agenda de tarefas.Coordenar }\end{array}$ \\
\hline & Participar & $\begin{array}{l}\text { Redes.Ferramenta de aula virtual.Participar } \\
\text { Redes.CompArquivosRepositório.Participar } \\
\text { EquipeX.Agenda de tarefas.Participar }\end{array}$ \\
\hline
\end{tabular}




\begin{tabular}{|c|c|c|}
\hline \multirow[t]{3}{*}{ Aluno } & Observar & $\begin{array}{l}\text { Consultor.Fórum.Observar } \\
\text { Redes.Ferramenta de aula virtual.Observar } \\
\text { Redes.CompArquivosRepositório.Observar } \\
\text { Redes.Fórum.Observar } \\
\text { EquipeX.Agenda de tarefas.Observar }\end{array}$ \\
\hline & Contribuir & $\begin{array}{l}\text { Consultor.Fórum.Contribuir } \\
\text { Redes.Fórum.Contribuir } \\
\text { EquipeX.Agenda de tarefas.Contribuir }\end{array}$ \\
\hline & Copiar & Redes.Ferramenta de aula virtual.Copiar \\
\hline \multirow{3}{*}{ Especialista } & Participar & $\begin{array}{l}\text { Redes.Ferramenta de aula virtual.Participar } \\
\text { Redes.CompArquivosRepositório.Participar } \\
\text { EquipeX.Agenda de tarefas.Participar }\end{array}$ \\
\hline & Observar & $\begin{array}{l}\text { Consultor.Fórum.Observar } \\
\text { Redes.Ferramenta de aula virtual.Observar } \\
\text { Redes.CompArquivosRepositório.Observar } \\
\text { Redes.Fórum.Observar } \\
\text { EquipeX.Agenda de tarefas.Observar }\end{array}$ \\
\hline & Contribuir & $\begin{array}{l}\text { Consultor.Fórum.Contribuir } \\
\text { Redes.Fórum.Contribuir } \\
\text { EquipeX.Agenda de tarefas.Contribuir } \\
\end{array}$ \\
\hline $\begin{array}{l}\text { Líder de } \\
\text { equipe }\end{array}$ & Participar & $\begin{array}{l}\text { Redes.Ferramenta de aula virtual.Participar } \\
\text { Redes.CompArquivosRepositório.Participar } \\
\text { EquipeX.Agenda de tarefas.Participar }\end{array}$ \\
\hline
\end{tabular}

Tabela 19 - Política Composta: atribuições do usuário

\begin{tabular}{|l|l|}
\hline \multicolumn{1}{|c|}{ Credencial em nome de } & \\
\hline José M. Pedroso (domínio Consultor) & Especialista \\
\hline Maria Cristina Moura (domínio Redes) & Professor \\
\hline Pedro Vidal (domínio EquipeX) & Aluno, Líder de equipe \\
\hline [Nome do aluno] (outros domínios) & Aluno \\
\hline
\end{tabular}

\subsubsection{Política Personalizada}

Os resultados apresentados acima são obtidos por processo automatizado, ou seja, uma vez selecionadas as ferramentas e suas respectivas operações compartilhadas com o multidomínio, a política de exportação é gerada automaticamente, verificando quais papéis têm autorização para executar o tipo de operação compartilhada pela ferramenta e fazendo a atribuição de permissão. O controlador de domínio pode, durante a negociação da política, optar por personalizar a política de exportação. Neste caso, o controlador de domínio pode 
adicionar ou remover as permissões atribuídas aos papéis para as operações compartilhadas por seu domínio.

Por exemplo, suponha que o domínio “Redes” configure para que a operação “Participar” para a ferramenta “Compartilhamento de arquivos e repositório” seja autorizada apenas para o papel “Líder de Equipe” e "Professor”. E que o domínio “EquipeX” configure para que a operação "Participar” e “Contribuir” da ferramenta “Agenda de Tarefas” seja autorizada apenas para o papel “Professor” e “Especialista”. Neste caso, a política composta seria como apresentado nas tabelas abaixo.

Tabela 20 - Política Composta: atribuições do usuário

\begin{tabular}{|l|l|}
\hline \multicolumn{1}{|c|}{ Credencial em nome de } & \multicolumn{1}{c|}{ Papel } \\
\hline José M. Pedroso (domínio Consultor) & Especialista \\
\hline Maria Cristina Moura (domínio Redes) & Professor \\
\hline Pedro Vidal (domínio EquipeX) & Aluno, Líder de equipe \\
\hline [Nome do aluno] (outros domínios) & Aluno \\
\hline
\end{tabular}

Tabela 21 - Política Composta: atribuições de permissões

\begin{tabular}{|c|c|c|}
\hline Papel & Autorização & Operações \\
\hline \multirow[t]{3}{*}{ Professor } & Observar & $\begin{array}{l}\text { Consultor.Fórum.Observar } \\
\text { Redes.Ferramenta de aula virtual.Observar } \\
\text { Redes.CompArquivosRepositório.Observar } \\
\text { Redes.Fórum.Observar } \\
\text { EquipeX.Agenda de tarefas.Observar }\end{array}$ \\
\hline & Coordenar & $\begin{array}{l}\text { Redes.Ferramenta de aula virtual.Coordenar } \\
\text { Redes.Fórum.Coordenar } \\
\text { EquipeX.Agenda de tarefas.Coordenar }\end{array}$ \\
\hline & Participar & $\begin{array}{l}\text { Redes.Ferramenta de aula virtual.Participar } \\
\text { Redes.CompArquivosRepositório.Participar } \\
\text { EquipeX.Agenda de tarefas.Participar }\end{array}$ \\
\hline \multirow[t]{3}{*}{ Aluno } & Observar & $\begin{array}{l}\text { Consultor.Fórum.Observar } \\
\text { Redes.Ferramenta de aula virtual.Observar } \\
\text { Redes.CompArquivosRepositório.Observar } \\
\text { Redes.Fórum.Observar } \\
\text { EquipeX.Agenda de tarefas.Observar } \\
\end{array}$ \\
\hline & Contribuir & $\begin{array}{l}\text { Consultor.Fórum.Contribuir } \\
\text { Redes.Fórum.Contribuir }\end{array}$ \\
\hline & Copiar & Redes.Ferramenta de aula virtual.Copiar \\
\hline
\end{tabular}




\begin{tabular}{|l|l|l|}
\hline \multirow{4}{*}{ Especialista } & Participar & Redes.Ferramenta de aula virtual.Participar \\
\cline { 2 - 3 } & Observar & $\begin{array}{l}\text { Consultor.Fórum.Observar } \\
\text { Redes.Ferramenta de aula virtual.Observar } \\
\text { Redes.CompArquivosRepositório.Observar } \\
\text { Redes.Fórum.Observar } \\
\text { EquipeX.Agenda de tarefas.Observar }\end{array}$ \\
\cline { 2 - 3 } & Contribuir & $\begin{array}{l}\text { Consultor.Fórum.Contribuir } \\
\text { Redes.Fórum.Contribuir }\end{array}$ \\
\hline $\begin{array}{l}\text { Líder de } \\
\text { equipe }\end{array}$ & Participar & $\begin{array}{l}\text { Redes.Ferramenta de aula virtual.Participar } \\
\text { Redes.CompArquivosRepositório.Participar }\end{array}$ \\
\hline
\end{tabular}

\subsection{Considerações}

Este capítulo apresentou um exemplo de aplicação do modelo em ambientes de ensino à distância. Neste exemplo, existe um conjunto de operações típicas que executam ações específicas dependendo do contexto em que são executadas. O exemplo mostrou que o MOS tem aplicação flexível quanto ao grau de especificidade utilizado no modelo para a definição da política.

O capítulo seguinte discute as principais características do MOS e como essas características vêm atender as necessidades dos cenários propostos no capítulo 2. 


\section{Capítulo 8 - Discussões}

Alguns cenários para a formação de multidomínios foram apresentados no capítulo 2 com o objetivo de ilustrar os principais aspectos de segurança destes ambientes, quanto à política de controle de acesso. Alguns trabalhos relacionados foram apresentados, os quais relatam soluções para o controle de acesso em diversos tipos de multidomínios. No entanto, estas soluções não atendem ao conjunto de requisitos levantados através dos cenários (2.2). O desenvolvimento desta pesquisa foi motivado por essas dificuldades e os resultados produzidos, especificamente o modelo MOS, vêm atender a essas necessidades conforme é discutido a seguir.

\section{a) Definição da política de controle de acesso do multidomínio}

Multidomínios são formados a partir da associação entre domínios de segurança. Esses domínios possuem administração de segurança independente e podem utilizar diferentes mecanismos de controle de acesso. A integração entre as políticas definidas por estes domínios para a formação da política do multidomínio exige a definição de uma linguagem comum que possa ser interpretada por todos os domínios (2.1.1).

O MOS resolve este problema através da definição de um modelo baseado em ontologias. A ontologia permite a utilização de uma linguagem padronizada, que pode ser interpretada semanticamente por todos os domínios. A utilização de ontologia permite a criação de uma política de segurança composta, a partir das políticas de importação e exportação definida pelos domínios. Adicionalmente, as restrições definidas sobre a ontologia delimitam sua interpretação e ajudam a garantir a consistência da política de segurança resultante. 
O modelo proposto define uma política de segurança para o multidomínio independente da política de segurança interna de cada domínio. Isto permite um isolamento entre a política aplicada ao multidomínio e a política aplicada aos membros internos de cada domínio. O isolamento é importante para garantir que uma alteração na política interna do domínio não afete a política do multidomínio e vice-versa, como ocorre com as soluções baseadas no mapeamento de papéis propostas em (ZHANG, 2001; FREUDENTHAL, 2002; JOSHI, 2004; KIM, 2005).

O MOS é um modelo de segurança definido em dois níveis (5.3.5), um abstrato e outro concreto. A utilização do modelo abstrato para a definição da política do multidomínio permite aos domínios fornecerem apenas as informações relevantes para a negociação da política de segurança, contribuindo para manter privacidade dos domínios.

\section{b) Identificação do usuário e definição de regras de autorização.}

Uma das dificuldades na definição da política de segurança de multidomínios está no desconhecimento sobre os usuários existentes (2.1.2) para a definição das regras de autorização. Nestes ambientes, os usuários estão distribuídos nos domínios associados e não existe uma entidade que detém o conhecimento sobre todos eles (3.5).

O MOS resolve este problema através do modelo de controle de acesso baseado em papéis, que permite o mapeamento indireto entre usuários e autorizações. O uso de papéis permite a atribuição de autorização aos papéis em momentos diferentes da atribuição desses papéis aos usuários. Desta forma, é possível a negociação da política de controle de acesso sobre papéis, independente do conhecimento de quais usuários efetivamente participarão da associação.

Adicionalmente, um papel tem implícito uma semântica relativa à autoridade e responsabilidade conferida ao usuário que assume o papel (5.3.1). Isto significa que os papéis devem estar relacionados aos objetivos da formação do multidomínio, ou seja, os papeis 
adequados a um multidomínio dependem do contexto em que os domínios se associam para a realização de atividade colaborativa. Por outro lado, um papel também tem implícito um conjunto de autorizações relacionadas às suas responsabilidades.

Desta forma, o uso de modelo baseado em papéis permite uma representação objetiva sobre a formação do multidomínio, quando define um conjunto de papéis e autorizações a serem utilizados. Este fato, adicionado ao uso de ontologia, permite aos domínios o conhecimento sobre os objetivos da associação, assim como serve de orientação para a definição de uma política de controle de acesso coerente com esses objetivos.

\section{c) Negociação da política e conflito de interesses}

A representação objetiva sobre a formação do multidomínio não implica na efetiva realização de seus objetivos. Através do modelo de controle de acesso baseado em papéis é possível delinear o perfil do multidomínio, mas os recursos disponibilizados e responsabilidades assumidas através dos papéis dependem da contribuição dos domínios participantes. Ou seja, a definição da política de controle de acesso do multidomínio depende da negociação entre os domínios sobre suas contribuições individuais. Durante a negociação podem ocorrer conflitos de interesses (2.1.3) sobre contribuições e responsabilidades a serem assumidas.

O MOS fornece um modelo de segurança (5.3) e propõe um conjunto de regras para a negociação da política (5.3.4.1) e resolução de conflitos (5.3.4.2), viabilizando a negociação e criação de uma política de controle de acesso composta pelas contribuições de cada domínio. Adicionalmente, o MOS define os conceitos de política de importação e exportação (5.3.4), as quais representam os interesses dos domínios como consumidores de recursos e provedores de recursos respectivamente. 


\section{d) Manutenção da política e renegociação}

A definição da política de controle de acesso em multidomínios envolve um processo de negociação. Este processo tem um custo de tempo, processamento, comunicação e eventualmente interações com o usuário. Portanto, a manutenção da política do multidomínio deve evitar a renegociação desnecessária desta política $(2.1 .4,3.5)$. Três situações podem alterar o estado da política de controle de acesso (2.2): adição ou remoção de domínios, adição ou remoção de usuários nos domínios, alteração na política de importação ou exportação dos domínios. Durante a negociação, a existência de conflitos também pode exigir uma renegociação.

O MOS trata essas questões através do conceito Multidomínio definido pela ontologia (5.3.1), pela utilização de um modelo baseado em papéis e pela definição de regras de resolução de conflitos (5.3.4.2).

O conceito Multidomínio possui atributos de orientação sobre a definição e manutenção de sua política de segurança, como por exemplo, se o número de domínios participantes é fixo ou se a renegociação da política é obrigatória, opcional ou desnecessária. Dependendo das características do multidomínio, pode ser necessária a aprovação dos domínios para qualquer alteração no acordo estabelecido durante a negociação da política, ou seja, a renegociação é obrigatória para qualquer alteração no estado da política. Em outros casos, pode ser aceitável uma latência entre o estado corrente da política e a política composta conhecida por todos. Por exemplo, quando um novo serviço é compartilhado por um domínio. Os atributos do conceito Multidomínio contribuem tanto para informar aos domínios sobre como proceder diante de uma alteração quanto sobre o que esperar do estado conhecido da política.

A utilização de modelo baseado em papéis permite abstrair sobre os usuários do multidomínio durante a atribuição de autorizações. Isto significa que a adição e remoção de 
usuários nos domínios não implicam numa renegociação das atribuições de autorização. O modelo sugere um outro nível de abstração quando define o conceito de credencial para representar o usuário no modelo. Uma credencial autoriza seu proprietário a assumir papéis, ficando a cargo do domínio distribuir estas credenciais aos seus usuários, o que contribui para a autonomia dos domínios sobre a distribuição de responsabilidades.

Adicionalmente, as regras definidas para a resolução de conflitos contribuem para minimizar a necessidade de renegociação e obter um modelo composto consistente e coerente com os objetivos definidos pelo multidomínio.

\section{e) Criação dinâmica}

A formação de multidomínios pessoais possui alguns requisitos específicos devido a sua característica pessoal e ad hoc. Soluções para estes domínios devem buscar o difícil equilíbrio entre segurança e usabilidade.

O MOS busca viabilizar este equilíbrio através da ontologia. A ontologia permite sua utilização em processos automatizados, uma vez que tem o objetivo de ser interpretável e forma uma base de conhecimento sobre a qual é possível obter informações e fazer inferências.

A seção 6.4.1 cita a definição da política de exportação por processo automatizado, quando os serviços compartilhados em um domínio são automaticamente associados aos papéis. Isto é possível através da busca de quais papéis são autorizados a realizar as operações oferecidas pelo serviço.

O MOS define o conceito de Multidomínio e apresenta um exemplo de multidomínio para projeto de pesquisa. A especialização da ontologia de multidomínio, a exemplo das ontologias de recursos e operações, possibilita que tipos comuns de multidomínios possam ser instanciados e diretamente utilizados, ou personalizados, pelos domínios pessoais. Isto reduz a 
necessidade de configurações para a definição de políticas comuns e contribui para a usabilidade do modelo em domínios pessoais. 


\section{Capítulo 9 - Considerações Finais}

Este trabalho apresentou o MOS - Modelo Ontológico de Segurança, que representa os elementos essenciais para a negociação e composição dinâmica da política de controle de acesso em multidomínios. O MOS foi validado através da análise de sua viabilidade de aplicação em multidomínios pessoais.

A definição do modelo baseado em ontologia permitiu a utilização de uma linguagem comum e padronizada, viabilizando sua interpretação por diferentes domínios. A inserção de restrições, utilizadas na ontologia para delimitar as interpretações sobre os conceitos, foram fundamentais para a verificação da consistência do modelo durante a negociação e composição da política de segurança.

As regras definidas para a negociação da política de segurança contribuíram para evitar conflitos e conduzir a negociação, de forma a convergir para um modelo coerente com os objetivos definidos para o multidomínio.

A utilização do modelo baseado em papéis permitiu que a política do multidomínio fosse negociada através das políticas de importação e exportação, que puderam ser dinamicamente relacionadas, através dos papéis, para a verificação de conflito de interesses. As regras para a resolução de conflitos contribuíram para minimizar a necessidade de renegociações e obter um modelo composto consistente e coerente com os objetivos definidos pelo multidomínio.

Adicionalmente, o modelo permitiu a negociação da política com abstração sobre os reais recursos disponibilizados e a obtenção de uma política resultante totalmente independente da política interna dos domínios. O que permitiu manter a autonomia e isolamento dos domínios. 
A definição de um modelo concreto e a simulação da negociação e composição da política de controle de acesso, através de um exemplo de multidomínio de projeto de pesquisa, mostraram que o MOS permite a definição de um procedimento automatizável para a criação da política de controle de acesso de multidomínios.

O modelo proposto inova na composição e integração de idéias isoladas, propondo a utilização de ontologia para a descrição dos elementos do modelo de controle de acesso baseado em papéis, tal que modelos pré-definidos possam ser dinamicamente interpretados e entendidos por diferentes domínios. Ao mesmo tempo, permite que diferentes modelos possam ser facilmente especializados a partir desta ontologia, diversificando sua aplicação.

\subsection{Trabalhos Futuros}

- Implementação e teste dos conceitos novos introduzidos pelo MOS no projeto MPSD para a análise da flexibilidade versus complexidade introduzidos pela utilização do MOS.

- Pesquisar por ontologias existentes em diversas áreas do conhecimento que possam contribuir para o amadurecimento e evolução da ontologia de recursos e operações, aprimorando e diversificando a aplicação do MOS.

- Especificação de uma ontologia de restrições não estáticas para autorização e serviço, viabilizando a troca de conhecimento sobre restrições dinâmicas.

- Estudo sobre as implicações e alterações no modelo para o suporte à hierarquia de papéis.

- Implementação de algoritmos que auxiliem na utilização do MOS em processos automatizados de negociação e criação da política. 
- Estudar mecanismos para garantir a autenticidade da política tanto durante a fase de negociação quanto da política composta resultante.

- Generalização do processo de negociação definido para a aplicação do MOS em ambientes naturalmente conflitantes, onde questões como segurança, privacidade e usabilidade se apresentam como elementos conflitantes. 


\section{REFERÊNCIAS}

ADAMS, C.; LLOYD, STEVE - Understanding Public-Key Infrastructure: Concepts, Standards, and Deployment Considerations. MacMillan Technical Publishing, Indianapolis, USA, 1999.

AGARWAL, S.; SPRICK, B.; WORTMANN, S. - Credential Based Access Control for Semantic Web Services. American Association for Artificial Intelligence Spring Symposium Series, Stanford, California, USA, March 2004.

ASOKAN, N.; GINZBOORG, P. - Key agreement in ad hoc networks. Computer Communications, v.23, i.17, p.1627-1637, Nov. 2000.

BASAGNI, S.; CONTI, M.; GIORDANO, S.; STOJMENOVIC - I. Mobile Ad Hoc Networking. IEEE Press - Wiley Interscience. 2004.

CAMPOS, R.; PINHO, C.; RICARDO, M.; RUELA, J.; PÖYHÖNEN, P. and KAPPLER, C. - Dymamic and Automatic Interworking between Personal Area Networks using Composition. Ambient Networks Project, European Commission under its Sixth Framework Programme, 2005. Disponível em: http://www.ambientnetworks.org. Acesso em: 30 de outubro de 2005.

CHANDRASIRI, P.; GURLEYEN, O.; SHAHABI, Y.; GEHRMANN, C.; JONSSON, A. and NÄSLUND, M. - Personal Security Domains. Contribution to the 10th Wireless World Research Forum (WWRF), New York, October 27-28, 2003.

FERRAIOLO, D. F.; SANDHU, R.; GAVRILA, S.; KUHN, D. R. and CHANDRAMOULI, R. - Proposed NIST Standard for Role-Based Access Control. ACM Transaction on Information and System Security, Vol. 4, No.3, August 2001, p. 224-274.

FOKINE, K. - Key Management in Ad Hoc Network. Undergraduate Thesis, Linköping University, Department of Electrical Engineering. Linköping University Electronic Press, 2002. Disponível em: http://www.diva-portal.org/liu/ undergraduate/abstract.xsql?dbid=1351.

FREUDENTHAL, E.; PESIN, T.; PORT, L.; KEENEN, E.; KARAMCHETI, V. dRBAC: Distributed Role-based Access Control for Dynamic Coalition Environments. Proceedings of the 22nd International Conference on Distributed Computing Systems (ICDCS’02), p. 411. IEEE Computer Society Washington, DC, USA, 2002, 
GHAFOOR, A. \& SPAFFORF, E. H. - Access Control Management and Security in a Heterogeneous Multidomain Environment. Acessado em 24/06/05: shay.ecn.purdue.edu/ dmultlab/Security/ nsfyr01rep.pdf.

GRUBER, T. R. - A Translation Approach to Portable Ontology Specification. Thecnical Report KSL 92-71, 1993. Knowledge System Laboratory, Computer Science Department Stanford University, Stanford, California, USA, 1993.

GRÜNINGER, M., FOX, M. S. - Methodology for the Design and Evaluation of Ontologies. Proceedings of IJCAI'95, Workshop on Basic Ontological Issues in Knowledge Sharing, Montreal, April 13, 1995.

GUTTMAN, E.; PERKINS, C.; VEIZADES, J. and DAY, M. Service Location Protocol: Version 2 - RFC 2608. IETF - Internet Engineering Task Force, Network Working Group, Jun. 1999. Disponível em: http://www.ietf.org. Acesso em: 30 de junho de 2005.

HOAGLAND, JAMES A.; PANDEY, RAJU; LEVITT, KARL N. - Security Policy Specification Using a Graphical Approach - Technical Report CSE-98-3, University of California, Davis Department of Computer Science, June 1998.

HOUSLEY, R.; FORD, W.; POLK, W.; SOLO, D. - Internet X.509 Public Key Infrastructure Certificate and CRL Profile - Network Working Group Request for Comments: 2459, January 1999. (RFC2459).

HOWKER, KEITH - SHAMAN: Final technical report - results, specifications and conclusions. IST SHAMAN project, Vodafone, 2003. Disponível em: http://www.ist-shaman.org. Acesso em: 26 de dezembro de 2005.

HUBAUX, J.P., BUTTYAN, L., CAPKUN, S. - The quest of security in mobile ad hoc networks. ACM Symposium on Mobile Ad Hoc Networking and Computing MOBIHOC'01, Long Beach, Oct. 2001. Proceedings. Long Beach, California, USA, 2001.

IEEE 802.15.1 Standard Report: Wireless Medium Access Control (MAC) and Physical Layer (PHY) Specifications for Personal Area Networks (WPANs). The Institute of Electrical and Electronics Engineers, Inc. New York, EUA. June, 2002.

JACKY, J. - The Way of $\mathrm{Z}$ : pratical programming with formal methods. Cambridge University Press, NY, USA, 2001, p. 350.

JOSHI, J. B. D.; AREF, W. G.; GHAFOOR, A. and SPAFFORD, E. H. - Security Models for Web-based Applications. Communications of the ACM, February 2001, vol. 44, No. 2. 
JOSHI, J. B. D.; BHATTI, R.; BERTINO, E. and GHAFOOR, A. - Access-Control Language for Multidomain Environments. IEEE Internet Computing, vol. 08, no. 6, pp. 40-50, November/December 2004.

KALAM, A. A.; BAIDA, R.; BALBIANI, P. - Organization Based Access Control. Proceedings of the 4th International Workshop on Policies for Distributed Systems and Networks (POLICY’03), p. 120. IEEE Computer Society, Washington, DC, USA, 2003.

KEOH, S. L. \& LUPU, E. - An Efficient Access Control Model for Mobile Ad-hoc Communities. In the Proceedings of the 2nd International Conference on Security in Pervasive Computing (SPC), Boppard, Germany, LCNS 3450. Springer-Verlag, April 2005, p. 210-224.

KEOH, S. L.; LUPU, E. and SLOMAN, M. - PEACE: A Policy-based Establishment of Ad-hoc Communities. Proceedings of the 20th Annual Computer Security Applications Conference (ACSAC), Tucson, Arizona, USA. IEEE Computer Society, December 2004, p. 386-395.

KIM, H-C; RAMAKRISHNA, R. S. and SAKURAI, K. - A Collaborative RoleBased Access Control for Trusted Operating System in Distributed Environment. IEICE Trans. Fundamentals, Vol.E88-A, No. 1, January 2005.

LARMAN, C. - Utilizando UML e Padrões: Uma introdução à análise e ao projeto orientados a objetos. Bookman, Porto Alegre, 2000. Tradução: Luiz Augusto Meireles Salgado. p. 492.

MARTUCCI, L.A.; CARVALHO, T.C.M.B.; RUGGIERO, W.V. - A Lightweight Distributed Group Authentication Mechanism. INC2004 - Fourth International Network Conference, July 6 - 9, 2004.

MICROSOFT CORPORATION. Universal Plug and Play Device Architecture. Microsoft Corporation, 2000. Disponível em: http://upnp.org. Acesso em: 30 de junho de 2005.

NEJDL, W.; OLMEDILLA, D.; WINSLETT, M.; ZHANG, C. C. - Ontology-Based Policy Specification and Management. European Semantic Web Conference (ESWC 2005), , Heraklion, Greece, May/Jun. 2005.

NIEBERT, N., SCHIEDER, A., ABRAMOWICZ, H., MALMGREN, G., SACHS, J., HORN, U., PREHOFER, C. and KARL, H. - Ambient Networks - An Architecture for Communication Networks Beyond 3G. IEEE Wireless Communications (Special Issue on 4G Mobile Communications - Towards Open Wireless Architecture), April 2004. 
NIEBERT, N.; PRYTZ, M.; SCHIEDER, A.; EGGERT, L.; PITTMANN, F.; PAPADOGLOU, N. and PREHOFER, C. - Ambient Networks: a Framework for Future Wireless Internetworking. To appear Proc. IEEE 61st Semiannual Vehicular Technology Conference (VTC 2005 Spring), Stockholm, Sweden, May 30 - June 1, 2005.

NOY, N. F.; MCGUINNESS, D. L. - Ontology Development 101: A Guide to Creating Your First Ontology. Stanford Knowledge Systems Laboratory Technical Report KSL-01-05 and Stanford Medical Informatics Technical Report SMI-20010880, March 2001. Disponível em: http://www.ksl.stanford.edu/people/dlm/ papers/ontology-tutorial-noy-mcguinness-abstract.html. Acesso em: 08/11/2001.

PARK, J. S.; HWANG, J. - Role-based Access Control for Collaborative Enterprise In Peer-to-Peer Computing Environments. Proceedings of the eighth ACM symposium on Access control models and technologies, p. 93 - 99. ACM Press New York, NY, USA, 2003.

PERRIG A.; CANETTI, R.; TYGAR, J. D. and SONG, D. - The Tesla Broadcast Authentication Protocol. RSA Cryptobytes, 2002.

SAKURAGUI, R. R. M. \& CARVALHO, T. C. M. B. - Service Location Protocol. 4th I2TS - International Information and Telecommunication Symposium, Florianópolis-SC, Brasil, 2005.

SANDHU, R. S. - Future Directions in Role-Based Access Control Models. Proc. Information Assurance in Computer Networks: Methods, Models, and Architectures for Network Security - International Workshop, St. Petersburg, Russia. Lecture Notes in Computer Science, May 2001, vol. 2052, pp. 67-73.

SANDHU, R. S. \& SAMARATI, PIERANGELA - Access Control: Principles and Practice. IEEE Communication Magazine, September 1994.

SANDHU, R. S.; COYNE, E. J.; FEINSTEIN, H. L. and YOUMAN C. E. - RoleBased Access Control Models. IEEE Computer, Vol. 29, No. 2, February 1996, p. 38-47.

SHIMAOKA, MASAKI - Memorandum for multi-domain PKI interoperability. Proceedings of the Fifty-Seventh Internet Engineering Task Force, Vienna, Austria, July 13-18, 2003. Disponível em: http://www.ietf.org/proceedings/03jul/slides/ pkix-9. Access em: 18 de outubro de 2004.

SHIN, M. E. and AHN, G-J - UML-Based Representation of Role-Based Access Control. Proceedings of the 9th IEEE International Workshops on Enabling Technologies: Infrastructure for Collaborative Enterprises. IEEE Computer Society, Washington, DC, USA, 2000, p. 195-200. 
SPIVEY, J. M. - The Z Notation: A Reference Manual. Second Edition. Oriel College, Oxford, England, 1998, p. 158.

STALLINGS, WILLIAM - Cryptography and network security: principles and practice. 2.ed. Upper Saddle River, New Jersey: Prentice Hall, 1998. 569p.

SUN MICROSYSTEMS. The Jini Architecture Specification: Version 1.2. Sun Microsystem, 2001. Disponível em: http://www.sun.com/software/ jini/specs/. Acesso em: 30 de junho de 2005.

THE SALUTATION CONSORTIUM. Salutation Architecture Specification (Part 1) Version 2.1a. The Salutation Consortium, 1999. Disponível em: http://www.salutation.org. Acesso em: maio de 2002.

TONINELLI, A.; BRADSHAW, J.; KAGAL, L.; MONTANARI, R. - Rule-based and Ontology-based Policies: Toward a. Hybrid Approach to Control Agents in Pervasive. Proceedings of the Semantic Web and Policy Workshop (SWPW'05), Galway, Ireland, November 7, 2005, in conjunction with the Fourth International Semantic Web Conference (ISWC'05).

VENTURINI, Y. R.; SAKURAGUI, R. R. M.; MATUSHIMA, R.; CARVALHO, T. C. M. B.; RUGGIERO, W. R.; NÄSLUND, M. and POURZANDI, M. - Security Enforcement Layer for Security Domain. $4^{\text {th }}$ I2TS - International Information and Telecommunication Symposium, Florianópolis-SC, Brasil, 2005.

YIN, G.; SHI, D.; JIA, Y.; TENG, M. - A rule-based framework for role-based constrained delegation. Proceedings of the 3rd international conference on Information security. ACM International Conference Proceeding Series, Vol. 85, p. 186-191; ACM Press New York, NY, USA, 2004.

ZHANG, C. N.; YANG, C. - An Object-Oriented RBAC Model for Distributed System. WICSA - Working IEEE/IFIP Conference on Software Architecture (WISCA'01), 2001, p. 24.

ZHOU, L., HAAS, Z.J. - Securing Ad Hoc Networks. IEEE Network, v.13, i.6, p.24-30, Nov./Dec. 1999. 


\title{
BIBLIOGRAFIA COMPLEMENTAR
}

\author{
ABDUL-RAHMAN, ALFAREZ \& HAILES, STEPHEN - A Distributed Trust \\ Model. New Security Paradigms Workshop 1997, ACM, 1997.
}

AHLGREN, B.; BRUNNER, M.; EGGERT, L.; HANCOCK, R. and SCHMID, E. Invariants - A new Design Methodology for Network Architectures. Proceedings of the ACM SIGCOMM workshop on Future directions in network architecture, Portland, Oregon, USA, 2004, p. 65-70.

BERTINO, E.; BONATTI, E. and FERRARI, E. - TRBAC: A Temporal RoleBased Access Control Model. ACM Transaction on Information and System Security, vol. 4, August 2001, p. 191-233.

BLAZEVIC, L., et al. Self-organization on mobile ad hoc networks: the approach of Terminodes. IEEE Communications Magazine, v.39, i.6, p.166-174. Jun. 2001.

Borisov, N.; Goldberg, I.; Wagner, D. - Intercepting mobile communications: the insecurity of 802.11. Annual International Conference On Mobile Computing And Networking - MOBICOM’01, 7, Jul. 2001. Proceedings. Roma, Italia, 2001.

BRITISH TELECOM - Computer Security Manual. British Telecom, 1993. Acesso em 20/12/05, http://www.flashback.se/archive/BT/btcsmg.html.

CROWCROFT, J.; HAND, S.; MORTIER, R.; ROSCOE, T. and WARFIELD, A. Plutarch: An Argument for Network Pluralism. Proc. ACM SIGCOMM Workshop on Future Direction in Network Architecture (FDNA), Karlsruhe, Germany, August, 2003, pp. 258-266.

FEENEY, L.M., AHLGREN, B., WESTERLUND A. - Spontaneous network: an application oriented approach to ad hoc networking. IEEE Communications Magazine, v.39, i.6, p.176-181, Jun. 2001.

FRANCIS, P. \& GUMMADI, R. - IPNL: A NAT-Extended Internet Architecture. Proc. ACM SIGCOMM, San Diego, CA, USA, August 2001, pp. 6980.

FRODIGH, M.; JOHANSSON, P.; LARSSON, P. Wireless ad hoc networks - The art of networking without a network. Ericsson Review, n.4 p.248-263, 2000.

GRANDISON, T.; SLOMAN, M. A survey of trust in Internet applications. IEEE Communications Surveys, vol.3, n.4, p.2-16, $4^{\text {th }}$ Quarter 2000. 
HOLT, KEITH - Wireless LAN: Past, Present, and Future. Proceedings of the conference on Design, Automation and Test in Europe - Volume 3 2005, March 2005.

HUBAUX, J.P. et al. Toward self-organized mobile ad hoc network: the Terminodes project. IEEE Communications Magazine, v.39, i.1, p.118-124, Jan. 2001.

IEEE COMPUTER SOCIETY. LAN/MAN Standards Committee. ANSI/IEEE 802.11 Std. Part 11: Wireless LAN Medium Access Control (MAC) and Physical Layer (PHY) Specifications. New York, New York, USA: IEEE, Sep. 1999. 512p.

IEEE COMPUTER SOCIETY. LAN/MAN Standards Committee. IEEE 802.11i Std. Ammendment to IEEE 802.11 Std. New York, New York, USA: IEEE, Jul. 2004, 175p.

IEEE COMPUTER SOCIETY. LAN/MAN Stds Committee. ANSI/IEEE 802.1X Std. Port-Based Network Access Control. New York, NY, USA: IEEE, Jun. 2001. 106p.

JOSHI, J. B.D.; BERTINO, E.; LATIF, U. and GHAFOOR, A. - A Generalized Temporal Role-Based Access Control Model. IEEE Transaction on Knowledge and Engineering, Vol. 17, No. 1, January 2005.

KAPPLER, C.; MENDES, PAULO; PREHOFER, C.; PÖYHÖNEN, P. and ZHOU, D. - A Framework for Self-organized Network Composition. International Workshop on Autonomic Communication, Berlin, October 18-19, 2004.

KÄRPIJOKI, V. Security in ad hoc networks. In: SEMINAR ON NETWORK SECURITY, Helsinki, Fall 2000. Proceedings. Helsinki, Finland: Helsinki University of Technology, 2000.

KOSHUTANSKI, H. and MASSACCI, F. - E pluribus unum: Deduction, abduction and induction, the reasoning services for access control in autonomic communication. In Proceedings of the 1st IFIP TC6 WG6.6 International Workshop on Autonomic Communication (WAC), Berlin, Germany, 2004. Lecture Notes in Computer Science, Springer-Verlag Heidelberg.

LEWIS, DAVID; FEENEY, K.; CAREY, K.; TIROPANIS, T. and COURTENAGE, S. - Semantic-based Policy Engineering for Autonomic System. Second International Workshop on Management of Ubiquitous Communications and Services, MUCS, Dublin, Ireland, December 2004. 
LUO, H. et al. - Self-securing ad hoc wireless network. Proceeding on IEEE Symposium on Computers and Communications - ISCC 2002, Taormina, Italy, 2002. IEEE Computer Society Press, p. 567-574, Jul. 2002.

LYYTINEN, K.; YOO, Y. - Issues and Challenges in Ubiquitous Computing. Communication of the ACM. December 2002/Vol 45, No.12.

OHMORI, SHINGO; YAMAO, YASUSHI; NAKAJIMA, NOBUO - The Future Generations of Mobile Communications Based on Broadband Access Methods. Wireless Personal Communications, Volume 17, Issue 2 - 3, Jun 2001, Pages 175 190.

PERKINS, C.E. - Ad hoc networking - an introduction. Addison Wesley, New Jersey, 2000, p. 1-28.

RAVI, S.; RAGHUNATHAN, A. and POTLAPALLY, N. - Securing Wireless Data: System Architecture Challenges. International Symposium on System Synthesis (ISSS), October 2002, Pages 195 - 200.

RAVI, SRIVATHS; RAGHUNATHAN, ANAND; KOCHER, PAUL and HATTANGADY, SUNIL - Security in embedded systems: Design challenges. ACM Transactions on Embedded Computing Systems (TECS), Volume 3, Issue 3, August 2004, Pages: $461-491$.

SCHMID, S.; EGGERT, L.; BRUNNER, M. and QUITTEK, J. - Towards Autonomous Network Domains. Proc. 8th IEEE Global Internet Symposium, Miami, FL, USA, March 17-18, 2005.

SCHMID, S.; EGGERT, L.; BRUNNER, M. and QUITTEK, J. - TurfNet: An Architecture for Dynamically Composable Networks. Proc. First IFIP TC6 WG6.6 International Workshop on Autonomic Communication (WAC 2004), Berlin, Germany, October 18-19, 2004. In Lecture Notes in Computer Science, Vol. 3457, (c) Springer Verlag, Heidelberg, Germany.

STAJANO, F. - The resurrecting duckling: what next?. International Workshop on Security Protocols, 8., Lecture Notes in Computer Science, Springer-Verlag, Santa Barbara, Apr. 2000. Proceedings. Santa Barbara, California, USA, 2000.

STAJANO, F.; ANDERSON, R. - The resurrecting duckling: security issues for ad hoc wireless networks. AT\&T Software Symposium, 3., Middletown, Oct. 1999. Proceedings. New Jersey, USA, 1999.

STALLINGS, WILLIAM - Wireless Communication and Networking. Prentice Hall, New Jersey, 2002, 584p. 
WEIMERSKIRCH, ANDRÉ \& THONET, GILLES - A Distributed Light-Weight Authentication Model for Ad-hoc Networks. The 4th International Conference on Information Security and Cryptology (ICISC), Dec. 2001, Seoul - Korea. 


\section{APÊNDICE A - AXIOMAS}

Este apêndice apresenta as restrições aplicadas sobre a ontologia, através de descrições axiomáticas em notação Z (SPIVEY, 1998; JACKY, 2001). Z é uma notação para especificação formal baseada na teoria dos conjuntos e lógica de predicados de primeira ordem. Para auxiliar na interpretação dos axiomas, seguem algumas definições e símbolos utilizados.

\section{Definições da ontologia}

- Um atributo associado a um conceito é um mapeamento entre este conceito e um valor. Por exemplo, um atributo B do conceito X é um mapeamento (X, valor de B).

- Um relacionamento associado a um conceito é um mapeamento entre este conceito e outro conceito. Por exemplo, um relacionamento R do conceito X com o conceito Y é um mapeamento (X, Y).

- Atributos e relacionamentos são conjuntos de mapeamentos. Por exemplo, se o conceito $\mathrm{X}$ possui um atributo $\mathrm{B}$, então $(\mathrm{X}$, valor de $\mathrm{B}) \in \mathrm{B}$. Se o conceito $\mathrm{X}$ possui um relacionamento $\mathrm{R}$ com a classe $\mathrm{Y}$, então $(\mathrm{X}, \mathrm{Y}) \in \mathrm{R}$.

\section{Símbolos da notação Z}

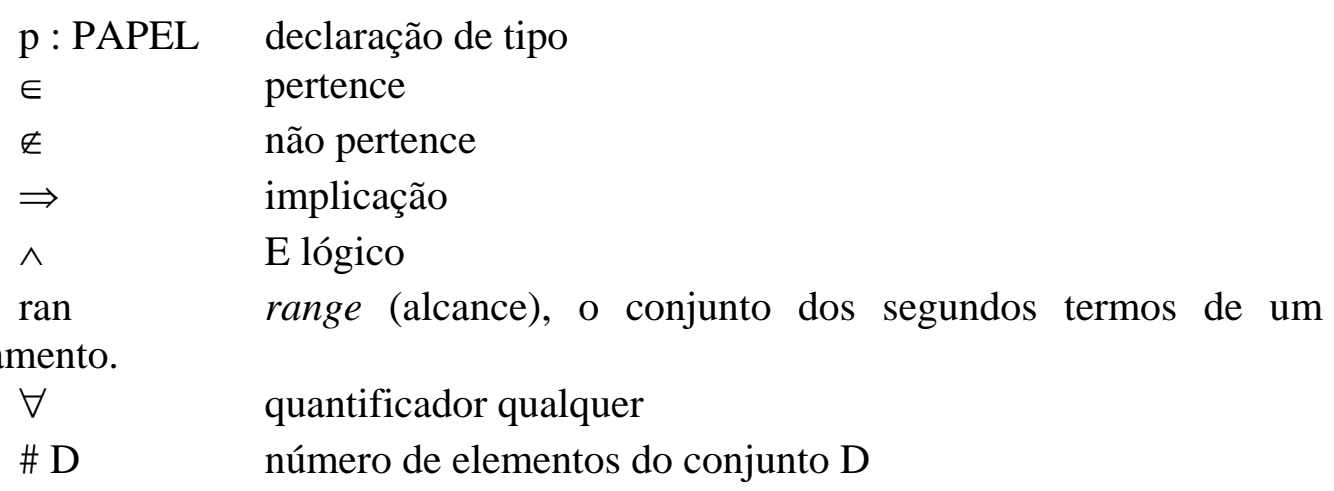




\section{Definição axiomática em notação $Z$}

declaração
$\begin{aligned} & \text { pré-condição> } \\ & \text { predicado }\end{aligned}$

\section{Restrições}

\section{a) Papel}

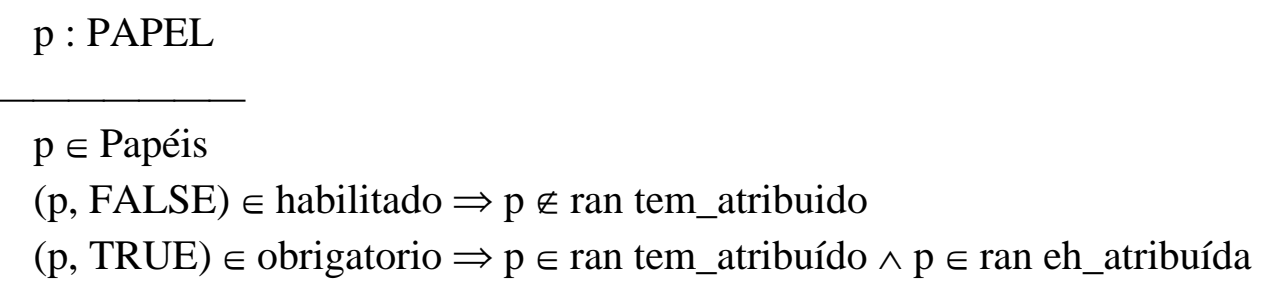

Dado p do tipo PAPEL, com p pertencente ao conjunto dos Papeis. Se p não está habilitado, implica que $\mathrm{p}$ não deve estar mapeado no relacionamento tem_atribuído (não deve estar atribuído a uma credencial). E se p é obrigatório, implica que p deve estar mapeado no relacionamento tem_atribuído E p deve estar mapeado no relacionamento eh_atribuída (deve possuir autorizações atribuídas).

\section{b) Operação}

A classe autorização possui um relacionamento não apresentado no diagrama, que permite definir um conjunto de operações obrigatórias.

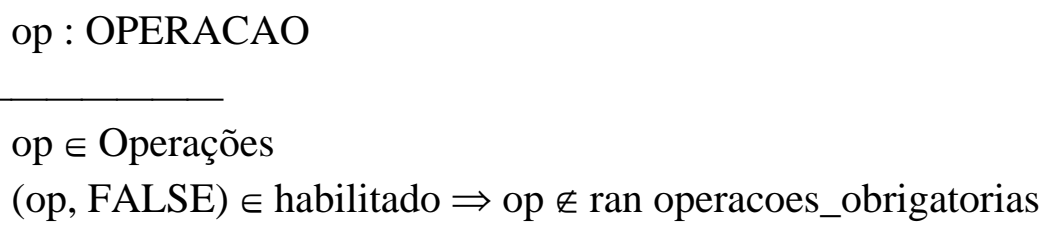

Dado op do tipo OPERAÇÃO, com op pertencente ao conjunto das Operações. Se op não está habilitado, implica que op não deve estar mapeado no relacionamento operações_obrigatorias. 


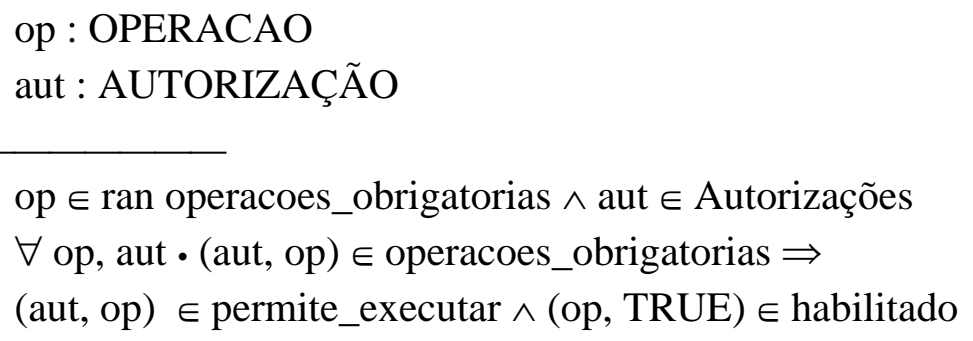

Dado op do tipo OPERAÇÃO e aut do tipo AUTORIZAÇÃO, com op pertencente ao conjunto das Operações e aut pertencente ao conjunto das Autorizações. Para qualquer op e aut, com aut mapeado para op no relacionamento operações_obrigatorias (op é uma operação obrigatória de aut), implica que deve existir um mapeamento de aut para op no relacionamento permite_executar (op deve ser uma das operações permitidas de aut) E op deve estar habilitado.

\section{c) Multidomínio}

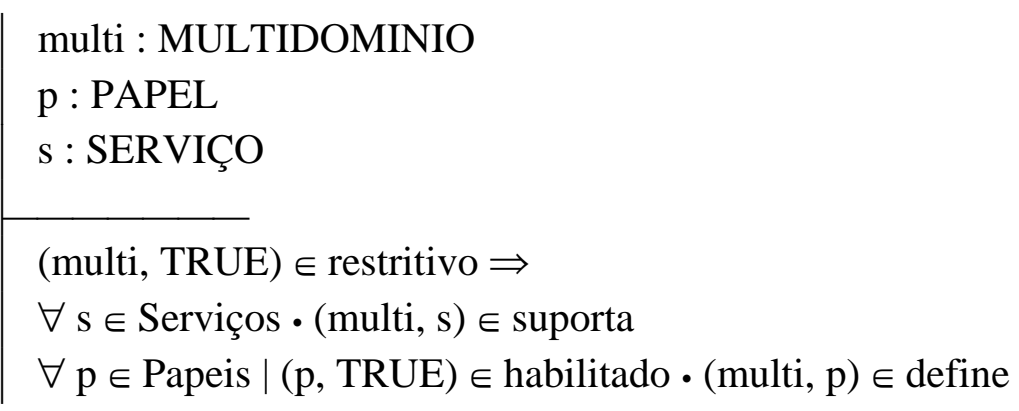

Dado multi do tipo MULTIDOMINIO, p do tipo PAPEL e s do tipo SERVIÇO. Se multi é restritivo, implica que para qualquer s pertencente ao conjunto Serviços, multi está mapeado para s no relacionamento suporta (s é um serviço suportado por multi) E para qualquer p pertencente ao conjunto Papeis tal que p está habilitado, multi está mapeado para p no relacionamento define (p é um papel definido por multi).

multi : MULTIDOMINIO

(multi, FIXO) $\in$ tipo_cardinalidade_multidominio $\Rightarrow$

(multi, \# Domínios) $\in$ valor_cardinalidade_multidomínio 
Dado multi do tipo MULTIDOMINIO. Se o atributo tipo_cardinalidade_ multidomínio associado à multi possui valor FIXO, implica que o número de elementos do conjunto Domínios deve ser igual ao valor do atributo valor_ cardinalidade_multidomínio associado à multi.

\section{d) Identificação}

A ontologia coloca restrições sobre o atributo identificação dentro e um mesmo tipo de conceito. Por exemplo, não pode haver dois papéis com mesma identificação. Esta restrição se aplica aos Papéis, Autorizações, Operações, Serviços e (RecursosFísicos $\cup$ RecursosLógicos). Exemplos:

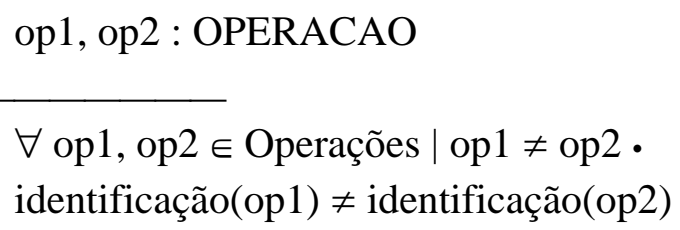

Dado op1 e op2 do tipo OPERAÇÃO. Para qualquer op1 e op2 pertencente ao conjunto das operações, tal que op1 seja diferente de op2, a identificação de op1 deve ser diferente da identificação de op2.

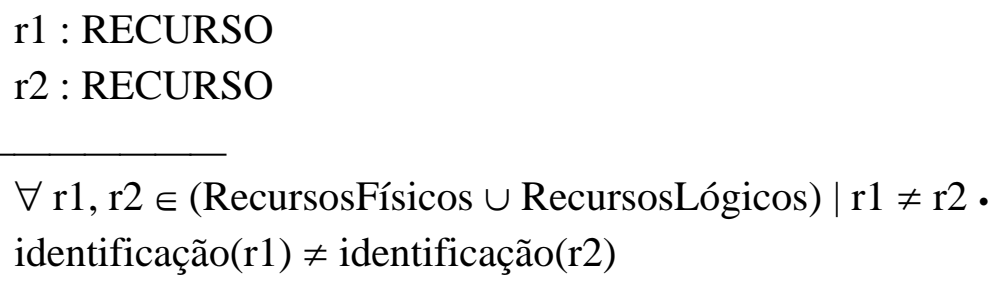

